\title{
Reticular Chemistry 3.2: Typical Minimal Edge-Transitive de- rived and related Nets for the Design and Synthesis of MOFs.
}

\author{
Zhijie Chen, ${ }^{\dagger}$ Hao Jiang, ${ }^{\dagger}$ Mian $\mathrm{Li}^{\S}$, Michael O’Keeffe ${ }^{\ddagger^{*}}$ and Mohamed Eddaoudi ${ }^{{ }^{*}}$ \\ ${ }^{\dagger}$ King Abdullah University of Science and Technology (KAUST), Division of Physical Sciences and Engineering \\ (PSE), Advanced Membranes and Porous Materials Center (AMPMC), Functional Materials Design, Discovery and \\ Development Research Group (FMD3), Thuwal 23955-690o, Kingdom of Saudi Arabia, E-mail: mohamed.ed- \\ daoudi@kaust.edu.sa \\ ¥ School of Molecular Sciences, Arizona State University, Tempe, Arizona 85287, United States, E-mail: \\ mokeeffe@asu.edu \\ § Department of Chemistry and Key Laboratory for Preparation and Application of Ordered Structural Materials of \\ Guangdong Province, Shantou University, Guangdong 515063, P. R. China
}

Supporting Information Placeholder

\begin{abstract}
Reticular chemistry has proven as a notable/distinctive discipline aimed at the deliberate assembly of periodic solids, offering great opportunities to effectively deploy the gained knowledge on net-topologies as a guide and toolbox for designed syntheses, based on the assembly of molecular building blocks into targeted and anticipated structures of crystalline extended solids. The effective practice of reticular chemistry has enriched the repertoire of crystal chemistry and afforded the notable accelerating development of crystalline extended frameworks, especially metal-organic frameworks (MOFs). Here, we review a special class of trinodal MOF structures based on the reticulation of special minimal edgetransitive nets (nets with transitivity [ 32 2], three distinct nodes and two kind of edges) derived from edge-transitive nets (one kind of edge). The rationale for deriving these special minimal edge-transitive nets is reviewed and their associated net-coded building (net-cBUs) for the design of trinodal MOFs is presented and discussed. The resultant inclusive list of the enumerated minimal edge-transitive nets provides a unique toolbox for the material's designer as it offers ideal blueprints for the deliberate design and rational assembly of building blocks with embedded multiple branch points into intricate trinodal MOFs.
\end{abstract}




\section{Contents}

1. INTRODUCTION

2. Parent Net, derived Net and related Net.

2.1 Vertex-Transitive Polyhedra.

2.2 Edge-Transitive parent Net

2.3 Minimal Edge-Transitive derived and related Net .. 4

2.3.1 The Replacement of the Tetrahedral Node...... 7

2.3.2 The Replacement of the Octahedral Node...... 7

2.3.3 The Replacement of the Trigonal Prismatic Node

2.3.4 The Replacement of the Hexagonal Node....... 9

2.3.5 The Replacement of the Cube Node

... 9

2.3.6 The Replacement of the Cuboctahedral Node

2.3.7 The Replacement of the Icosahedral Node ......11

2.3.8 The Replacement of the Truncated Tetrahedral Node

2.3.9 The Replacement of the Hexagonal Prismatic Node.

2.3.10 The Replacement of the Truncated Octahedral Node

... 12

2.3.11 The Teplacement of the Rhombicuboctahedral Node . .13

2.4 Minimal Edge-Transitive derived Nets from NonCrystallograpic parent Nets

3. MOFs based on Minimal Edge-Transitive Nets.

3.1 MOFs based on acs and acs-derived Nets

3.2 MOFs based on $\mathrm{ftw}$ and $\mathrm{ftw}$-derived Nets

3.3 MOFs based on alb and alb-derived Nets

3.4 MOFs based on twf and twf-derived Nets.

3.5 MOFs based on nia and nia-related Nets.

3.6 MOFs based on shp, alb and their related Nets.... 23

4. Reticular Chemistry 3.2 for the Designed Synthesis of MOFs.

5. Concluding Remarks and Future Prospects

\section{INTRODUCTION}

The prediction of crystal structures from the basic knowledge of their chemical composition was presumed as an illusion. " The term "designed synthesis" remains challenging to deploy for the construction of traditional porous solid-state materials (e.g. porous carbon and zeolites), although their fascinating properties have certainly impacted our daily life and found key in various essential vital industrial applications. ${ }^{2-4}$ Conversely, the institution of Metal-organic frameworks (MOFs), a distinctive class of porous solids, emerged to offer the prospect to deliberately direct the assembly of periodic solids, as exemplified by the report of the first isoreticular MOFs, with the same pcu topology, based on linking the 6-c zinc tetranuclear cluster $\left[\mathrm{Zn}_{4} \mathrm{O}\left(\mathrm{O}_{2} \mathrm{C}-\right)_{6}\right]$ with various carboxylate based ditopic ligands (i.e. the iconic MOF- 5 and its isoreticular series IRMOFs).$^{5-6}$ Albeit the question ${ }^{7}$ of designed syntheses for MOFs continues, numerous MOF examples and their associated assembly strategies pinpoint to the authenticity of MOF design, especially for those based on highly-connected and symmetrical MOFs. ${ }^{8-12}$ Markedly, MOFs ${ }^{13-17}$ are recognized by academia and industry alike, due to their unique attributes, such as crystallinity, permanent porosity, exceptional surface areas and pore volumes, structure/composition tunability affording controlled pore sizes and pore-apertures, to offer prospect solutions in various applications pertaining to gas storage/separation, ${ }^{18-25}$ water capture, ${ }^{26-34}$ crystal sponges ${ }^{35-36}$ and heterogenerous catalysis. ${ }^{37-45}$

The alliance of the molecular building block (MBB) approach with reticular chemistry afforded, par excellence, the rational assembly of preselected and preprogrammed/coded MBBs into targeted MOFs and covalent organic frameworks (COFs), addressing the longawaited questions pertaining to the prospect of constructing porous crystalline extended materials by design. ${ }^{4-49}$ Markedly, the successful deployment of reticular chemistry for the design of MOFs entailed several geometrical/topological prerequisites to be considered and taken into account, at the design stage prior to the assembly process, for the net selection and the election of suitable MBBs affording their points of extension to match the vertex figure of the augmented net. Rationally, access to appropriate organic and inorganic MBBs embedding the necessary coded structural information (i.e. shape, connectivity and directionality) is critical for the successful reticulation of their associated secondary building units (SBUs), defined by the positioning of the MBBs points of extension, into the target net. ${ }^{50-51}$ Undeniably, not every designed experiment is assured to be successful; however, it conveys a message that a delicate design is plausible and can evolve from those failed trials..$^{52-53}$

Progress in the last two decades afforded the enumeration and rational cataloging of nets as suitable blueprints for the directed assembly of periodic solids and the effective practice of reticular chemistry. ${ }^{11-12,46,48,54-63}$ Markedly, edgetransitive nets (one kind of edge, transitivity [21] or [11]) are recognized as suitable targets in crystal chemistry. It is to be noted that each net can be defined by it associated tiles and commendably the application of mathematical tiling theory afforded the systematic enumeration of 3periodic networks with their associated tilling, as each tiling expresses a unique net. ${ }^{64-65}$ The transitivity is a very powerful way of characterizing a tiling, a 3-D Euclidean space by generalized polyhedra or cages in the case of 3periodic networks (face-to-face packing). ${ }^{62}$ Topologically, a transitivity [pqrs] denotes that there are $p$ kinds of vertices, $q$ kinds of edges, $r$ kinds of faces and $s$ kinds of 
tiles. Edge-transitive emanates from the jargon of graph theory and denotes one kind of edge (all linkers are related by symmetry). Those edge-transitive nets ${ }^{57}, 60,66$ are acknowledged as significant and suitable targets in crystal chemistry and have been extensively used in MOF designed syntheses. $55,67-71$

Interestingly, the overwhelming majority of the synthesized MOFs have underlying nets with minimal transitivity, as an analogy to Pauling's Rule of Parsimony. ${ }^{72-73}$ The minimal transitivity (MT) indicates the smallest possibility; say, the edge-transitive nets have one type of edge with transitivity pq $=\left[\begin{array}{ll}1 & 1\end{array}\right]$ or $\left[\begin{array}{l}2 \\ 1\end{array}\right]$ for uninodal and binodal nets, respectively. When the net of a compound can be deconstructed into three kinds of nodes, the minimal possible transitivity is [32]; that is, the net has 3 kinds of nodes and 2 kinds of edges (links). All transitivity [ $\left[\begin{array}{ll}3 & 2\end{array}\right]$ nets are known for polyhedra and 2periodic tilings but not, as yet, for 3-periodic nets. ${ }^{74}$ To be noted that these minimal edge-transitive trinodal nets (particularly, highly connected nets) are of great prominence in designed syntheses or to evaluate theoretical possibilities for crystalline porous networks such as MOFs ${ }^{11-12}, 73,75-80$ and $\mathrm{COFs}^{49},{ }^{81-82}$. Accordingly, it was our proposition and concept to enrich the repertoire of reticular chemistry by introducing highly-connected and minimal edge-transitive nets (with one or two kinds of edge) as ideal blueprints for the rational design and construction of MOFs." ${ }^{1,} 8_{3}$

Notably, highly-connected building units can be reticulated into a limited number of edge-transitive nets and thus asserting the distinctiveness of highly-connected nets as suitable targets in reticular chemistry for the design and synthesis of MOFs. Reasonably, the augmented highly-connected binodal edge-transitive nets offer a unique and precise positioning and connectivity of the net vertex figures, that we termed net-coded building units (net-cBUs). The net-cBUs offer the potential to encompass precise geometrical information that codes matchlessly and uniquely a selected net, an incontestable perquisite for the rational design of MOFs. The introduction of net-cBUs afforded the rational construction of highly-connected MOFs based on minimal edge-transitive nets," namely the two binodal edgetransitive the $(4,12)$-coordinated shp net (square and hexagonal prism) and the (6,12)-coordinated alb net (aluminium diboride, hexagonal prism and trigonal prism), sole edge-transitive nets with the vertex figure as hexagonal prism $(\mathrm{d} 6 \mathrm{R}),{ }^{62}$ and their minimal edgetransitive derived nets. ${ }^{8}$ Markedly, the concept to use netcBUs afforded the rational design of branched organic ligands as tertiary building units (TBUs) with their peripheral points of extension matching the vertices of the net-cBU.

The highly coordinated building units of the highlyconnected nets, especially those with MT, are ideal and persuasive net-cBUs for the practical designed syntheses. It is worth noting that the identification and description of the nets for the underlying topology of MOF structures was provided in an early review. ${ }^{84}$ Especially, MOFs with intricate branch ligands can be correlated to a parent net (e.g. binodal edge-transitive nets) but can express different derived nets (e.g. trinodal minimal edgetransitive nets). Topological analysis ${ }^{85}$ of MOFs with polytopic linkers and/or multiple building units has been partially reviewed. ${ }^{73}$ Nevertheless, the uniqueness and exceptional prominence of the highly-connected trinodal nets with transitivity [32] for the design of MOFs is yet to be recognized and thus in this review we bridge this gap and provide the systematic generation of derived nets from their associated parent net. ${ }^{11,}{ }_{33}$

In this review, we discuss recent examples of MOFs with minimal edge transitivity and disclose the enumeration of 3-periodic trinodal nets with transitivity $[32] .{ }^{86}$ Here, we thoroughly define the deployed approach for the generation of minimal edge-transitive derived and related trinodal nets from their respective edge-transitive parent binodal net. The design strategies for the practice of reticular chemistry 3.2, based on reticular chemistry supported by the concept of net-cBUs, are discussed and presented as a comprehensive design toolbox for the materials' designer. Most of the newly generated related nets represent a novel class of highly-coordinated minimal edge transitive nets, providing new suitable blueprint net targets for the rational design and synthesis of highlyconnected MOFs. In addition, encouraged by the large number of derived and related nets from the edgetransitive nets suitable for design, we decided to envisage the non-crystallographic edge transitive nets that show collisions and not suitable for simple building approaches, and enumerate their derived nets with the aim to unveil potential suitable derived nets for design. Lastly, various modelled MOF structures were presented to validate the feasibility and practicality of these nets for the anticipated construction of the associated chemically. The resulting minimal edge-transitive derived and related trinodal nets have been encompassed in Reticular Chemistry Structure Resource $(\mathrm{RCSR})^{87}$ - a searchable database to aid chemists and material scientists who would like pursue new designed syntheses.

Table 1. Vertex-transitive polyhedra compatible with crystallographic symmetry ${ }^{a}$

$\begin{array}{lllll}\text { coordination, } z & \text { symbol } & \text { figure } & \text { symmetry } & \mathrm{VS}^{\mathrm{b}} \\ 3 & 3 & \text { triangle } & \overline{6} 2 \mathrm{~m} & 3 \\ 4 & \mathrm{~S} & \text { square } & 4 / \mathrm{mmm} & 4 \\ 4 & \mathrm{~T} & \text { tetrahedron } & \overline{4} 3 \mathrm{~m} & 3^{3} \\ 6 & \mathrm{O} & \text { octahedron } & \mathrm{m} \overline{3} \mathrm{~m} & 3^{4} \\ 6 & \mathrm{P} & \text { trigonal prism } & \overline{6} 2 \mathrm{~m} & 3.4^{2}\end{array}$




\begin{tabular}{|c|c|c|c|c|}
\hline 6 & $\mathrm{H}$ & hexagon & $6 / \mathrm{mmm}$ & 6 \\
\hline 8 & $\mathrm{C}$ & cube & $m \overline{3} m$ & $4^{3}$ \\
\hline 8 & $\mathrm{~A}$ & square antiprism* & 422 & $3^{3} \cdot 4$ \\
\hline 8 & $\mathrm{E}$ & octagon* & $4 / \mathrm{mmm}$ & 8 \\
\hline 12 & $\mathrm{~B}$ & cuboctahedron & $m \overline{3} m$ & $3 \cdot 4 \cdot 3 \cdot 4$ \\
\hline 12 & I & icosahedron* & $m \overline{3}$ & $3^{5}$ \\
\hline 12 & $\mathrm{U}$ & truncated tetrahedron & $\overline{4} 3 m$ & $3.6^{2}$ \\
\hline 12 & $\mathrm{X}$ & hexagonal prism & $6 / \mathrm{mmm}$ & $4^{2} \cdot 6$ \\
\hline 16 & G & octagonal prism* & $4 / \mathrm{mmm}$ & $4^{2} .8$ \\
\hline 24 & $\mathrm{M}$ & dodecagonal prism* & $6 / \mathrm{mmm}$ & $4^{2} .12$ \\
\hline 24 & K & truncated octahedron & $m \overline{3} m$ & $4.6^{2}$ \\
\hline 24 & $\mathrm{R}$ & rhombicuboctahedron & $m \overline{3} m$ & $3 \cdot 4^{3}$ \\
\hline 24 & $\mathrm{~N}$ & snub cube & 432 & $3^{4} \cdot 4$ \\
\hline 24 & W & truncated cube & $m \overline{3} m$ & $3.8^{2}$ \\
\hline 48 & $\mathrm{Z}$ & truncated cuboctahedron & $m \overline{3} m$ & 4.6 .8 \\
\hline
\end{tabular}

$a *$ represents the full symmetry non-crystallographic (incompatible with 3-periodicity) and the reported symmetry is crystallographic; we also recognize square pyramid and hexagon pyramid as symbol Q and V, respectively.

${ }^{b}$ VS = vertex symbol.

\section{Parent Net, derived Net and related Net}

\subsection{Vertex-Transitive Polyhedra}

It is recommended to use a vertex symbol (VS) for vertices in polyhedra to describe the local topology of a vertex. ${ }^{88}$ Vertex symbol is occasionally also referring to a vertex type or a vertex configuration. The form A.B.C.D... in cyclic order for vertex symbol means the shape of the polygons meeting at a vertex for a polyhedron. Thus, the vertex symbol of a trigonal prism is $3.4^{2}$ and that of a cuboctahedron is 3.4.3.4. It is to be noted that in the vertex symbol, the smaller rings (shortest rings) come first (e.g. 3.4.3.4. instead of 4.3.4.3).

The vertex-transitive (with one kind of vertex) polyhedra shown in Table $\mathbf{1}$ include all the possibilities for coordination figures occurring in edge-transitive nets. The corresponding abbreviations were established for the vertex-transitive polyhedra ( $\mathrm{P}$ for trigonal prism, $\mathrm{X}$ for hexagonal prism, $\mathrm{R}$ for rhombicuboctahedron, etc.) for the convenience of searching in RCSR (e.g. alb is a PX net).

An augmented net (net-a) is generated from the original net via the augmentation process. $^{89}$ A vertex figure (polygon or polyhedron) is generally used to substitute an n-connected vertex in such a process. It is commonly recommended to use augmented nets for the illustration of the nets as they depict the essential structural and geometrical information, as well as points of extension, for their associated vertex figures. ${ }^{10,69,90-91}$ Perceptibly, the net augmentation is a critical step/process in the design stage as it provides the essential geometrical information that codes the net and to be targeted and embedded in the looked-for building units. All 3-periodic nets in this review are represented as augmented nets for the rational design and targeted synthesis of MOFs.

\subsection{Edge-Transitive parent Net}

MOF crystal structures in which all the links between MBBs are equivalent by symmetry are particularly vital. The nets of these MOF structures have one kind of edge (edge-transitive). The parent nets here denote the nets which will further generate derived or related nets, by replacing one of the vertices with groups of vertices.

It has been realized that MOFs with complicated linkers encompassing two or more branch points can be correlated to the same parent net although they express different derived or related nets. ${ }^{83}$ In view of that, it is suggested that both the parent net and the derived/related net, with a clear procedure for the deconstruction of the branched linker, should be provided for the topological analysis of a MOF structure with branched ligands. The parent net is important for the design process of MOF crystal structure, with the desired directional information in selecting the looked-for MBBs. On the other hand, the derived net gives the underlying topology of a specific MOF with polytopic ligands, because each branch point of the linker is regarded unambiguously as a vertex of the net. $^{84}$

\subsection{Minimal Edge-Transitive derived and related Net}

In edge-transitive binodal parent nets (for single nodal nets, the binary versions were chosen, such as dia-b and acs-b for dia and acs, respectively), replacing one of the vertices by an edge-transitive binodal group generates the corresponding derived and related net. As a result, the transitivity increases from [21] in edge-transitive binodal parent nets to [32] in the resultant derived and related net (Scheme 1). This process refers to the operation shown in Figures. 1-11. 
The operation process shown here started from tetrahedron $(\mathrm{T})$, octahedron $(\mathrm{O})$, trigonal prism $(\mathrm{P})$, hexagon $(\mathrm{H})$, cube $(\mathrm{C})$ to rhombicuboctahedron $(\mathrm{R})$. The operation procedure denotes vertices with this coordination are the ones in the parent nets being replaced with groups of vertices. In the operation $W-n_{1}-n_{2}$, $W$ denotes the overall shape of the building unit (e.g. cuboctahedron (B)); $\mathrm{n}_{1}$ represents the number of nodes in the center of the aforementioned building unit; $\mathrm{n}_{2}$ signifies the number of derived nodes between the central nodes and vertices of the parent building unit.

The abbreviation of the parent binodal net by coordination figure $(\mathrm{CF})$ referred to $\mathrm{W}_{1}, \mathrm{~W}_{2}$. Coordination figures was from the symbols of the said vertex-transitive polyhedra; that is, $3=$ triangle, $\mathrm{S}=$ square, $\mathrm{T}=$ tetrahedron, $\mathrm{O}=$ octahedron, $\mathrm{P}=$ trigonal prism, $\mathrm{H}=$ hexagon, $\mathrm{C}=$ cube, $\mathrm{B}=$ cuboctahedron, $\mathrm{X}=$ hexagonal prism etc. For example, the CF for acs-b is P,P and that for soc is S,O. The according derived/related net is defined as $\left[\mathrm{X}_{\mathrm{m}} \mathrm{Y}\right] \mathrm{Z}_{\mathrm{n}}$ by coordination figure. This means $\mathrm{Y}$ is linked to $m \mathrm{X}$ and $n \mathrm{Z}$, or $m$ plus $n$ is equal to the connectivity of $\mathrm{Y} .\left[\mathrm{X}_{\mathrm{m}} \mathrm{Y}\right]$ is derived from the parent net after the operation process. It is worth noting that in this review we derived nets starting from tetrahedron because the replacement of square building block has been extensively reviewed in previous work. ${ }^{73}$ Moreover, the emphasis of this review is the derived and related net with transitivity [32], or minimal edge-transitive net (Table. 2 ).

It is to be mentioned that the distinction between derived and related nets is simple. Nets with transitivity [32] are derived from nets with transitivity [21] with vertices type A and type B. Vertex A is replaced by a group of linked vertices to produce a [32] net. If the coordination number of $B$ is unchanged then the new net is derived from the old one. If the coordination number of $B$ is increased, the new net is related. ${ }^{92}$

To further illustrate the relationship between parent net and derived/related net, the 4,6-c soc net, 3,6-c edq net, and 3,4,12-c kce net were depicted in Scheme. 1. The edq net was obtained from the soc net via replacing 4 -c square node by two symmetrical triangular nodes with the operation of S-o-2. The coordination number of 6-c node remains unaltered, thus the edq net is a soc-derived net. It is to be noted that the transitivity of the edq net is [2232] with two kinds of nodes due to the two triangular nodes are symmetrically identical. By substituting the 4 -c nodes with a set of $3^{-\mathrm{C}}$ and $4^{-\mathrm{C}}$ nodes, the kce net was obtained from the soc net with the operation of S-1-4. The coordination number of vertex B of the kce net (i.e. 12) is double than that of soc net (i.e. 6), so the kce net with the $\mathrm{CF}=\left[\mathrm{S}_{3}\right] \mathrm{X}_{2}$ is a soc-related net. Their associated augmented nets were illustrated to pinpoint the needed information in the associated building units for their use as blueprint nets for the assembly of crystalline MOF materials. 
Scheme.1 An illustration of the relationship between parent net and derived/related nets using Al-soc-MOF-193 (socderived edq net) and RE-kce-MOF-1 ${ }^{92}$ (soc-related kce net). Reproduced with permission from reference ${ }^{92}$. Copyright 2019 American Chemical Society.
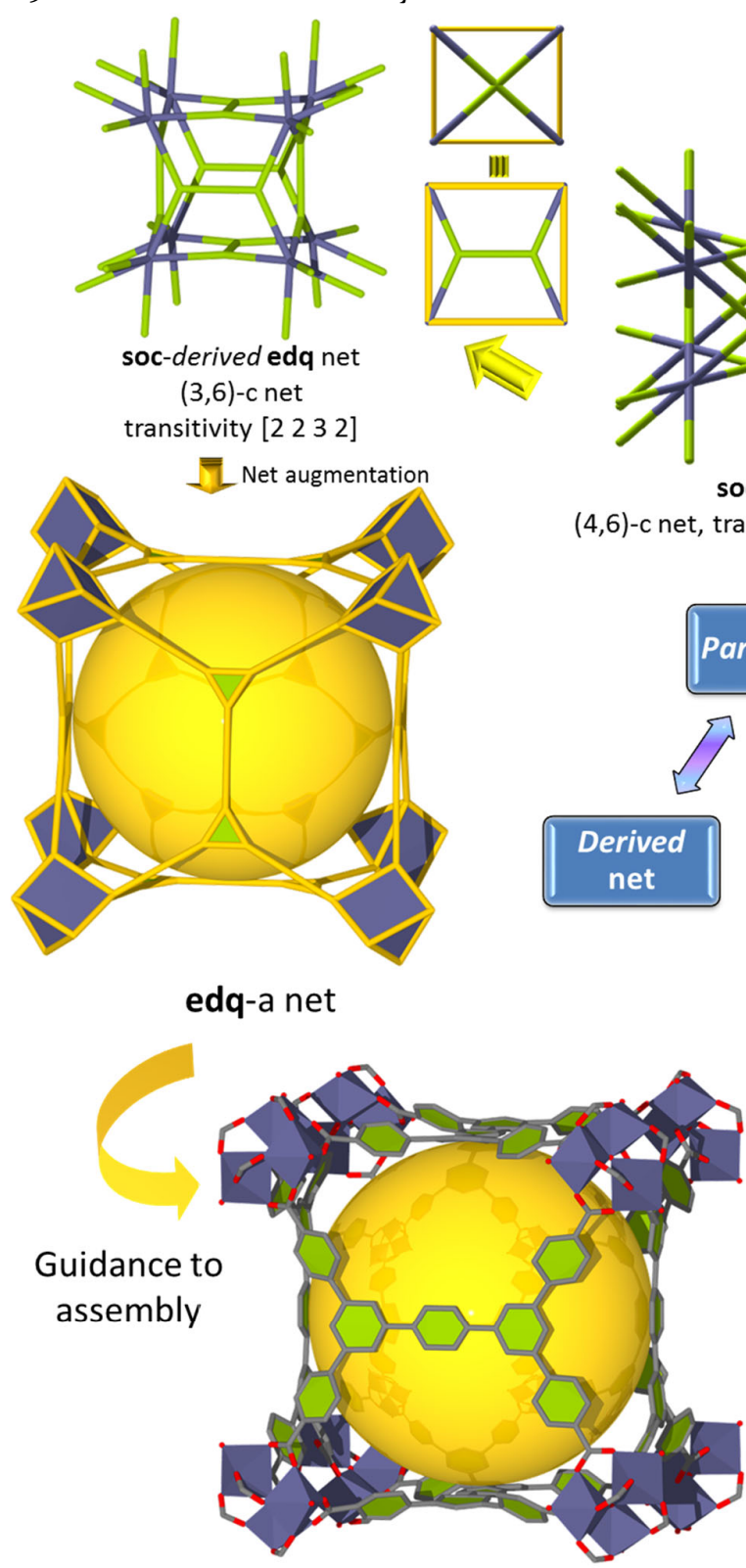

Al-soc-MOF-1

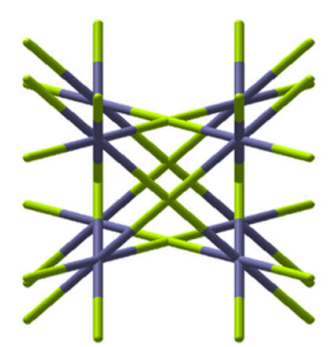

soc net

$(4,6)$-c net, transitivity [ $\left[\begin{array}{llll}2 & 1 & 2 & 2\end{array}\right]$
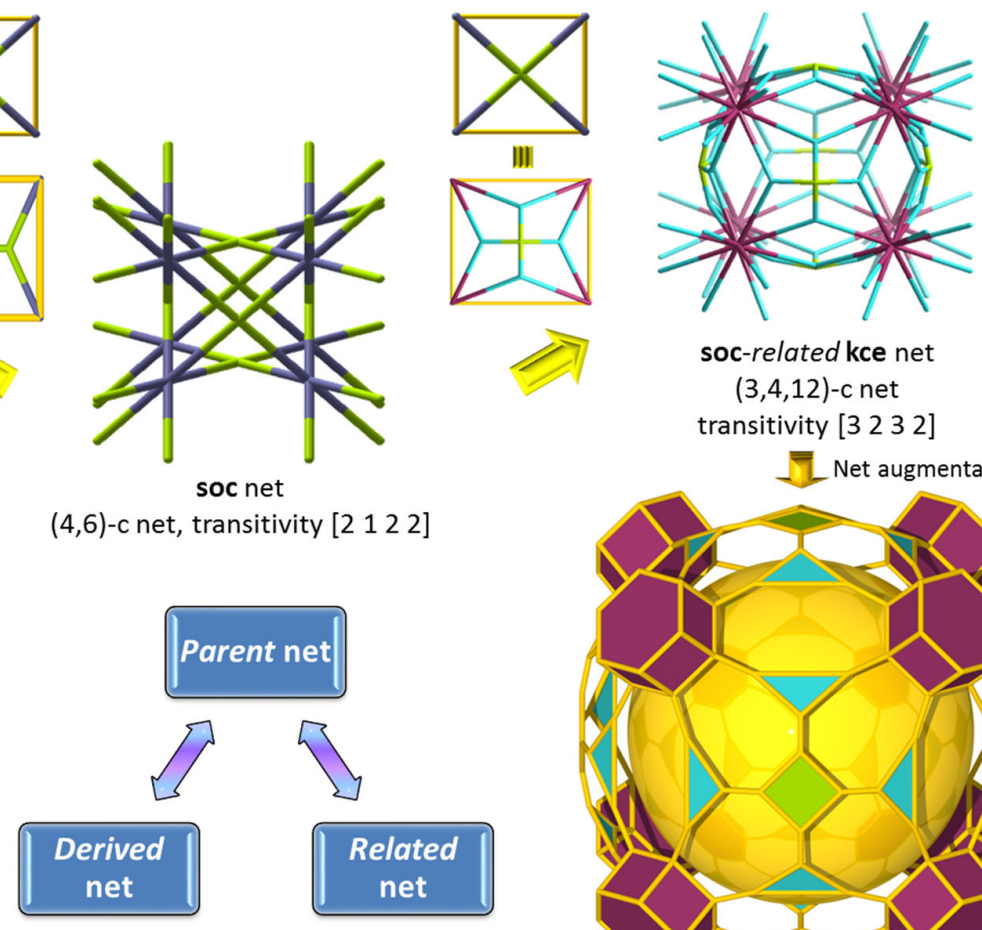

soc-related kce net

$(3,4,12)-c$ net

transitivity [ [ $\left.\begin{array}{llll}3 & 2 & 3 & 2\end{array}\right]$

- Net augmentation

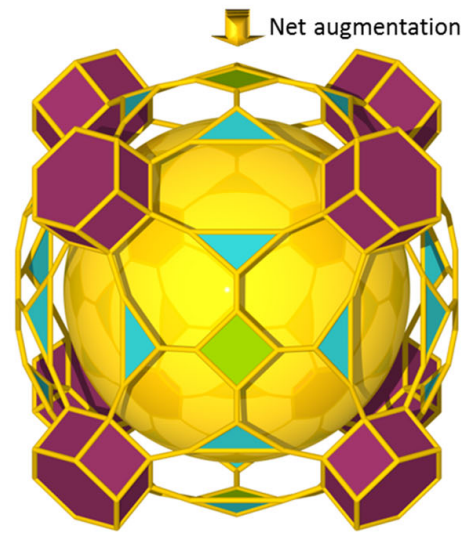

kce-a net

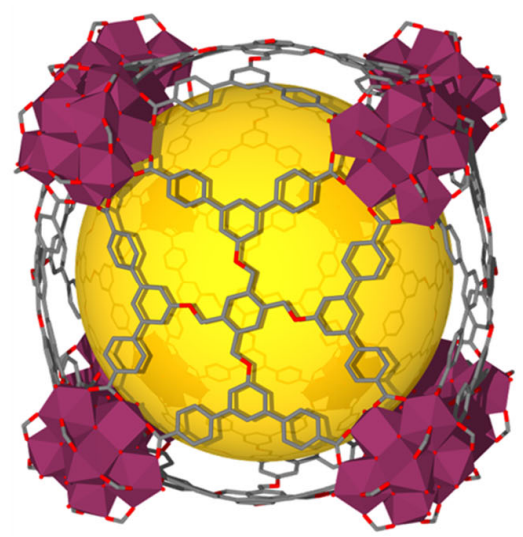

RE-kce-MOF-1

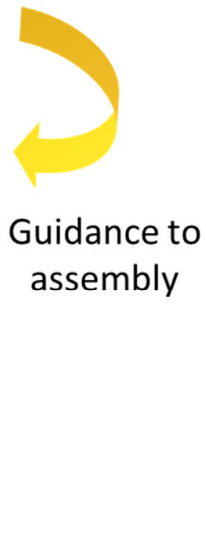




\subsubsection{The Replacement of the Tetrahedral Node}

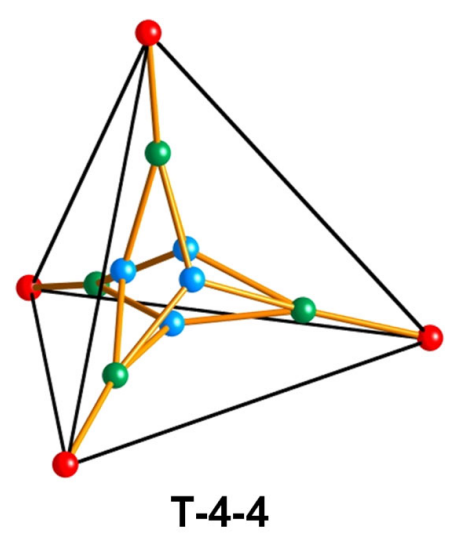

Figure. 1 The replacement of the 4-c tetrahedral node (T) with a group of two kinds of nodes.

As shown in the Figure. 1, one tetrahedral node is replaced with an edge-transitive binodal group (e.g. blue and green atoms). Thus, the derived nets of the parent nets with vertex figure $\mathrm{T}$, for example, dia-b (the binary version of dia net, $\mathrm{CF}=\mathrm{T}, \mathrm{T})$ or flu $(\mathrm{CF}=\mathrm{T}, \mathrm{C})$ net, are generated by this operation (T-4-4). In the T-4-4 operation, the first integer 4 means the four blue 3 -c nodes in the center of this binodal group, the second 4 denotes the 4 -c green nodes linking the central nodes and the vertices of the parent building blocks (red atoms). The $\mathrm{CF}$ for the newly generated net from the parent dia net, xbz net, is $\left.{ }_{3{ }_{3}} \mathrm{~T}\right] \mathrm{T}$, indicating the 4 -c tetrahedral node (green, $\mathrm{T}$ ) is linked to three 3-c triangular nodes (blue, 3 ) and one tetrahedral node (red, $\mathrm{T}$ from parent net). Therefore, the $\mathbf{x b z}$ net is the derived net of the dia net, since the coordination number of the red node (from parent net) remains unchanged. Following the same rationale, the $\mathrm{CF}\left(\left[{ }_{3} \mathrm{~T}\right] \mathrm{C}\right)$ of ntu net, the flu-derived net, indicates the tetrahedral node $(T)$ is linked to three triangular nodes (3) and one 8-c cubic node (C). Note that the space groups (SPGRs) of the aforementioned derived nets are identical with their according parent nets but this is not universal. A previous reported organic-inorganic structure based on polyhedral oligomeric silsesquioxanes (POSS) could be analyzed as a $(3,4,8)$-c ntu net. ${ }^{94}$

\subsubsection{The Replacement of the Octahedral Node}

The possibilities of replacing octahedral node with two kinds of nodes are listed above. (Figure. 2) 7 edge transitive nets (pcu, nia, soc, spn, ocu, toc, ibd) with VF $=\mathrm{O}$, are selected for these operations. For the pcu net, the pcu-b net is chosen (i.e. binary version). Through the operation $\mathrm{O}-1-3$, the tsh net $\left(\mathrm{CF}=\left[{ }_{33}\right] \mathrm{O}_{2}\right)$ is derived from the pcu net. In this case, the octahedron building block is split into two kinds of triangular nodes (blue and green). The generation of new nets from the parent pcu net by the operations (O-1-4, O-1-6a, O-1-6b, O-1-8, O-1-12) give the nets with minimal transitivity [32], dnb, epu, epv, dnc, and dnd net, respectively. MOFs95-97 based on the $(3,6)-\mathrm{c}$ zxc net derived from pcu, have been discussed in the previous review 73 and will not be included here. A special example is a $\mathrm{MOF}^{9} 8$ made from $\mathrm{Zn}_{4} \mathrm{O}\left(\mathrm{O}_{2} \mathrm{C}-\right)_{6}$ and hexatopic linkers, which can be deconstructed into two symmetrical tetrahedral nodes. The overall topology of this MOF is based on 4,6-c pcu-derived fsn net with transitivity [22], which is a uniform net (all rings are 5membered).

Those newly generated nets are pcu-related nets because the coordination numbers of vertices from parent net (red nodes) are increased; say, two distinct routes from the central blue atom(s) to the red atoms. This is also exemplified by the CF of these nets. For example, CF of the dnb net, $[\mathrm{TT}] \mathrm{U}_{3}$ (operation $\left.=\mathrm{O}-1-4\right)$, means that the tetrahedral node (green, $\mathrm{T}$ (middle)) links to one central tetrahedral node (blue, $\mathrm{T}$ ) and three truncated tetrahedral nodes (red, U). The coordination number of truncated tetrahedron (12; $\mathrm{U})$ is two times higher than the original octahedron $(6 ; \mathrm{O})$. In other nets, epu $\left(\left[\mathrm{H}_{3}\right] \mathrm{X}_{2}\right)$, epv $\left(\left[\mathrm{O}_{3}\right] \mathrm{X}_{2}\right)$, dnc $\left([\mathrm{CT}] \mathrm{R}_{3}\right)$, and dnd $\left(\left[\mathrm{B}_{3}\right] \mathrm{K}_{2}\right)$ net, the coordination numbers of new red nodes (hexagonal prism $(\mathrm{X})$, rhombicuboctahedron (R), and truncated octahedron (K)) are enlarged compared to octahedron. Other new generated nets, $\mathbf{x b q}$ and $\mathbf{n t v}$, by the operation O-4-6 and $\mathrm{O}-8-6$, are the pcu-derived net, with $\mathrm{CF}=\left[{ }_{323}\right] \mathrm{O}$ and $\left[{ }_{3} \mathrm{Q}\right] \mathrm{O}, \mathrm{Q}=$ square pyramid. To be noted that the operation O-8-12 on pcu-b net did not give the minimal edge-transitive net, thus the net was not included here.

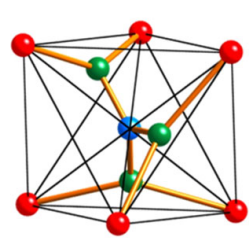

0-1-3

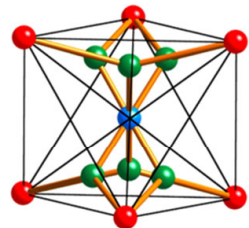

$0-1-6 b$

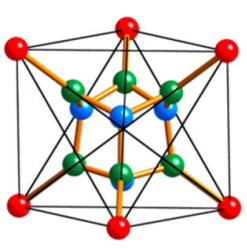

0-4-6

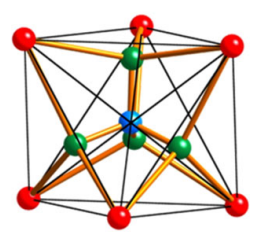

0-1-4

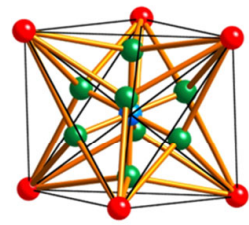

0-1-8

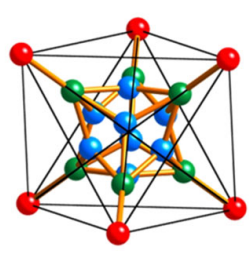

0-8-6

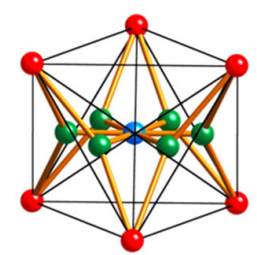

0-1-6a
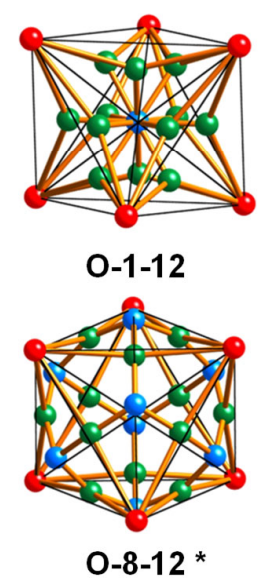

Figure. 2 The replacement of the 6 -c octahedral node (O) with a group of two kinds of nodes. * denotes that this operation does not give MT net. ${ }^{86}$ 
The replacement of the octahedron in the nia net $(\mathrm{CF}=$ $\mathrm{O}, \mathrm{P})$, by the operation $\mathrm{O}-\mathbf{1 - 3}$, led to the $(3,3,6)$-c jjt net ${ }^{99^{-}}$ ${ }^{100}$, a nia-derived net with $C F=[33] \mathrm{P}_{2}$. Triangle in the middle is linked to two trigonal prisms and one central triangle. The kex and urx net are two related net of the nia net, by the operation O-1-6a and O-1-6b. Both kex (CF $\left.=\left[\mathrm{H}_{3}\right] \mathrm{X}_{2}\right)$ and urx $\left(\mathrm{CF}=\left[\mathrm{O}_{3}\right] \mathrm{X}_{2}\right)$ are the $(3,6,12)$-c net with the same symmetry $P 6_{3} / m m c$, but kex net includes triangle, hexagon, and double six-membered-ring (d6R; hexagonal prism) while urx net contains triangle, octahedron and d6R..$^{2}$ Again, the coordination numbers of the new generated red nodes (12) are increased in the kex and urx net compared to the nia net (6). This class of highly-connected minimal edge-transitive nets offers great potential for the rational construction of MOFs with specific pore geometry and pore-aperture, as discussed and highlighted later in this review.

The operation $\mathrm{O}-1-3$ of the $(4,6)$-c soc net ${ }^{101}(C F=S, O)$, led to the $(3,3,4)$-c hey net $\left(C F=S_{2}[33]\right)$. The hey net was observed in a lanthanide-based MOF, UTSA-61, made from $\operatorname{TbO}\left(-\mathrm{CO}_{2}\right)_{4}$ and hexacarboxylate ligands, which can be viewed as an octahedral SBU. ${ }^{102}$ The triangular building block (3) in this soc-derived net is linked to two squares (S) and one triangle (3). This is quite different from the socMOFs based on the derived edq net with $4^{-c}$ ligands and 6-c trinuclear metal cluster nodes so it is important to give both the parent and derived/related net for a new structure. The process O-1-6a and O-1-6b of the $(3,6)$-c spn net (CF $=3, \mathrm{O})$, afforded the $\mathbf{d n f}$ and $\mathbf{d n g}$ nets, with the $\mathrm{CF}=$ $\left[\mathrm{H}_{3}\right] \mathrm{H}_{2}$ and $\left[\mathrm{O}_{3}\right] \mathrm{H}_{2}$, respectively. These two nets are the spn-related net, as indicated by the triangle in the spn net converted to the hexagon ( $\mathrm{H}$, outside the bracket) in the new nets.

The operation O-1-6a on the $(6,8)$-c ocu net $(\mathrm{CF}=\mathrm{O}, \mathrm{C})$, produced the uro net $\left(\mathrm{CF}=\left[\mathrm{H}_{3}\right] \mathrm{G}_{2}\right)$. The uro net, the ocurelated net, is a novel $(3,6,16)$-c net, with three classes of SBUs (triangle, hexagon and octagonal prism). The octagonal prism comes from the cube in the ocu net. The dni net, an ocu-derived net, is created by the procedure $\mathrm{O}$ $1-3$, with the $\mathrm{CF}=[33] \mathrm{A}^{*}$. The $A^{*}$ means square antiprism, from the morphing of the cube $(C)$ in the original ocu net. Note that the reasonable morphing phenomenon has already been exemplified in the soc-MOF, where the octahedron of the parent soc net morphed into the trigonal prismatic SBU in the derived edq net (3,6-c net)..$^{73}$

The procedure O-1-3 and O-1-6a on the toc net $(\mathrm{CF}=\mathrm{T}, \mathrm{O})$ give two new nets, tot and $\mathbf{d n j}$, respectively. The tot net, with the $C F=T_{2}[33]$, is the toc-derived net. The green triangle (3) in this new derived net is linked to two tetrahedral (T) and one central blue triangle (3). The dnj net, with the $C F=\left[\mathrm{H}_{3}\right] \mathrm{E}_{2}$, is the toc-related net. The coordination number of the tetrahedron (4) in the parent is half compared to that of the octagon (8) in the new net. The iac-d net is produced from the cubic ibd net by the process $\mathrm{O}-1-3$ with the $\mathrm{CF}=\mathrm{T}_{2}[33]$.

\subsubsection{The Replacement of the Trigonal Prismatic Node}

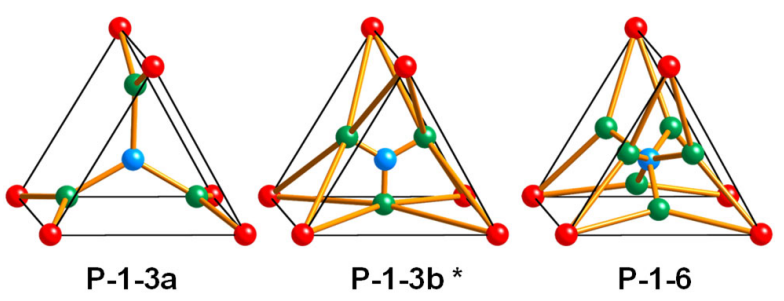

Figure. 3 The replacement of the 6-c trigonal prismatic node $(\mathrm{P})$ with a group of two kinds of nodes. * denotes that this operation does not give MT net. ${ }^{86}$

The five edge transitive nets (acs-b, nia, alb, stp, tpt) based on the trigonal prismatic SBU were used to generate new derived nets in this part. As exemplified in the Figure. 3, the 6-c trigonal prismatic node can be split into two types of nodes in three different ways. To be noted that the trigonal prism can also be replaced with two symmetrical tetrahedral nodes. Thus, a series of the derived net with minimal transitivity [22] can be generated from the edge transitive parent net. For example, the xai net ${ }^{103}$ can be derived from the stp net and the cen net ${ }^{83}$ can be generated from the alb net, by the replacement of the trigonal prismatic node in the parent net with two symmetrically equal tetrahedra. The reticular synthesis of MOFs based on the $(4,4)$-c stp-derived xai net has been accomplished recently by the combination of tetratopic metalloporphyrinic linkers and trigonal prismatic building units, formed by bridging frusta building units $\left(\mathrm{Zn}_{4}\left(1,2,3^{-}\right.\right.$ triazole $\left.)_{3}\right)$ with ditopic carboxylates (2,5thiophenedicarboxylate). ${ }^{103}$ Additionally, MOFs based on trinuclear metal trimers and tetratopic linkers have been reported based on the stp and its derived net. ${ }^{104^{-105}}$ In the review, the particular emphasis will be on the derived or related net with MT [32].

The process $\mathrm{P}-1-3 \mathrm{a}$ of the $(6,6)-\mathrm{c}$ acs-b net $(\mathrm{CF}=\mathrm{P}, \mathrm{P})$, resulted in the $(3,3,6)$-c tsg net $\left(\mathrm{CF}=[33] \mathrm{P}_{2}\right)$. The acs net was previously observed in metal trinuclear cluster based MOF-235 $5^{106}$ and MIL-88 series $^{107}$. One of triangular building blocks (arms) from the 6-c trigonal prism in acsb net is linked to two trigonal prisms and one central triangle. The tsg net is the derived net of acs net. The early attempt to achieve MOF structures with acs-derived tsg net was unsuccessful due to the rotation of branched organic ligands. ${ }^{99}$ The tsg net was later observed in a MOF called

tp-

PMBB-5-acs-1 via a two-step crystal engineering approach. ${ }^{108}$ The operation $\mathrm{P}-\mathbf{1}-6$ of the acs-b net led to the dnm net, with the $C F=\left[\mathrm{P}_{3}\right] \mathrm{X}_{2}$. This net is the acs-related net, as indicated by the fact that the coordination number of the trigonal prism (6) in the acs-b net increased to 12 (X; $\mathrm{d} 6 \mathrm{R})$ in the new net.

The operation P-1-za on the $(6,6)$-c nia net $(C F=P, O)$, generated the tsa net $\left(\mathrm{CF}=[33] \mathrm{O}_{2}\right)$. The tsa net, the niarelated net, is a $(3,3,6)$-c net, with three kinds of SBUs (two symmetrically different triangles and one octahedron). The dnn net is the related net of the nia net, by the operation $\mathrm{P}-1-6$. The dnn $\left(\mathrm{CF}=\left[\mathrm{P}_{3}\right] \mathrm{X}_{2}\right)$ is the $(3,6,12)$-c net. It contains the same SBUs as the $\mathbf{d n m}$ net (triangle, 
trigonal prism and $\mathrm{d} 6 \mathrm{R})$, but with different space groups $\left(P \overline{6} m_{2}(\mathbf{d n m})\right.$ versus $\left.P 6_{3} m m c(\mathbf{d n n})\right)$. It is worth noting that MODF-1 with $\mathrm{Zn}_{4} \mathrm{O}\left(-\mathrm{CO}_{2}\right)_{6}$, one of the early MOFs with hexatopic ligands, is based on the nia parent net. ${ }^{109}$ However, the derived mod net has a transitivity of [45], and this is one special case that doesn't comply with minimal transitivity principle. ${ }^{73}$

The ury net is derived from the alb net $(\mathrm{P}, \mathrm{X})$, with the $\mathrm{CF}$ $=[33] \mathrm{X}_{2}$, by the operation P-1-3a. The triangular arm is linked to two hexagonal prisms and one central triangle. A MOF based on this net has been recently reported by our group by the introduction of the trigonal prism shaped hexatopic branched ligand. ${ }^{.1}$ The operation P-1- 6 on the alb net led to the $(3,6,24)$-c dno net, with the $C F=\left[\mathrm{P}_{3}\right] \mathrm{M}_{2}$. $\mathrm{M}$ means 24-c dodecagonal prism. This kind of operation led to the generation of highly-coordinated minimal edge transitive net.

The operation P-1-3a of both $(4,6)$-c stp (CF = S,P) and tpt $(\mathrm{CF}=\mathrm{T}, \mathrm{P})$ net, led to the generation of the $(3,3,4)$-c tfp net, with the $C F=S_{2}[33]$ and $S^{*}{ }_{2}[33]$, respectively. It is to be noted that the tetrahedral building unit of the tpt net morphed into the square building unit of the tpt-derived tfp net. In this case, the different parent nets have the same derived net. This is yet an exemplar why both the parent and derived nets should be provided when describing the underlying topology of an unknown network materials. The $(3,3,4)$-c tfp net was observed in tp-PMBB-6-stp-1 via a two-step crystal engineering approach. ${ }^{108}$ The operation P-1- 6 on the stp net led to the dnp net, with the $\mathrm{CF}=\left[\mathrm{P}_{3}\right] \mathrm{C}_{2}$. This net is the stp-related net, as revealed that the tetrahedron in the stp net transformed to the cube in the new net. Note that UTSA20 based on the (3,3,4)-c stp-derived zyg net has been discussed previously.73, 10

\subsubsection{The Replacement of the Hexagonal Node}

The operation $\mathrm{H}-1-3$ of the $(3,6)-\mathrm{c}$ nts net $(\mathrm{CF}=3, \mathrm{H})$, led to the $(3,3,4)-\mathrm{c}$ ntt net $\left(\mathrm{CF}=[33] \mathrm{S}_{2}\right)$ (Figure. 4). It should be mentioned that this beautiful cubic net is also the derived net of rht. The $(3,3,6)$-c dne net is derived from the hxg-b net, by the operation of $\mathrm{H}-1-3$, with $\mathrm{CF}=[33] \mathrm{H}_{2}$. It is to be noted that a $\mathrm{Zr}$-based MOF have been recently reported based on the 6-c hxg net and the augmented version of hxg net (hxg-a) is the $3^{-c} \mathbf{p b z}$ net (polybenzene). ${ }^{54}$ The operation $\mathrm{H}-1-6$ of the hxg-b net led to the epw net, with the $\mathrm{CF}=\left[\mathrm{H}_{3}\right] \mathrm{X}_{2}$. This net is the $\mathbf{h x g}$ related net, as indicated by the coordination number of the hexagon (6) in the hxg-b net enlarged to 12 (X; d6R) in the new epw net.

The operation $\mathrm{H}-1-3$ on the $(4,6)$-c she net $(\mathrm{CF}=\mathrm{S}, \mathrm{H})$, generated the het net $\left(\mathrm{CF}=\mathrm{T}^{*}{ }_{2}[33]\right)$ and the epn net (CF $=\mathrm{S}_{2}[33]$ ). The tetrahedral SBU in the derived het net rose from the morphing of the square SBU in the parent she net (the star indicates morphing). The dna net, the sherelated net, is a $(3,6,8)$-c net, with three kinds of SBUs (triangle, hexagon, and cube), by the operation $\mathrm{H}-1-6$.

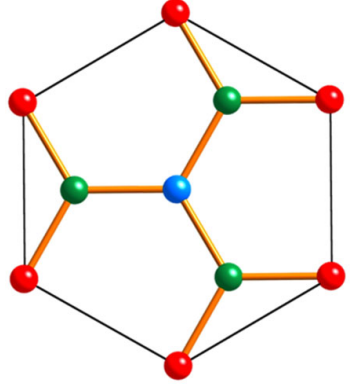

H-1-3

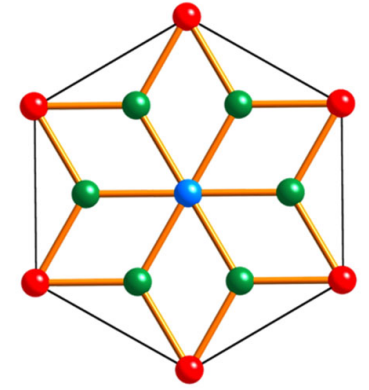

H-1-6
Figure. 4 The replacement of the 6-c hexagonal node (H) with a group of two kinds of nodes.

\subsubsection{The Replacement of the Cube Node}

The five edge transitive nets (bcu, flu, the, scu, csq) with the cube building unit were deployed to generate new nets. As illustrated in the Figure.5, the 8-c cubic node can be split into two kinds of nodes in eight ways.

The bcu net was observed in MOFs ${ }^{111-112}$ constructed from zirconium hexanuclear clusters and ditopic linkers, or $\mathrm{MOFs}^{13}$ assembled from metal organic polyhedrons (MOPs). Recently, a bcu structure was identified as a periodic "missing-linker" defective structure of a fcu structure by using high-resolution transmission electron microscopy. ${ }^{114}$

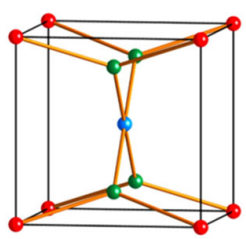

C-1-4a

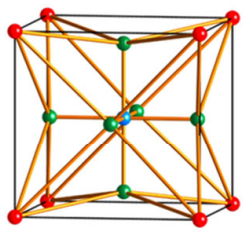

C-1-6 *

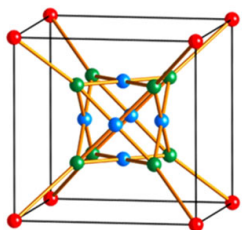

C-6-8

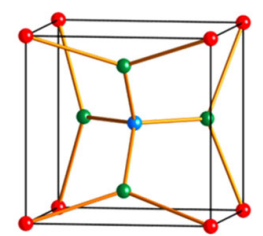

C-1-4b

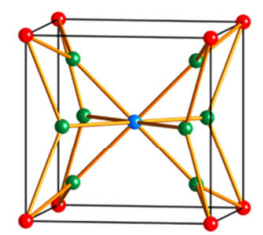

C-1-8

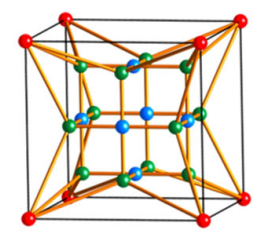

C $-6-12$ *

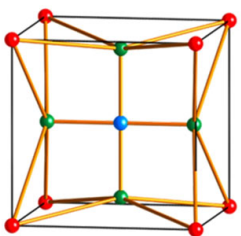

C-1-4c *

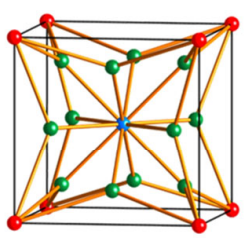

C-1-12
Figure. 5 The replacement of the 8-c cube (C) node with a group of two kinds of nodes. * denotes that this operation does not give MT net. ${ }^{86}$

Here, we attempted to derive the nets from the parent $\mathbf{b c u}$ net. The eft net is derived from the bcu-b net $(C, C)$, with 
the $\mathrm{CF}=\left[\mathrm{S}_{3}\right] \mathrm{C}_{2}$, by the operation $\mathrm{C}-\mathbf{1}-4 \mathrm{a}$. The triangular arm is linked to two cubes and one central square. The process $C-1-4 b$ on the bcu-b net led to the $(3,4,8)$-c dnq net, with the $C F=\left[\mathrm{T}_{3}\right] \mathrm{C}_{2}$. The operation $\mathrm{C}_{-1-8}-8$ and $\mathrm{C}_{-1-12}$ on the 8-c bcu-b net gave the $(3,8,16)$-c urs net $(\mathrm{CF}=$ $\left.\left[\mathrm{C}_{3}\right] \mathrm{G}_{2}\right)$ and the $(3,12,24)-\mathrm{c}$ uru net $\left(\mathrm{CF}=\left[\mathrm{B}_{3}\right] \mathrm{R}_{2}\right)$, respectively. The triangle (3) in the uru net is linked to one cuboctahedron (B) and two rhombicuboctahedron (R) SBUs. Again, this type of procedure resulted in the generation of related nets, mainly highly coordinated minimal edge transitive nets, offering prospect suitable targets for designed syntheses.

Additionally, two bcu-related nets-urt and urf netwere generated from the parent bcu net via the operation $\mathrm{C}-1-8$ and $\mathrm{C}-1-12$, respectively. The urt net $\left(\mathrm{CF}=\mathrm{S}_{2}\left[{ }_{3} \mathrm{C}\right]\right)$ and urf net $\left(\mathrm{CF}=\mathrm{O}_{2}[3 \mathrm{~B}]\right)$ have the space group $I_{4} / \mathrm{mmm}$ and $\operatorname{Im} \overline{3} m$, respectively. Note that the symmetry of bcu $(\operatorname{Im} \overline{3} m)$ differs from that of bcu-b $(P m \overline{3} m)$, so their related nets are also different.

The operation C-1-4a and C-1-4b of $(4,8)-c$ flu $(C F=T, C)$ produced the flu-derived $(3,4,4)$-c tfj and ofp net, with the $\mathrm{CF}=\mathrm{T}_{2}\left[{ }_{3} \mathrm{~S}\right]$ and $\mathrm{T}_{2}\left[{ }_{3} \mathrm{~T}\right]$, respectively. A polyoxometalateBased MOF was synthesized based on the ofp net ${ }^{115}$, which can further be regarded as A-B-A pillaring of sql layers ( square lattice $=\mathbf{s q l}$ ) by the supermolecular building layer (SBL) approach. ${ }^{9}$ The operation $\mathrm{C}-1-8$ and $\mathrm{C}-1-12$ on the flu net formed the tee net and urw net, with the $C F=\left[C_{3}\right] E_{2}$ and $C F=\left[B_{3}\right] U_{2}$, respectively. These nets are the flurelated nets, as revealed that the tetrahedron $(\mathrm{T})$ in the flu net converted to the related octagon (E) and truncated tetrahedron (U) in the novel nets. The dpd net derived from the flu net by the C-6-8 operation, with the coordination figure $\mathrm{T}\left[\mathrm{TS}_{3}\right]$.

The operation $\mathrm{C}-1-4 \mathrm{a}$ and $\mathrm{C}-1-4 \mathrm{~b}$ on the $(3,8)-\mathrm{c}$ the net led to the $(3,3,4)-\mathrm{c}$ tfe and $\mathbf{t f y}$ net, with the $\mathrm{CF}=3_{2}\left[{ }_{3} \mathrm{~S}\right]$ and $\mathrm{CF}$ $=3_{2}\left[3_{\mathrm{T}} \mathrm{T}\right.$, respectively. These nets are the the-derived nets. The tfe net was previous observed in MOFs based on tritopic linkers and two zinc clusters (i.e. 4-c $\mathrm{Zn}_{2}\left(\mathrm{O}_{2} \mathrm{C}-\right)_{4}$ and 3-c $\left.\mathrm{Zn}_{2}\left(\mathrm{O}_{2} \mathrm{C}-\right)_{3}\right)$. ${ }^{116}$

The operation $\mathrm{C}-1-4 \mathrm{a}$ of $(4,8)$-c scu $(\mathrm{CF}=\mathrm{S}, \mathrm{C})$ led to the $(3,4,4)$-c ffc and eed net, with the $\mathrm{CF}=\mathrm{S}_{2}[3 \mathrm{~S}]$ and $\mathrm{T}_{2}^{*}{ }_{2}[3 \mathrm{~S}]$, respectively. It is to be mentioned that the square building unit of the scu net morphed into the tetrahedral building block of the scu-derived eed net. In this case, the same parent nets have two different derived nets by the same operation. This is another good example why both the parent and derived should be stated. The operation $\mathrm{C}-1-4 \mathrm{~b}$ on the scu net led to the derived $\mathbf{m m m}$ net, with the $\mathrm{CF}=$ $\mathrm{S}_{2}\left[{ }_{3} \mathrm{~T}\right]$. The use of octacarboxylate linker based on the tetrahedral core, in combination with copper paddlewheels, led to a MOF based on scu-derived $\mathbf{m m m}$ topology. ${ }^{117-119}$ And we didn't include other MOFs based on scu-derived net with higher transitivity here. ${ }^{120}$

MOFs based on the csq net have been widely explored for many applications such as catalysis and gas sorption thanks to the open pore structure features. ${ }^{121-124}$ These MOFs are often made with zirconium hexanuclear clusters nodes and tetretopic organic linkers. The $(3,4,4)$-c dnr net is derived from the $(4,8)$-c csq net with the hexagonal space group, by the operation $\mathrm{C}-1-4 \mathrm{a}$. This denotes a possible way to achieve the very open csq structure by the facile arrangement of copper paddlewheel clusters and octacarboxylate ligands based on the square core (e.g. C-1$4 a)$.

The operation C-1-4a and C-1-8 of $(6,8)$-c ocu $(C F=O, C)$ net, led to the generation of the $(3,4,6)$-c twf-d net and $(3,8,12)$-c urp net, with the $\mathrm{CF}=\mathrm{H}^{*}{ }_{2}[3 \mathrm{~S}]$ and $\left[\mathrm{C}_{3}\right] \mathrm{X}_{2}$, respectively. The twf-d net is an ocu-derived net while the urp net is an ocu-related net. It is worth nothing that the twf-d net was observed in copper-based MOFs. ${ }^{125}$

\subsubsection{The Replacement of the Cuboctahedral Node}

Essentially, highly-connected nets with at least one node higher than 12-connected greatly limit the number of the conceivable outcome nets for the assembly of their concomitant highly-coordinated MBBs. ${ }^{87}$ For illustration, only one edge-transitive net is based on the cuboctahedral building unit; that is the $(4,12)$-c ftw net. ${ }^{60}$

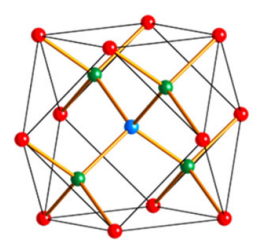

B-1-4 *

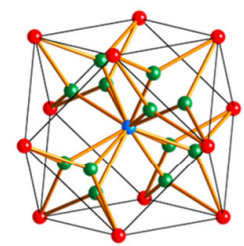

B-1-12

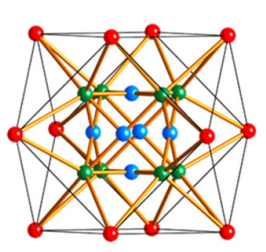

B-6-12

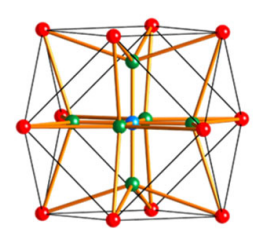

B-1-6 *

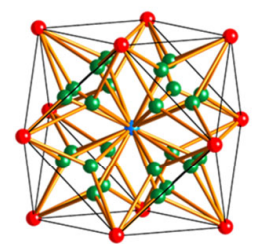

B-1-24

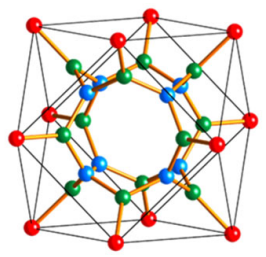

B-8-12

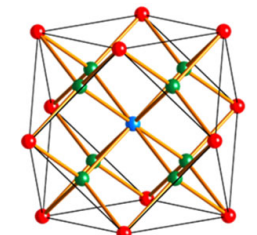

B-1-8 *

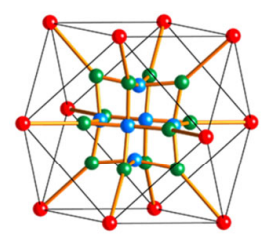

B-6-8
Figure. 6 The replacement of the 12-c cuboctahedral node (B) with a group of two kinds of nodes. * denotes that this operation does not give MT net. ${ }^{86}$

Herein, the ftw net would be used to generate new derived nets. The operation of $\mathrm{B}-1-4$ and $\mathrm{B}-1-8$ generated the derived nets with two vertices, which are out of the scope we discussing this review. The operation B-1-12 and B-1-24 of $(4,8)$-c ftw $(C F=S, B)$ led to the $(3,8,12)$-c dns net and $(3,16,24)$-c urq net, with the $C F=C_{2}[3 U]$ and $G_{2}[3 R]$, respectively. The operation $\mathrm{B}-6-8$ on the $\mathrm{ftw}$ net led to the dpe net, with the $\mathrm{CF}=\left[\mathrm{S}_{3} \mathrm{O}\right] \mathrm{C}_{3}$. These nets are the $\mathbf{f t w}$ related nets, as indicated by the coordination number of 
2

3

4

5

6

7

8

9 square in the $\mathrm{ftw}$ net increased in the new nets. The $(3,4,4)$-c gee net $\left(\mathrm{CF}=\left[\mathrm{S}_{23}\right] \mathrm{S}\right)$ and $(3,3,4)$-c tfe net $(\mathrm{CF}=$ $\left.\left[{ }_{23} 3\right] \mathrm{S}\right)$ are derived from the ftw net by the operation B-612 and B-8-12, respectively. It is to be noted that, some of ftw-derived net (i.e. $(3,3,12)$-c ttv, kle and kxe net) from the splitting of the square building unit were not included in this discussion. ${ }^{91}$

\subsubsection{The Replacement of the Icosahedral Node}

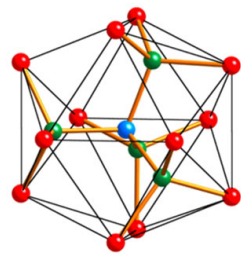

I-1-4

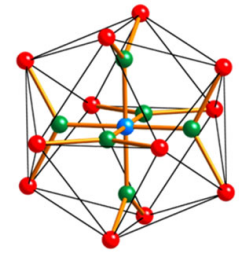

|-1-6

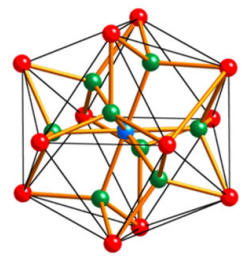

$\mathrm{I}-1-8$ *
Figure. 7 The replacement of the 12-c icosahedral node (I) with a group of two kinds of nodes. * denotes that this operation does not give MT net. ${ }^{86}$

The ith net $(\mathrm{CF}=\mathrm{T}, \mathrm{I})$, the sole possible edge-transitive net based on icosahedron, was used to generated the new minimal edge transitive net by the operation listed in Figure. 7. The I-1-4 led to the generation of ith-derived net, the $(4,4,4)-\mathrm{c}$ urh net, with the $\mathrm{CF}=[\mathrm{TT}] \mathrm{S}^{*}{ }_{3}$. MOFs based on a parent net with the icosahedral node is challenging for designed synthesis, although urh was observed in two metal cyanides. ${ }^{26}$

The [TT] came from the replacement of the icosahedral node and $\mathrm{S}^{*}$ from the morphing of tetrahedron in the parent net. The $(3,4,6)$-c gao net, with $\mathrm{CF}=\mathrm{T}_{2}[3 \mathrm{O}]$, was derived from the ith net by the operation I-1- 6 .

\subsubsection{The Replacement of the Truncated Tetrahedral Node}

Only two edge transitive nets are based on the 12-c truncated tetrahedral building unit; that is, the $(6,12)-\mathrm{c}$ mgc net $\left(\mathrm{CF}=\mathrm{H}, \mathrm{U} ; \mathbf{m g c}=\mathrm{MgCu}_{2}\right)$ and $(3,12)-\mathrm{c} \mathbf{t t t}^{-\mathrm{net}^{127}}$ $(\mathrm{CF}=3, \mathrm{U})$ (Figure. 8). $\mathrm{MgCu}_{2}$ is the simplest of a large family of binary intermetallic compounds. The $(4,4,6)$-c spl net (spinel) was derived from the mgc net by the operation $\mathrm{U}-1-4$, with the $\mathrm{CF}=[\mathrm{TT}] \mathrm{O}^{*}$. The operation $\mathrm{U}$ $1-6$ of the mgc net led to the $(3,6,6)-\mathrm{c}$ mgd net, with the $\mathrm{CF}=\left[\mathrm{O}_{3}\right] \mathrm{H}_{2}$. The $\mathbf{m g d}$ net is a derived net of the $\mathbf{m g c}$ net. The $(3,12,12)$-c dny net with coordination figure $\left[\mathrm{B}_{3}\right] \mathrm{X}_{2}$ is a mgc-related net by the operation U-1-12. The operation U4-6a and U-4-6b led to the generation of two mgc-derived nets, i.e. the $(3,4,6)-\mathrm{c} \mathbf{d n l}$ and $\mathbf{d n z}$ net, with the $\mathrm{CF}=$ $\left[{ }_{3} \mathrm{~S} \mathrm{O}^{*}{ }_{2}\right.$ and $\left[{ }_{3} \mathrm{~T}\right] \mathrm{O}^{*}{ }_{2}$, respectively. The operation $\mathrm{U}-1-4$ and $\mathrm{U}-1-6$ on the $(3,12)-\mathrm{c}$ ttt net led to the generation of the $(3,4,4)$-c xbz net and $(3,4,6)$-c xbq net, with the $\mathrm{CF}=$ $3_{3}[\mathrm{TT}]$ and $\mathrm{CF}=3_{2}\left[{ }_{3} \mathrm{O}\right]$, respectively. These nets are the tttderived nets.

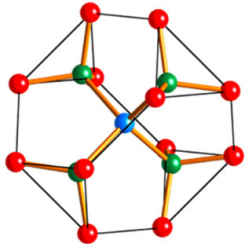

$\mathrm{U}-1-4$
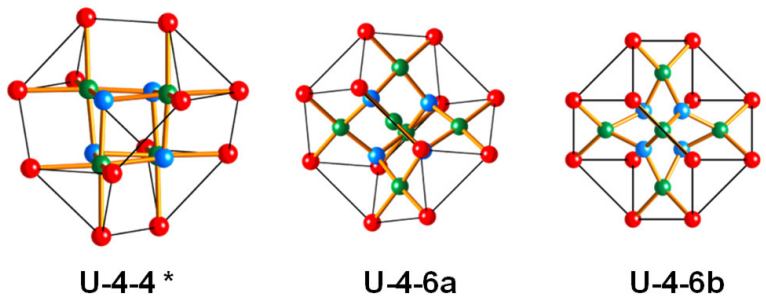

U-4-6b

Figure. 8 The replacement of the 12-c truncated tetrahedral node $(\mathrm{U})$ with a group of two kinds of nodes. * denotes that this operation does not give MT net. ${ }^{86}$

\subsubsection{The Replacement of the Hexagonal Prismatic Node}

The minimal edge-transitive shp- and alb-derived nets for the design and construction of highly-connected MOFs have been recently published. ${ }^{11,83}$ Herein, the related and derived nets with transitivity [32] would be systematically generated by the replacement of the hexagonal prism or double six-membered-ring (d6R). It is to be noted that the shp net and alb net are the only two possible edgetransitive nets based on d6R or hexagonal prism prior to most recent work (see Section 2.4). The operation X-1-3 on the shp net gave a shp-derived cei net with the $\mathrm{CF}=[3 \mathrm{Q}] \mathrm{S}_{4}$ (Figure. 9). The square pyramid is linked to four squares and one triangle. By enlarging unit cell $\left(c^{\prime}=2 c\right)$ of the parent shp net, the same operation produced another different shp-derived net with same coordination figure, the cek net. The cek net has a different space group compared to the cei net, $P 6_{3} / m m c$ vs. $P \overline{6} m 2$. Noted that the three letter codes (i.e. cei came from term 'Chen', 'Eddaoudi', and an alphabet from a-z; in this case were assigned to most of newly derived or related nets of the shp and alb net, which have been included in the RCSR database. 


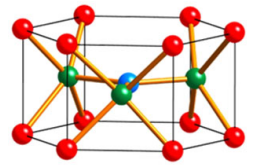

$\mathrm{X}-1-3$

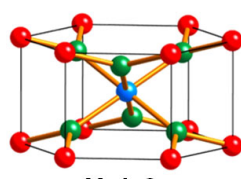

$X-1-6 c$

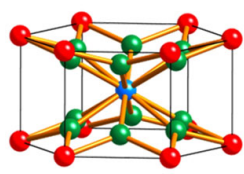

X-1-12

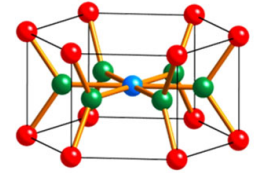
$X-1-6 a$

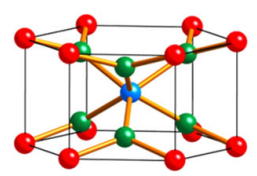

$X-1-6 d$

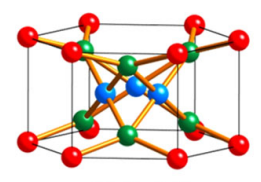

$X-3-6$ *

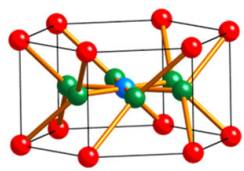

$x-1-6 b$

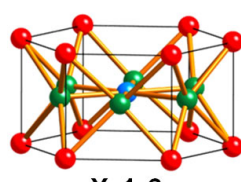

$x-1-6 e$

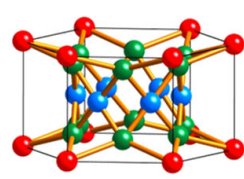

$X-6-12$ *
Figure. 9 The replacement of the 12-c hexagonal prismatic node $(\mathrm{X})$ with a group of two kinds of nodes. * denotes that this operation does not give MT net. ${ }^{86}$

The operation X-1-6a and X-1-6b on the shp net led to the generation of the $(3,4,6)$-c cee and ceh net, with the $\mathrm{CF}=$ $\mathrm{S}_{2}\left[{ }_{3} \mathrm{H}\right]$ and $\mathrm{CF}=\mathrm{T}^{*}{ }_{2}\left[{ }_{3} \mathrm{H}\right]$, respectively. These nets are the shp-derived nets. The operation X-1-6b $2 \mathrm{c}$, by the double of the unit cell of the parent shp net, formed another different shp-derived cez net, with the $\mathrm{CF}=\mathrm{S}_{2}\left[{ }_{3} \mathrm{H}\right]$. The ceh net has a space group $P 622$ while the cez net $P 6 /$ mcc. The operation $\mathrm{X}-1-6 \mathrm{c}$ and $\mathrm{X}-1-6 \mathrm{c} 2 \mathrm{c}$ gave the shp-derived nets, the ceg $(P \overline{3} m 1)$ and cej $\left(P 6_{3} / m m c\right)$ net, with the same $\mathrm{CF}=\mathrm{S}_{2}\left[{ }_{3} \mathrm{O}\right]$. The X-1-6d and X-1-6d 2c led to the shpderived nets, the cef $(P \overline{6} m 2)$ and agw $\left(P_{3} / m m c\right)$ net, with the same $\mathrm{CF}=\mathrm{S}_{2}\left[{ }_{3} \mathrm{P}\right]$. It should be mentioned that the agw net with MOF structures has been reported a long time ago yet to be recognized as a shp-derived net. ${ }^{128-129}$

The operation X-1-6e and X-1-12 on the shp net led to the generation of the $(5,6,8)$-c cel net and $(3,8,12)$-c pek net ${ }^{130}$, with the $\mathrm{CF}=[\mathrm{HQ}] \mathrm{C}_{4}$ and $\mathrm{CF}=\mathrm{C}_{2}[3 \mathrm{X}]$, respectively. These nets are the shp-related nets, as shown that the square in the parent net transformed to the cube in the newly generated nets.

The operation X-1-3 and X-1-3 2c on the $(6,12)$-c alb net gave the alb-derived nets, the $(3,5,6)-\mathrm{c}$ ala $\left(P \overline{6} \mathrm{~m}_{2}\right)$ and ceo $\left(P 6_{3} / \mathrm{mcm}\right)$ net, with the $\mathrm{CF}=\left[{ }_{3} \mathrm{Q}\right] \mathrm{P}_{4}$ and $\mathrm{CF}=\left[{ }_{3} \mathrm{Q}\right] \mathrm{O}^{*}{ }_{4}$, respectively. The octahedron in the ceo net is from the morphing of the trigonal prism in the alb net. The X-1-6a generated an alb-derived $(3,6,6)$-c kew net with the coordination figure $\left[\mathrm{H}_{3}\right] \mathrm{P}_{2}$. A mixed-metal MOF constructed from Cobalt-based nodes and $\mathrm{Ru}_{3} \mathrm{O}(\mathrm{OAc})^{6+}$ cluster-based struts is based on the $(3,6,6)$-c kew net. ${ }^{131}$

The operation X-1-6b and X-1-6b 2c on the alb-net led to the generation of the alb-derived nets, the $(3,6,6)-c$ key $(P 622)$ and kez $(P 6 / m c c)$ net, with the $\mathrm{CF}=\left[\mathrm{H}_{3}\right] \mathrm{O}^{*}{ }_{2}$ and $\mathrm{CF}=\left[\mathrm{H}_{3}\right] \mathrm{P}_{2}$, respectively. Another two alb-derived nets, the $(3,6,6)$-c cep $\left(P \overline{3} \mathrm{ml} ; \mathrm{CF}=\left[\mathrm{O}_{3}\right] \mathrm{O}_{2}^{*}\right)$ and cer $(P 6 / \mathrm{mcm}$; $\left.\mathrm{CF}=\left[\mathrm{O}_{3}\right] \mathrm{P}_{2}\right)$ net, are generated by the operation $\mathrm{X}-1-6 \mathrm{c}$ and $\mathrm{X}-1-6 \mathrm{c} 2 \mathrm{c}$, respectively. The ceq and cet net are newly

derived nets of alb net by the X-1-6d and X-1-6d 2C operation. The ceq net have a space group $P-6 m 2$ with $C F$ $=\left[\mathrm{P}_{3}\right] \mathrm{P}_{2}$ while the cet net $P 6_{3} / \mathrm{mcm}$ with $\mathrm{CF}=\left[\mathrm{O}_{3}\right] \mathrm{P}_{2}$.

The operation $\mathrm{X}-1-6 e$ and $\mathrm{X}-1-12$ on the alb net gave the alb-related nets, the $(5,6,12)$-c alc net and $(3,12,12)$-c aea net $^{130}$, with the $C F=[\mathrm{HQ}] \mathrm{X}_{4}$ and $\mathrm{CF}=\left[{ }_{3} \mathrm{X}\right] \mathrm{X}_{2}$, respectively.

2.3.10 The Replacement of the Truncated Octahedral Node

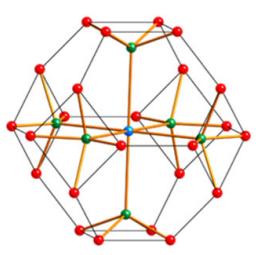

$\mathrm{K}-1-6$

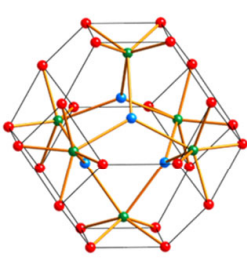

$\mathrm{K}-4-6$ *

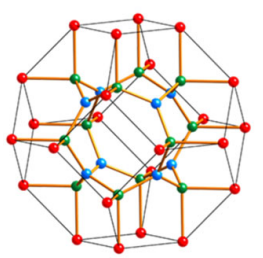

K-8-12

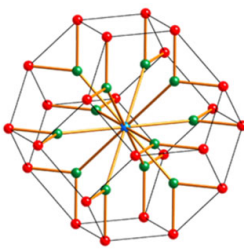

K-1-12

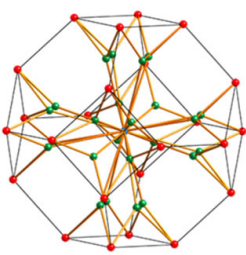

$\mathrm{K}-1-24$

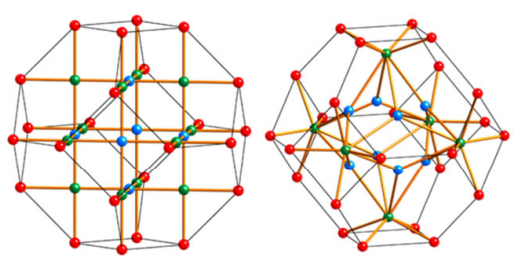

K-6-12

K-8-6

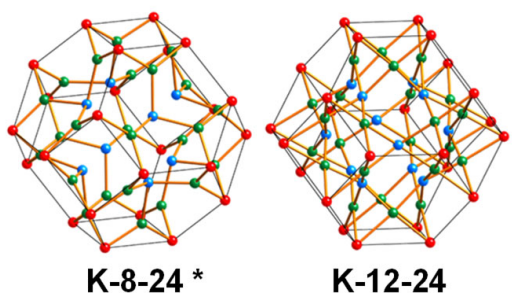

Figure. 10 The replacement of the 24-c truncated octahedral node $(\mathrm{K})$ with a group of two kinds of nodes. * denotes that this operation does not give MT net. ${ }^{86}$

The $\mathbf{t w f}$ net $(\mathrm{CF}=\mathrm{T}, \mathrm{K})$ is the only edge transitive net based on the truncated octahedral building unit. Deriving this net into the minimal edge-transitive net was performed based on the possibilities listed in Figure. 10. The operation K-1-6 generated the $(4,5,6)$-c twf-derived dnv net with coordination figure $\mathrm{T}_{4}[\mathrm{QO}]$. The xag net is a newly derived net of twf net by the operation K-1-12, with the $C F=S^{*}{ }_{4}[3 B]$. The xag net is a $(3,4,12)$-c net and the square building unit is morphing from the tetrahedron in the parent twf net. The xag net was observed in indiumbased MOFs with a cage-within-cage type structure. ${ }^{132}$ The operation $\mathrm{K}-1-24$ led to the generation of the twf-related $(3,8,24)$-c urv net with the $\mathrm{CF}=\mathrm{C}_{2}[3 \mathrm{R}]$. The coordination number of the tetrahedron (4) in the parent twf net is doubled compared to that of the cube (8) in the new urv net. The K-8-6 and K-8-12 gave the twf-derived nets, the $(3,4,8)$-c dnw and $(3,4,4)$-c dnx net, with the $\mathrm{CF}=\left[{ }_{3} \mathrm{~A}\right] \mathrm{T}_{4}$ and $\mathrm{CF}=\left[{ }_{32} \mathrm{~T}\right] \mathrm{S}_{2}^{*}$, respectively. The $\mathbf{d n x}$ net was observed in a silver-based twf-MOF. ${ }^{133} \mathrm{~A}$ new twf-related net, the 
2

3

4

5

6

7

8

9

$(4,4,8)$-c dnu net, was generated by K-12-24 with the $\mathrm{CF}=$ $\left[\mathrm{S}_{2} \mathrm{~S}\right] \mathrm{C}_{2}$. The K-4-8, an uncommon operation generating $7^{-}$ coordinated nodes, led to the formation of the twf-derived hcz net based on square, tetrahedron, and hexagonal pyramid, with $\mathrm{CF}=\mathrm{S}_{6}{ }_{6}[\mathrm{VT}]$. Recently, a multi-component MOF based on this unique hcz net has been synthesized, and the thorough analysis will be discussed later. ${ }^{134}$

\subsubsection{The Teplacement of the Rhombicuboctahedral Node}

Highly-connected MOFs based on the (3,24)-c rht net represent an important class of MOFs, with many applications relating to the gas storage and separation. ${ }^{69}$, ${ }^{135-144}$ The rht net $(\mathrm{CF}=3, \mathrm{R})$ was used to generate new derived or related nets based on the splitting of the rhombicuboctahedral node into two kinds of nodes (Figure. 11). It is to be noted that some of the generated nets with 2 vertices were not included in this discussion.

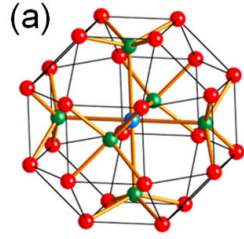

R-1-6

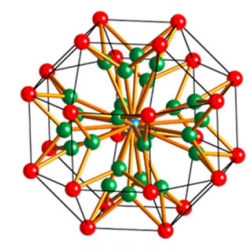

R-1-24

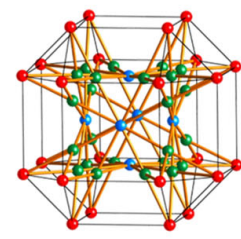

R-6-24 *

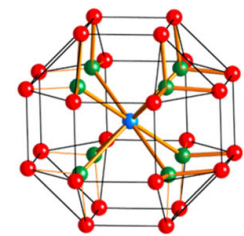

R-1-8

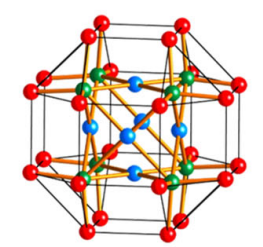

R-6-8

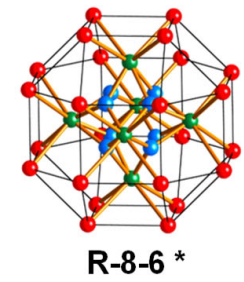

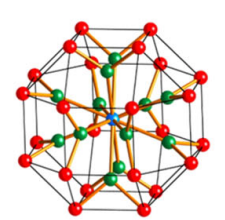

R-1-12

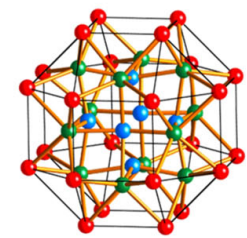

R-6-12

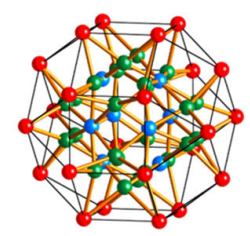

R-8-24 (b)

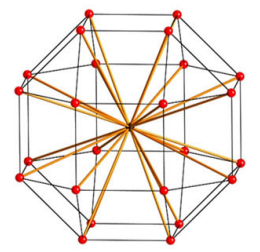

rht $=\mathrm{R}-1$

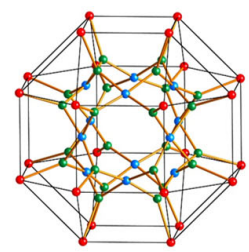

ntt $=\mathrm{R}-12-24$

Figure. 11. (a) The replacement of the 24-c rhombicuboctahedral node (R) with a group of two kinds of nodes. (b) The operation R-12-24 of rht net gave the rhtderived ntt net. ${ }^{*}$ denotes that this operation does not give MT net. ${ }^{86}$

The operation R-1-8 and R-1-12 on the rht net gave the rhtderived nets, the $(3,4,8)$-c ntu and $(3,3,12)-\mathrm{c}$ ntw net, with the $\mathrm{CF}=3_{3}[\mathrm{TC}]$ and $\mathrm{CF}=3_{2}\left[{ }_{3} \mathrm{I}\right]$, respectively. A new rhtrelated net, the $(3,6,24)$-c dnt net with the $\mathrm{CF}=\mathrm{H}_{2}\left[{ }_{3} \mathrm{~K}\right]$, was generated by the operation R-1-24. The $(3,5,6)-\mathrm{c}$ ntv net $\left(\mathrm{CF}={ }_{3}[\mathrm{QO}]\right)$, a rht-derived net, was given via the $\mathrm{R}-\mathrm{-1}^{-}$ 6 . The operation R-6-8 on rht net produced the $(3,4,6)$-c hmc net with the $\mathrm{CF}=3_{3}\left[\mathrm{PS}_{3}\right]$. A MOF based on this hmc net has been reported yet to be recognized as the rhtderived net. ${ }^{145}$ The dnk net with the $\mathrm{CF}=\left[\mathrm{S}_{2} \mathrm{P}\right] \mathrm{H}_{4}$, was engendered through the operation R-6-12. The dnk net is a new rht-related $(4,6,6)$-c net.

The rht-derived ntt net with coordination figure $3\left[{ }_{3} \mathrm{~S}_{2}\right]$, was generated from the operation R-12-24. It is to be noted that ntt net is also an nts-derived net. Thus, it is suggested to provide both the parent and derived net for a MOF compound with a novel topology; say, the underlying ntt net, depending on the strategic approach of synthesis, could be a nts-derived or rht-derived net.

\subsection{Minimal Edge-Transitive derived Nets from Non- Crystallograpic parent Nets}

We now turn to a new family of edge-transitive nets, somewhat unexpected but indeed opening a new venue to MOFs that are truly designable and highly porous. Essentially the nets of particular interest in the designed synthesis of crystalline MOFs are those called crystallograpic nets. A non-crystallographic net has symmetries that do not correspond to a space group operation. ${ }^{146}$ In fact, the early enumeration of edgetransitive nets, based on tiling theory, excluded the noncrystallograpic ones. ${ }^{61}$ Soon later a MOF was made with 4c square $\mathrm{Zn}_{2}$ paddlewheel and 6-c branched hexatopic carboxylate; ${ }^{144}$ however its parent net, which is $(4,6)$-c nts, has not been deposited in RCSR for many years. It turns out nts is a non-crystallographic edge-transitive net.

As shown in Figure 12 (top), nts has a local symmetry in which two vertices can be interchanged keeping the rest of the structure unchanged. Such a symmetry occurs when two vertices (here the 4-c ones) have the same neighbors, and fails to be recognized by the program Systre ${ }^{147}$ which can unambigously distinguish periodic nets. Through the operation $\mathrm{H}-1-3$ on the hexagonal vertex, the derived net, (3,3,4)-c ntt (MT [3 2]), is obtained (Figure 12, bottom). This prototype (nts-derived $\mathbf{n t t}$ ) represents a remarkable success in MOF chemistry with extensive designs made on the 2 edges in [3 2] to target ultrahigh surface areas. ${ }^{73}$ 

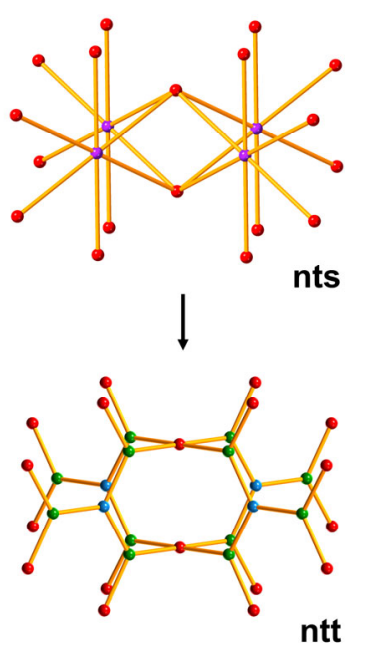

Figure. 12 A fragment of the non-crystallographic net nts and its derived net ntt through $\mathrm{H}-1-3$ operation. Note the two central 4-c nodes in nts have the same neighbors.

The same logic delineated in Section 2.3 has been applied to the newly found non-crystallographic edge-transitive nets ${ }^{148}$ to obtain their derived nets (Table 3 ). It is worth noting that minimal transitivity means minimal transitivity for given components (e.g. for 3 kinds of vertices the minimal number of edges is 2) so we say nets with MT [ 32 2] are minimal edge-transitive nets (specifically edge-2-transitive trinodal nets). ${ }^{74}$ Many of these noncrystallographic parent nets have planar vertex figures, including hexagon $(\mathrm{H})$, octagon (E) and dodecagon (D), which can be split in a similar way. Apart from the ones with $\mathrm{VF}=\mathrm{H}$, treated above $(\mathrm{H}-1-3)$, the derived [ 32 ] nets of

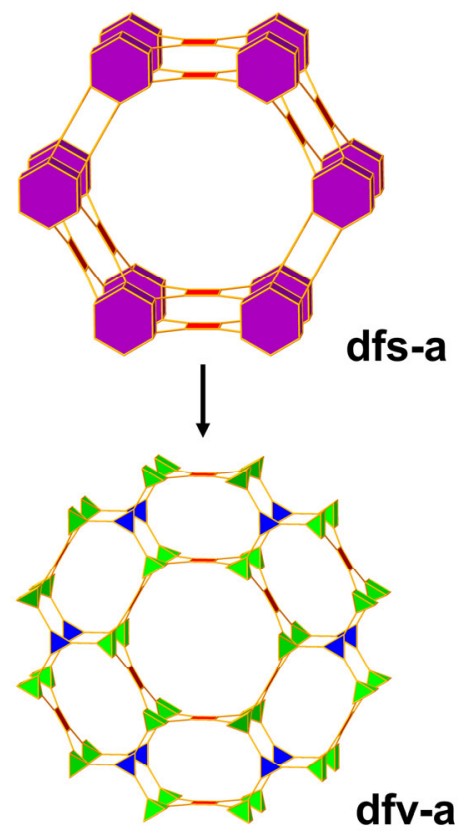

those $\mathrm{VF}=\mathrm{E}$ and $\mathrm{D}$ are obtained by adding a node between the center and two adjacent vertices of VF while keeping the coordination number of the rest unchanged, that is, through E-1-4 and D-1-6 operations, respectively. Occasionally, the derived net has the same or even lower transitivity compared with the parent net, or the derived net is still non-crystallographic, such as those derived from $(4,8)$-c cyc $(C F=S, C)$ through $C-1-4$ operation (therefore omitted).

Those highly-connected edge-transitive nets allow true design in MOF chemistry, which is the central topic of the present review. We also meet some of this sort in noncrystallographic nets of $\mathrm{VF}=\mathrm{X}$ (hexagonal prism, $\mathrm{z}=12$ ), $G$ (octagonal prism, $z=16$ ) and $U$ (truncated cube, $z=24$ ). A good example is the recently emerged mesoporous MOF, PCN-905- $\mathrm{SO}_{2},{ }^{149}$ with $(4,12)$-c dfs parent net (Figure 13, top left), a platform for joining square and hexagonal prism with large voids. Previously the only edge-transitive net offered for such a combination is shp (Figure 13, top right) ${ }^{61}$ the enumeration excluded the option of $\mathbf{d f s}$ because it is non-crystallographic, and now a MOF out of experimental trials has provided the missing piece. The shp platform (symmetry $P 6 / \mathrm{mmm}$ ) has been well established, including many derived and related nets of MT [3 2] (Table 2d), although the simplest derived net $(3,4,5)$ c cei (Figure 13, bottom right), met above, has a lower symmetry $(P \overline{6} m 2)$. The same operation $(\mathrm{X}-1-3)$ on the noncrystallographic dfs (symmetry $P 6 / \mathrm{mmm}$ ) gives $(3,4,5)$-c dfv (Figure 13, bottom left) with the same space group of the parent. In principle, the sophisticated blueprints outlined here (see the next section) should play the same magic.

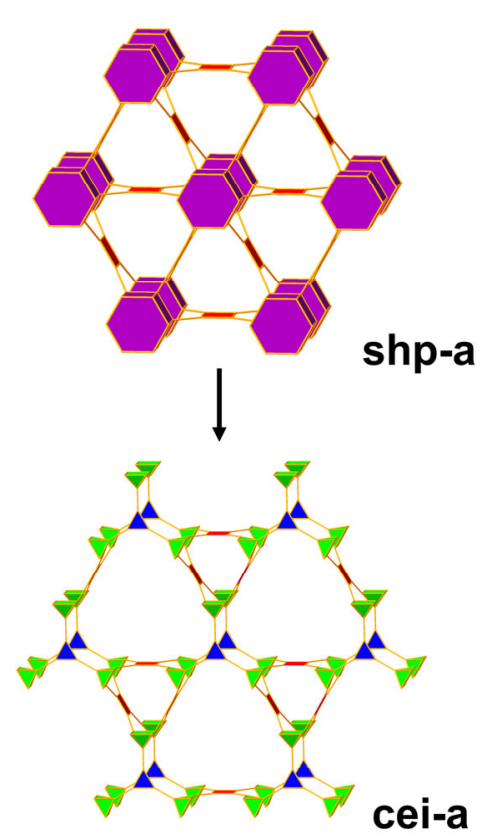

Figure. 13 Comparison between the augmented versions of non-crystallographic dfs net and crystallographic shp net, along with their derived $\left[\begin{array}{ll}3 & 2\end{array}\right]$ nets obtained from the same operation $(\mathrm{X}-1-3)$. 
Table. 2a Edge-transitive binodal parent nets and their minimal edge-transitive derived and related nets $(\mathrm{VF}=\mathrm{T}, \mathrm{O}, \mathrm{P}$, $\mathrm{H})$.

\begin{tabular}{|c|c|c|c|c|c|c|c|c|c|}
\hline $\mathrm{VF}^{a}$ & Parent net $\left(\mathrm{SPGR}^{b}\right)$ & $\mathrm{CF}^{c}$ & Coordination & Operation $^{d}$ & $\mathrm{~d}$ or $\mathrm{r}^{e}$ & $\mathrm{CF}^{c}$ & Coordination & $\mathrm{d}^{e}$ & $\mathrm{SPGR}^{b}$ \\
\hline \multirow[t]{2}{*}{$\mathrm{T}$} & dia-b $(\bar{F} \overline{4} 3 m)$ & $\mathrm{T}, \mathrm{T}$ & 4,4 & $\mathrm{~T}-4-4$ & $\mathbf{x b z}$ & {$\left[{ }_{33} \mathrm{~T}\right] \mathrm{T}$} & $3,4,4$ & $\times$ & $\overline{F 4} 3 m$ \\
\hline & flu $(F m \overline{3} m)$ & $\mathrm{T}, \mathrm{C}$ & 4,8 & $\mathrm{~T}-4-4$ & ntu & {$\left[{ }_{33} \mathrm{~T}\right] \mathrm{C}$} & $3,4,8$ & $x$ & $F m \overline{3} m$ \\
\hline \multirow[t]{20}{*}{$\mathrm{O}$} & pcu-b $(F m \overline{3} m)$ & $\mathrm{O}, \mathrm{O}$ & 6,6 & $\mathrm{O}-1-3$ & tsh & {$[33] \mathrm{O}_{2}$} & $3,3,6$ & $x$ & $R_{32}$ \\
\hline & & & & $\mathrm{O}-1-32 \mathrm{C}$ & zxc & {$[33] \mathrm{O}_{2}$} & $3,3,6$ & $x$ & $R \overline{3} c$ \\
\hline & & & & $\mathrm{O}-1-4$ & dnb & {$[\mathrm{TT}] \mathrm{U}_{3}$} & $4,4,12$ & & $\overline{F 4} 3 m$ \\
\hline & & & & $O-1-6 a^{f}$ & epu & {$\left[\mathrm{H}_{3}\right] \mathrm{X}_{2}$} & $3,6,12$ & & $R \overline{3} m$ \\
\hline & & & & $O-1-6 b^{f}$ & epv & {$\left[\mathrm{O}_{3}\right] \mathrm{X}_{2}$} & $3,6,12$ & & $R \overline{3} m$ \\
\hline & & & & $\mathrm{O}-1-8$ & dnc & {$[\mathrm{CT}] \mathrm{R}_{3}$} & $4,8,24$ & & $F m \overline{3} m$ \\
\hline & & & & $\mathrm{O}-1-12$ & dnd & {$\left[\mathrm{B}_{3}\right] \mathrm{K}_{2}$} & $3,12,24$ & & $F m \overline{3} m$ \\
\hline & & & & $O-4-6$ & $\mathbf{x b q}$ & {$[323] \mathrm{O}$} & $3,3,6$ & $x$ & $\overline{F 4} 3 m$ \\
\hline & & & & O-8-6 & ntv & {$\left[{ }_{3} \mathrm{Q}\right] \mathrm{O}$} & $3,5,6$ & $x$ & $F m \overline{3} m$ \\
\hline & nia $\left(P 6_{3} / m m c\right)$ & $\mathrm{O}, \mathrm{P}$ & 6,6 & $\mathrm{O}-1-3$ & jjt & {$[33] \mathrm{P}_{2}$} & $3,3,6$ & $x$ & $P \overline{6} 2 C$ \\
\hline & & & & $O-1-6 a^{f}$ & kex & {$\left[\mathrm{H}_{3}\right] \mathrm{X}_{2}$} & $3,6,12$ & & $\mathrm{PG}_{3} / \mathrm{mmc}$ \\
\hline & & & & $O-1-6 b^{f}$ & urx & {$\left[\mathrm{O}_{3}\right] \mathrm{X}_{2}$} & $3,6,12$ & & $\mathrm{~Pb}_{3} / \mathrm{mmc}$ \\
\hline & $\operatorname{soc}(\operatorname{Im} \overline{3} m)$ & $\mathrm{S}, \mathrm{O}$ & 4,6 & $\mathrm{O}-1-3$ & hey & $\mathrm{S}_{2}[33]$ & $3,3,4$ & $x$ & $I_{432}$ \\
\hline & spn $(F d \overline{3} m)$ & $3, \mathrm{O}$ & 3,6 & $O-1-6 a^{f}$ & $\operatorname{dnf}$ & {$\left[\mathrm{H}_{3}\right] \mathrm{H}_{2}$} & $3,6,6$ & & $F d \overline{3} m$ \\
\hline & & & & $O-1-6 b^{f}$ & dng & {$\left[\mathrm{O}_{3}\right] \mathrm{H}_{2}$} & $3,6,6$ & & $F d \overline{3} m$ \\
\hline & ocu $(\operatorname{Im} \overline{3} m)$ & $\mathrm{O}, \mathrm{C}$ & 6,8 & $O-1-6 a^{f}$ & uro & {$\left[\mathrm{H}_{3}\right] \mathrm{G}_{2}$} & $3,6,16$ & & $\operatorname{Im} \overline{3} m$ \\
\hline & & & & $\mathrm{O}-1-3$ & dni & {$[33] \mathrm{A}_{2}^{*}$} & $3,3,8$ & $x$ & $I 432$ \\
\hline & toc $(\operatorname{Pn} \overline{3} m)$ & $\mathrm{T}, \mathrm{O}$ & 4,6 & $\mathrm{O}-1-3$ & tot & $\mathrm{T}_{2}[33]$ & $3,3,4$ & $x$ & $P_{4232}$ \\
\hline & & & & $O-1-6 a^{f}$ & dnj & {$\left[\mathrm{H}_{3}\right] \mathrm{E}_{2}$} & $3,3,8$ & & $P n \overline{3} m$ \\
\hline & ibd $(I a \overline{3} d)$ & $\mathrm{T}, \mathrm{O}$ & 4,6 & $\mathrm{O}-1-3$ & iac-d & $\mathrm{T}_{2}[33]$ & $3,3,4$ & $\times$ & $\operatorname{Ia} \overline{3} d$ \\
\hline \multirow[t]{10}{*}{$\mathrm{P}$} & acs-b $(P \overline{6} 2 m)$ & $\mathrm{P}, \mathrm{P}$ & 6,6 & $P-1-3 a$ & tsg & {$[33] \mathrm{P}_{2}$} & $3,3,6$ & $\times$ & $P \overline{6} m 2$ \\
\hline & & & & $P-1-6$ & dnm & {$\left[\mathrm{P}_{3}\right] \mathrm{X}_{2}$} & $3,6,12$ & & $P \overline{6} m 2$ \\
\hline & nia $\left(P 6_{3} / m m c\right)$ & $\mathrm{P}, \mathrm{O}$ & 6,6 & P-1-за & tsa & {$[33] \mathrm{O}_{2}$} & $3,3,6$ & $x$ & $\mathrm{P}_{3} / \mathrm{mmc}$ \\
\hline & & & & $P-1-6$ & dnn & {$\left[\mathrm{P}_{3}\right] \mathrm{X}_{2}$} & $3,6,12$ & & $\mathrm{PG}_{3} / \mathrm{mmc}$ \\
\hline & alb $(P 6 / \mathrm{mmm})$ & $\mathrm{P}, \mathrm{X}$ & 6,12 & $\mathrm{P}-1-3 \mathrm{a}$ & ury & {$[33] \mathrm{X}_{2}$} & $3,3,12$ & $\times$ & $\mathrm{P6} / \mathrm{mmm}$ \\
\hline & & & & $P-1-6$ & dno & {$\left[\mathrm{P}_{3}\right] \mathrm{M}_{2}$} & $3,6,24$ & & $P 6 / \mathrm{mmm}$ \\
\hline & stp $(P 6 / \mathrm{mmm})$ & $\mathrm{S}, \mathrm{P}$ & 4,6 & P-1-за & $t f p$ & $\mathrm{~S}_{2}[33]$ & $3,3,4$ & $x$ & $P 6 / \mathrm{mmm}$ \\
\hline & & & & $\mathrm{P}-1-3 \mathrm{a} 2 \mathrm{c}^{g}$ & zyg & $\mathrm{S}_{2}[33]$ & $3,3,4$ & $x$ & $\mathrm{P}_{3} / \mathrm{mcm}$ \\
\hline & & & & $P-1-6$ & dnp & {$\left[\mathrm{P}_{3}\right] \mathrm{C}_{2}$} & $3,6,8$ & & $\mathrm{P} 6 / \mathrm{mmm}$ \\
\hline & tpt $(P 6 / m c c)$ & $\mathrm{T}, \mathrm{P}$ & 4,6 & $\mathrm{P}-1-3 \mathrm{a}$ & $t f p$ & $\mathrm{~S}_{2}^{*}[33]$ & $3,3,4$ & $\times$ & $\mathrm{P6} / \mathrm{mmm}$ \\
\hline \multirow[t]{5}{*}{$\mathrm{H}$} & $\mathbf{h x g}-\mathbf{b}(F d \overline{3} m)$ & $\mathrm{H}, \mathrm{H}$ & 6,6 & $\mathrm{H}-1-3$ & dne & {$[33] \mathrm{H}_{2}$} & $3,3,6$ & $\times$ & $\overline{F 4} 3 m$ \\
\hline & & & & $\mathrm{H}-1-6$ & epw & {$\left[\mathrm{H}_{3}\right] \mathrm{X}_{2}$} & $3,6,12$ & & $F d \overline{3} m$ \\
\hline & she $(\operatorname{Im} \overline{3} m)$ & $\mathrm{S}, \mathrm{H}$ & 4,6 & $\mathrm{H}-1-3$ & het & $\mathrm{T}^{*}{ }_{2}[33]$ & $3,3,4$ & $x$ & $I \overline{4} 3 \mathrm{~m}$ \\
\hline & & & & $\mathrm{H}-1-3$ & epn & $\mathrm{S}_{2}[33]$ & $3,3,4$ & $x$ & $P m \overline{3} m$ \\
\hline & & & & $H-1-6$ & dna & {$\left[\mathrm{H}_{3}\right] \mathrm{C}_{2}$} & $3,6,8$ & & $\operatorname{Im} \overline{3} m$ \\
\hline
\end{tabular}

${ }^{a} \mathrm{VF}=$ vertex figures, indicating the vertex figures of the parent edge-transitive nets.

${ }^{b}$ SPGR = space group, indicating the space group of parent and according derived and related net.

${ }^{c} \mathrm{CF}=$ coordination figure (shape of coordination). For binodal parent nets, $\mathrm{CF}$ referred to $\mathrm{W}, \mathrm{W}$. For example, $3 . \mathrm{R}$ is the $\mathrm{CF}$ for rht net. For trinodal derived and related net, the $\mathrm{CF}$ is specified as the form $\left[\mathrm{X}_{\mathrm{m}} \mathrm{Y}\right] \mathrm{Z}_{\mathrm{n}}$, indicating $\mathrm{Y}$ is linked to $\mathrm{m}$ $\mathrm{X}$ and $\mathrm{n} \mathrm{Z}$ and $\left[\mathrm{X}_{\mathrm{m}} \mathrm{Y}\right]$ is derived from the parent net. In special cases, derived and related nets are edge-transitive binodal nets, thus $\mathrm{CF}$ is in the form as $\mathrm{W}, \mathrm{W}$ and specified with $2 \mathrm{v}(2 \mathrm{~V}=2$ vertexs). If $\mathrm{Z}$ has a lower coordination number than $[\mathrm{XY}]$, the $\mathrm{CF}$ is in the form of $\mathrm{Z}_{\mathrm{n}}\left[\mathrm{YX}_{\mathrm{m}}\right]$. 
${ }^{d} \mathrm{~W}-n_{1}-n_{2}$, W represent overall shape of the building block (e.g. $\mathrm{R}=$ rhombicuboctahedron); $\mathrm{n}_{1}$ denotes the number of one node or several nodes in the center of this building block; $\mathrm{n}_{2}$ represents the number of derived nodes between the central nodes and vertices.

${ }^{e} \mathrm{~d}$ or $\mathrm{r}=$ derived or related nets. $\times$ denotes derived nets.

${ }^{f}$ The replacement of the 6-c octahedral node $(\mathrm{O})$ with a group of two kinds of nodes. O-1-6a denotes the central node is connected to six planar nodes, and the generated net contains hexagonal nodes. O-1-6b denotes the central node is connected to six nodes sitting in octahedral geometry, and the generated net contains 6-c octahedral nodes.

${ }^{g} 2 \mathrm{c}$ means enlarged unit cell $\mathrm{c}^{\prime}=2 \mathrm{c}$ in the operation process.

Table. 2b Edge-transitive binodal parent nets and their minimal edge-transitive derived and related nets $(\mathrm{VF}=\mathrm{C})$.

\begin{tabular}{|c|c|c|c|c|c|c|c|c|c|}
\hline $\mathrm{VF}^{a}$ & Parent net $\left(\mathrm{SPGR}^{b}\right)$ & $\mathrm{CF}^{c}$ & Coordination & Operation $^{d}$ & $\mathrm{~d}$ or $\mathrm{r}^{e}$ & $\mathrm{CF}^{c}$ & Coordination & $\mathrm{d}^{e}$ & $\mathrm{SPGR}^{b}$ \\
\hline \multirow[t]{20}{*}{$\mathrm{C}$} & bcu-b $(P m \overline{3} m)$ & $\mathrm{C}, \mathrm{C}$ & 8,8 & $C-1-4 a$ & eft & {$\left[\mathrm{S}_{3}\right] \mathrm{C}_{2}$} & $3,4,8$ & $\times$ & $\mathrm{P}_{4} / \mathrm{mmm}$ \\
\hline & & & & $C-1-4 b$ & dnq & {$\left[\mathrm{T}_{3}\right] \mathrm{C}_{2}$} & $3,4,8$ & $x$ & $P \overline{4} m 2$ \\
\hline & & & & $C-1-8$ & urs & {$\left[C_{3}\right] G_{2}$} & $3,8,16$ & & $\mathrm{P}_{4} / \mathrm{mmm}$ \\
\hline & & & & $C-1-12$ & uru & {$\left[\mathrm{B}_{3}\right] \mathrm{R}_{2}$} & $3,12,24$ & & $P m \overline{3} m$ \\
\hline & bcu $(\operatorname{Im} \overline{3} m)$ & $\mathrm{C}$ & 8 & $C-1-8$ & urt & $\mathrm{S}_{2}\left[{ }_{3} \mathrm{C}\right]$ & $3,4,8$ & & $I_{4} / \mathrm{mmm}$ \\
\hline & & & & $C-1-12$ & urf & $\mathrm{O}_{2}\left[{ }_{3} \mathrm{~B}\right]$ & $3,6,12$ & & $\operatorname{Im} \overline{3} m$ \\
\hline & flu $(F m \overline{3} m)$ & $\mathrm{T}, \mathrm{C}$ & 4,8 & $C-1-4 a$ & $\mathbf{t f j}$ & $\mathrm{T}_{2}[3 \mathrm{~S}]$ & $3,4,4$ & $x$ & $I_{4} / \mathrm{mmm}$ \\
\hline & & & & $C-1-4 a$ & eec & $\mathrm{T}_{2}[3 \mathrm{~S}]$ & $3,4,4$ & $x$ & $P_{42} / m n m$ \\
\hline & & & & $C-1-4 b$ & ofp & $\mathrm{T}_{2}[3 \mathrm{~T}]$ & $3,4,4$ & $\times$ & $I \overline{4} 2 \mathrm{~m}$ \\
\hline & & & & $C-1-8$ & tee & {$\left[C_{3}\right] 8_{2}$} & $3,8,8$ & & $I_{4} / \mathrm{mmm}$ \\
\hline & & & & $C-1-12$ & urw & {$\left[\mathrm{B}_{3}\right] \mathrm{U}_{2}$} & $3,12,12$ & & $F m \overline{3} m$ \\
\hline & & & & $C-6-8$ & dpd & $\mathrm{T}\left[\mathrm{TS}_{3}\right]$ & $4,4,4$ & $x$ & $F m \overline{3} m$ \\
\hline & the $(P m \overline{3} m)$ & $3, \mathrm{C}$ & 3,8 & $C-1-4 a$ & tfe & $3_{2}[3 \mathrm{~S}]$ & $3,3,4$ & $\times$ & $P m \overline{3} m$ \\
\hline & & & & $C-1-4 b$ & tfy & $32[3 \mathrm{~T}]$ & $3,3,4$ & $x$ & $F m \overline{3} c$ \\
\hline & $\mathbf{s c u}\left(P_{4} / \mathrm{mmm}\right)$ & $\mathrm{S}, \mathrm{C}$ & 4,8 & $C-1-4 a$ & ffc & $\mathrm{S}_{2}[3 \mathrm{~S}]$ & $3,4,4$ & $\times$ & $\mathrm{P}_{4} / \mathrm{mmm}$ \\
\hline & & & & $C-1-4 a$ & eed & $\mathrm{T}_{2}^{*}{ }_{2}[3 \mathrm{~S}]$ & $3,4,4$ & $x$ & $\mathrm{P}_{4_{2}} / \mathrm{mcm}$ \\
\hline & & & & $C-1-4 b$ & $\mathbf{m m m}$ & $\mathrm{S}_{2}[3 \mathrm{~T}]$ & $3,4,4$ & $x$ & $P_{4} / n m m$ \\
\hline & $\operatorname{csq}(P 6 / \mathrm{mmm})$ & $\mathrm{S}, \mathrm{C}$ & 4,8 & $C-1-4 a$ & dnr & $\mathrm{S}_{2}[3 \mathrm{~S}]$ & $3,4,4$ & $x$ & $\mathrm{P6} / \mathrm{mmm}$ \\
\hline & ocu $(\operatorname{Im} \overline{3} m)$ & $\mathrm{O}, \mathrm{C}$ & 6,8 & $C-1-4 a$ & twf-d & $\mathrm{H}^{*}{ }_{2}[3 \mathrm{~S}]$ & $3,4,6$ & $x$ & $\operatorname{Im} \overline{3} m$ \\
\hline & & & & $C-1-8$ & urp & {$\left[C_{3}\right] X_{2}$} & $3,8,12$ & & $\operatorname{Im} \overline{3} m$ \\
\hline
\end{tabular}

${ }^{a} \mathrm{VF}=$ vertex figures, indicating the vertex figures of the parent edge-transitive nets.

${ }^{b}$ SPGR = space group, indicating the space group of parent and according derived and related net.

${ }^{c} \mathrm{CF}=$ coordination figure (shape of coordination). For binodal parent nets, $\mathrm{CF}$ referred to W,W. For example, 3.R is the $\mathrm{CF}$ for rht net. For trinodal derived and related net, the $\mathrm{CF}$ is specified as the form $\left[\mathrm{X}_{\mathrm{m}} \mathrm{Y}\right] \mathrm{Z}_{\mathrm{n}}$, indicating $\mathrm{Y}$ is linked to $\mathrm{m}$ $\mathrm{X}$ and $\mathrm{n} \mathrm{Z}$ and $\left[\mathrm{X}_{\mathrm{m}} \mathrm{Y}\right]$ is derived from the parent net. In special cases, derived and related nets are edge-transitive binodal nets, thus $C F$ is in the form as $\mathrm{W}, \mathrm{W}$ and specified with $2 \mathrm{v}(2 \mathrm{~V}=2$ vertexs $)$. If $\mathrm{Z}$ has a lower coordination number than $[\mathrm{XY}]$, the $\mathrm{CF}$ is in the form of $\mathrm{Z}_{\mathrm{n}}\left[\mathrm{YX}_{\mathrm{m}}\right]$.

${ }^{d} \mathrm{~W}-n_{1}-n_{2}$, W represent overall shape of the building block (e.g. $\mathrm{R}=$ rhombicuboctahedron); $\mathrm{n}_{1}$ denotes the number of one node or several nodes in the center of this building block; $\mathrm{n}_{2}$ represents the number of derived nodes between the central nodes and vertices.

${ }^{e} \mathrm{~d}$ or $\mathrm{r}=$ derived or related nets. $\times$ denotes derived nets.

Table. 2c Edge-transitive binodal parent nets and their minimal edge-transitive derived and related nets $(\mathrm{VF}=\mathrm{B}, \mathrm{I}, \mathrm{U})$.

\begin{tabular}{|c|c|c|c|c|c|c|c|c|c|}
\hline $\mathrm{VF}^{a}$ & Parent net $\left(\mathrm{SPGR}^{b}\right)$ & $\mathrm{CF}^{c}$ & Coordination & Operation $^{d}$ & $\mathrm{~d}$ or $\mathrm{r}^{e}$ & $\mathrm{CF}^{c}$ & Coordination & $\mathrm{d}^{e}$ & $\mathrm{SPGR}^{b}$ \\
\hline \multirow[t]{5}{*}{ B } & $\mathbf{f t w}(P m \overline{3} m)$ & S,B & 4,12 & B-1-12 & dns & $\mathrm{C}_{2}\left[{ }_{3} \mathrm{U}\right]$ & $3,8,12$ & & $P \overline{4}_{3 m}$ \\
\hline & & & & $B-1-24$ & urq & $\mathrm{G}_{2}\left[{ }_{3} \mathrm{R}\right]$ & $3,16,24$ & & $P m \overline{3} m$ \\
\hline & & & & B-6-8 & dpe & {$\left[\mathrm{S}_{3} \mathrm{O}\right] \mathrm{C}_{3}$} & $4,6,8$ & & $\operatorname{Pm} \overline{3} m$ \\
\hline & & & & B-6-12 & gee & {$\left[\mathrm{S}_{23}\right] \mathrm{S}$} & $3,4,4$ & $x$ & $\operatorname{Pm} \overline{3} m$ \\
\hline & & & & B-8-12 & tfe & {$[323] \mathrm{S}$} & $3,3,4$ & $x$ & $P m \overline{3}$ \\
\hline
\end{tabular}




\begin{tabular}{|c|c|c|c|c|c|c|c|c|c|}
\hline I & ith $(\operatorname{Pm} \overline{3} n)$ & $\mathrm{T}, \mathrm{I}$ & 4,12 & $\mathrm{I}-1-4$ & urh & {$[\mathrm{TT}] \mathrm{S}_{3}^{*}$} & $4,4,4$ & $x$ & $P \overline{4}_{3 n}$ \\
\hline & & & & $\mathrm{I}-1-6$ & gao & $\mathrm{T}_{2}[3 \mathrm{O}]$ & $3,4,6$ & $x$ & $P m \overline{3} n$ \\
\hline $\mathrm{U}$ & $\mathbf{m g c}(F d \overline{3} m)$ & $\mathrm{H}, \mathrm{U}$ & 6,12 & U-1-4 & spl & {$[\mathrm{TT}] \mathrm{O}_{3}{ }_{3}$} & $4,4,6$ & $x$ & $F d \overline{3} m$ \\
\hline & & & & U-1-6 & mgd & {$\left[\mathrm{O}_{3}\right] \mathrm{H}_{2}$} & $3,6,6$ & $x$ & $F d \overline{3} m$ \\
\hline & & & & U-1-12 & dny & {$\left[\mathrm{B}_{3}\right] \mathrm{X}_{2}$} & $3,12,12$ & & $F d \overline{3} m$ \\
\hline & & & & $U-4-6 a$ & dnl & {$\left[{ }_{32} \mathrm{~S} \mathrm{O}_{2}^{*}\right.$} & $3,4,6$ & $x$ & $F d \overline{3} m$ \\
\hline & & & & $U-4-6 b$ & $\operatorname{dnz}$ & {$\left[3_{2} \mathrm{~T}\right] \mathrm{O}_{2}^{*}$} & $3,4,6$ & $x$ & $F d \overline{3} m$ \\
\hline & $\mathbf{t t t}\left(F \overline{4}_{3 m}\right)$ & $3, \mathrm{U}$ & 3,12 & U-1-4 & $\mathbf{x b z}$ & $3_{3}[\mathrm{TT}]$ & $3,4,4$ & $x$ & $\overline{F 4} 3 m$ \\
\hline & & & & U-1-6 & $\mathbf{x b q}$ & $3_{2}[3 \mathrm{O}]$ & $3,3,6$ & $x$ & $F \overline{4} 3 m$ \\
\hline
\end{tabular}

${ }^{a} \mathrm{VF}=$ vertex figures, indicating the vertex figures of the parent edge-transitive nets.

${ }^{b}$ SPGR $=$ space group, indicating the space group of parent and according derived and related net.

${ }^{c} \mathrm{CF}=$ coordination figure (shape of coordination). For binodal parent nets, $\mathrm{CF}$ referred to W,W. For example, $3 . \mathrm{R}$ is the $\mathrm{CF}$ for rht net. For trinodal derived and related net, the $\mathrm{CF}$ is specified as the form $\left[\mathrm{X}_{\mathrm{m}} \mathrm{Y}\right] \mathrm{Z}_{\mathrm{n}}$, indicating $\mathrm{Y}$ is linked to $\mathrm{m}$ $\mathrm{X}$ and $\mathrm{n} \mathrm{Z}$ and $\left[\mathrm{X}_{\mathrm{m}} \mathrm{Y}\right]$ is derived from the parent net. In special cases, derived and related nets are edge-transitive binodal nets, thus $\mathrm{CF}$ is in the form as $\mathrm{W}, \mathrm{W}$ and specified with $2 \mathrm{v}(2 \mathrm{v}=2$ vertexs). If $\mathrm{Z}$ has a lower coordination number than $[\mathrm{XY}]$, the $\mathrm{CF}$ is in the form of $\mathrm{Z}_{\mathrm{n}}\left[\mathrm{YX}_{\mathrm{m}}\right]$.

${ }^{d} \mathrm{~W}-n_{1}-n_{2}$, W represent overall shape of the building block (e.g. $\mathrm{R}=$ rhombicuboctahedron); $\mathrm{n}_{1}$ denotes the number of one node or several nodes in the center of this building block; $\mathrm{n}_{2}$ represents the number of derived nodes between the central nodes and vertices.

${ }^{e} \mathrm{~d}$ or $\mathrm{r}=$ derived or related nets. $\times$ denotes derived nets.

Table. 2d Edge-transitive binodal parent nets and their minimal edge-transitive derived and related nets ( $\mathrm{VF}=\mathrm{X}$ ).

\begin{tabular}{|c|c|c|c|c|c|c|c|c|c|}
\hline $\mathrm{VF}^{a}$ & Parent net $\left(\mathrm{SPGR}^{b}\right)$ & $\mathrm{CF}^{c}$ & Coordination & Operation $^{d}$ & $\mathrm{~d}$ or $\mathrm{r}^{e}$ & $\mathrm{CF}^{c}$ & Coordination & $\mathrm{d}^{e}$ & $\mathrm{SPGR}^{b}$ \\
\hline \multirow[t]{22}{*}{$\mathrm{X}$} & $\operatorname{shp}(P 6 / \mathrm{mmm})$ & $\mathrm{S}, \mathrm{X}$ & 4,12 & $X-1-3$ & cei & {$\left[{ }_{3} \mathrm{Q}\right] \mathrm{S}_{4}$} & $3,4,5$ & $x$ & $P \overline{6} m 2$ \\
\hline & & & & $\mathrm{X}-1-32 \mathrm{c}^{f}$ & cek & {$\left[{ }_{3} \mathrm{Q}\right] \mathrm{S}_{4}$} & $3,4,5$ & $x$ & $P 6_{3} / m m c$ \\
\hline & & & & $X-1-6 a$ & cee & $\mathrm{S}_{2}[3 \mathrm{H}]$ & $3,4,6$ & $x$ & $P 6 / m m m$ \\
\hline & & & & $X-1-6 b$ & ceh & $\mathrm{T}^{*}{ }_{2}[3 \mathrm{H}]$ & $3,4,6$ & $x$ & $P 622$ \\
\hline & & & & $\mathrm{X}-1-6 \mathrm{~b} 2 \mathrm{c}^{f}$ & cez & $\mathrm{S}_{2}\left[{ }_{3} \mathrm{H}\right]$ & $3,4,6$ & $x$ & $P 6 / m c c$ \\
\hline & & & & $X-1-6 c$ & ceg & $\mathrm{S}_{2}[3 \mathrm{O}]$ & $3,4,6$ & $x$ & $P \overline{3} m 1$ \\
\hline & & & & $\mathrm{X}-1-6 \mathrm{c} 2 \mathrm{c}^{f}$ & сеј & $\mathrm{S}_{2}[3 \mathrm{O}]$ & $3,4,6$ & $x$ & $P 6_{3} / m m c$ \\
\hline & & & & $X-1-6 d$ & cef & $\mathrm{S}_{2}\left[{ }_{3} \mathrm{P}\right]$ & $3,4,6$ & $x$ & $P \overline{6} m_{2}$ \\
\hline & & & & $\mathrm{X}-1-6 \mathrm{~d} 2 \mathrm{c}^{f}$ & agw & $\mathrm{S}_{2}\left[{ }_{3} \mathrm{P}\right]$ & $3,4,6$ & $x$ & $P 6_{3} / m m c$ \\
\hline & & & & X-1-6e & cel & {$[\mathrm{HQ}] \mathrm{C}_{4}$} & $5,6,8$ & & $P 6 / \mathrm{mmm}$ \\
\hline & & & & $X-1-12$ & pek & $\mathrm{C}_{2}[3 \mathrm{X}]$ & $3,8,12$ & & $P 6 / m m m$ \\
\hline & alb $(P 6 / \mathrm{mmm})$ & $\mathrm{P}, \mathrm{X}$ & 6,12 & $X-1-3$ & ala & {$[3 \mathrm{Q}] \mathrm{P}_{4}$} & $3,5,6$ & $x$ & $P \overline{6} m 2$ \\
\hline & & & & $\mathrm{X}-1-32 \mathrm{c}^{f}$ & ceo & {$[3 \mathrm{Q}] \mathrm{O}^{*}{ }_{4}$} & $3,5,6$ & $x$ & $\mathrm{PG}_{3} / \mathrm{mcm}$ \\
\hline & & & & $X-1-6 a$ & kew & {$\left[\mathrm{H}_{3}\right] \mathrm{P}_{2}$} & $3,6,6$ & $x$ & $P 6 / m m m$ \\
\hline & & & & $X-1-6 b$ & key & {$\left[\mathrm{H}_{3}\right] \mathrm{O}^{*}{ }_{2}$} & $3,6,6$ & $x$ & $P 622$ \\
\hline & & & & $\mathrm{X}-1-6 \mathrm{~b} 2 \mathrm{c}^{f}$ & kez & {$\left[\mathrm{H}_{3}\right] \mathrm{P}_{2}$} & $3,6,6$ & $x$ & $P 6 / m c c$ \\
\hline & & & & $X-1-6 c$ & сер & {$\left[\mathrm{O}_{3}\right] \mathrm{O}^{*}{ }_{2}$} & $3,6,6$ & $x$ & $P \overline{3} m ı$ \\
\hline & & & & $\mathrm{X}-1-6 c 2 c^{f}$ & cer & {$\left[\mathrm{O}_{3}\right] \mathrm{P}_{2}$} & $3,6,6$ & $x$ & $\mathrm{PG}_{3} / \mathrm{mcm}$ \\
\hline & & & & $X-1-6 d$ & ceq & {$\left[\mathrm{P}_{3}\right] \mathrm{P}_{2}$} & $3,6,6$ & $x$ & $P \overline{6} m_{2}$ \\
\hline & & & & $\mathrm{X}-1-6 \mathrm{~d} 2 \mathrm{c}^{f}$ & cet & {$\left[\mathrm{O}_{3}\right] \mathrm{P}_{2}$} & $3,6,6$ & $x$ & $P 6_{3} / \mathrm{mcm}$ \\
\hline & & & & $X-1-6 e$ & alc & {$[\mathrm{HQ}] \mathrm{X}_{4}$} & $5,6,12$ & & $P 6 / m m m$ \\
\hline & & & & $X-1-12$ & aea & {$\left[\mathrm{X}_{3}\right] \mathrm{X}_{2}$} & $3,12,12$ & & $P 6 / \mathrm{mmm}$ \\
\hline
\end{tabular}

${ }^{a} \mathrm{VF}=$ vertex figures, indicating the vertex figures of the parent edge-transitive nets.

${ }^{b}$ SPGR $=$ space group, indicating the space group of parent and according derived and related net.

${ }^{c} \mathrm{CF}=$ coordination figure (shape of coordination). For binodal parent nets, $\mathrm{CF}$ referred to W,W. For example, 3.R is the $\mathrm{CF}$ for rht net. For trinodal derived and related net, the $\mathrm{CF}$ is specified as the form $\left[\mathrm{X}_{\mathrm{m}} \mathrm{Y}\right] \mathrm{Z}_{\mathrm{n}}$, indicating $\mathrm{Y}$ is linked to $\mathrm{m}$ $\mathrm{X}$ and $\mathrm{n} \mathrm{Z}$ and $\left[\mathrm{X}_{\mathrm{m}} \mathrm{Y}\right]$ is derived from the parent net. In special cases, derived and related nets are edge-transitive binodal 
nets, thus $\mathrm{CF}$ is in the form as $\mathrm{W}, \mathrm{W}$ and specified with $2 \mathrm{v}(2 \mathrm{v}=2$ vertexs). If $\mathrm{Z}$ has a lower coordination number than $[\mathrm{XY}]$, the CF is in the form of $\mathrm{Z}_{\mathrm{n}}\left[\mathrm{YX}_{\mathrm{m}}\right]$.

${ }^{d} \mathrm{~W}-n_{1}-n_{2}$, W represent overall shape of the building block (e.g. $\mathrm{R}=$ rhombicuboctahedron); $\mathrm{n}_{1}$ denotes the number of one node or several nodes in the center of this building block; $\mathrm{n}_{2}$ represents the number of derived nodes between the central nodes and vertices.

${ }^{e} \mathrm{~d}$ or $\mathrm{r}=$ derived or related nets. $\times$ denotes derived nets.

$f_{2} \mathrm{C}$ means enlarged unit cell $\mathrm{c}^{\prime}=\mathbf{2} \mathrm{C}$ in the operation process.

Table. 2e Edge-transitive binodal parent nets and their minimal edge-transitive derived and related nets (VF $=\mathrm{K}, \mathrm{R})$.

\begin{tabular}{|c|c|c|c|c|c|c|c|c|c|}
\hline $\mathrm{VF}^{a}$ & Parent net $\left(\mathrm{SPGR}^{b}\right)$ & $\mathrm{CF}^{c}$ & Coordination & Operation $^{d}$ & $\mathrm{~d}$ or $\mathrm{r}^{e}$ & $\mathrm{CF}^{c}$ & Coordination & $\mathrm{d}^{e}$ & $\mathrm{SPGR}^{b}$ \\
\hline \multirow[t]{7}{*}{$\mathrm{K}$} & $\mathbf{t w f}(\operatorname{Im} \overline{3} m)$ & $\mathrm{T}, \mathrm{K}$ & 4,24 & K-1-6 & dnv & $\mathrm{T}_{4}[\mathrm{QO}]$ & $4,5,6$ & $x$ & $\operatorname{Im} \overline{3} m$ \\
\hline & & & & $\mathrm{K}-1-12$ & xag & $\mathrm{S}_{2}{ }_{2}\left[{ }_{3} \mathrm{~B}\right]$ & $3,4,12$ & $x$ & $\operatorname{Im} \overline{3} m$ \\
\hline & & & & $K-1-24$ & urv & $\mathrm{C}_{2}\left[{ }_{3} \mathrm{R}\right]$ & $3,8,24$ & & $\operatorname{Im} \overline{3} m$ \\
\hline & & & & $\mathrm{K}-4-8$ & hcz & $\mathrm{S}_{6}^{*}[\mathrm{VT}]$ & $4,4,7$ & $\times$ & $I \overline{4} 3 m$ \\
\hline & & & & K-8-6 & dnw & {$\left[{ }_{34} \mathrm{~A}\right] \mathrm{T}_{4}$} & $3,4,8$ & $x$ & $\operatorname{Im} \overline{3} m$ \\
\hline & & & & $\mathrm{K}-8-12$ & $\operatorname{dn} x$ & {$\left[3_{2} \mathrm{~T}\right] \mathrm{S}_{2}^{*}$} & $3,4,4$ & $x$ & $\operatorname{Im} \overline{3} m$ \\
\hline & & & & $\mathrm{K}-12-24$ & dnu & {$\left[\mathrm{S}_{2} \mathrm{~S}\right] \mathrm{C}_{2}$} & $4,4,8$ & & $\operatorname{Im} \overline{3} m$ \\
\hline \multirow[t]{7}{*}{$\mathrm{R}$} & rht $(F m \overline{3} m)$ & 3, R & 3,24 & $\mathrm{R}-1-8$ & ntu & $3_{3}[\mathrm{TC}]$ & $3,4,8$ & $x$ & $F m \overline{3} m$ \\
\hline & & & & $\mathrm{R}-1-12$ & ntw & $3_{2}[3 \mathrm{I}]$ & $3,3,12$ & $x$ & $F m \overline{3}$ \\
\hline & & & & $R-1-24$ & dnt & $\mathrm{H}_{2}[3 \mathrm{~K}]$ & $3,6,24$ & & $F m \overline{3} m$ \\
\hline & & & & $R-1-6$ & ntv & $3_{4}[\mathrm{QO}]$ & $3,5,6$ & $x$ & $F m \overline{3} m$ \\
\hline & & & & $\mathrm{R}-6-8$ & hmc & $3_{3}\left[\mathrm{PS}_{3}\right]$ & $3,4,6$ & $x$ & $F m \overline{3} m$ \\
\hline & & & & $\mathrm{R}-6-12$ & dnk & {$\left[\mathrm{S}_{2} \mathrm{P}\right] \mathrm{H}_{4}$} & $4,6,6$ & & $F m \overline{3} m$ \\
\hline & & & & $R-12-24$ & ntt & $3\left[3 S_{2}\right]$ & $3,3,4$ & $x$ & \\
\hline
\end{tabular}

${ }^{a} \mathrm{VF}=$ vertex figures, indicating the vertex figures of the parent edge-transitive nets.

${ }^{b} \mathrm{SPGR}=$ space group, indicating the space group of parent and according derived and related net.

${ }^{c} \mathrm{CF}=$ coordination figure (shape of coordination). For binodal parent nets, $\mathrm{CF}$ referred to W,W. For example, 3.R is the $\mathrm{CF}$ for rht net. For trinodal derived and related net, the $\mathrm{CF}$ is specified as the form $\left[\mathrm{X}_{\mathrm{m}} \mathrm{Y}\right] \mathrm{Z}_{\mathrm{n}}$, indicating $\mathrm{Y}$ is linked to $\mathrm{m}$ $\mathrm{X}$ and $\mathrm{n} \mathrm{Z}$ and $\left[\mathrm{X}_{\mathrm{m}} \mathrm{Y}\right]$ is derived from the parent net. In special cases, derived and related nets are edge-transitive binodal nets, thus $C F$ is in the form as $\mathrm{W}, \mathrm{W}$ and specified with $2 \mathrm{v}(2 \mathrm{v}=\mathbf{2}$ vertexs). If $\mathrm{Z}$ has a lower coordination number than $[X Y]$, the $C F$ is in the form of $Z_{n}\left[Y_{m}\right]$.

${ }^{d} \mathrm{~W}-n_{1}-n_{2}$, W represent overall shape of the building block (e.g. $\mathrm{R}=$ rhombicuboctahedron); $\mathrm{n}_{1}$ denotes the number of one node or several nodes in the center of this building block; $\mathrm{n}_{2}$ represents the number of derived nodes between the central nodes and vertices.

${ }^{e} \mathrm{~d}$ or $\mathrm{r}=$ derived or related nets. $\times$ denotes derived nets.

Table. 3 Non-crystallographic edge-transitive binodal parent nets and their derived nets of minimal transitivity [3 2].

\begin{tabular}{|c|c|c|c|c|c|c|c|c|}
\hline $\mathrm{VF}^{a}$ & Parent net $\left(\mathrm{SPGR}^{b}\right)$ & $\mathrm{CF}^{c}$ & Coordination & Operation $^{d}$ & derived $^{\mathrm{e}}$ & $\mathrm{CF}^{c}$ & Coordination & $\mathrm{SPGR}^{b}$ \\
\hline \multirow[t]{3}{*}{$\mathrm{H}$} & cys $\left(P_{43} 32\right)$ & $3, \mathrm{H}$ & 3,6 & $\mathrm{H}-1-3$ & pyo & $32[33]$ & $3,3,3$ & $P_{4,32}$ \\
\hline & nts $(F m \overline{3} m)$ & $\mathrm{S}, \mathrm{H}$ & 4,6 & $\mathrm{H}-1-3$ & ntt & $\mathrm{S}_{2}[33]$ & $3,3,4$ & $F m \overline{3} m$ \\
\hline & $\mathbf{c y b}(P m \overline{3} n)$ & $\mathrm{S}, \mathrm{H}$ & 4,6 & $\mathrm{H}-1-3$ & czb & $\mathrm{S}_{2}[33]$ & $3,3,4$ & $\operatorname{Pm} \overline{3} n$ \\
\hline \multirow[t]{3}{*}{ E } & cya $(P m \overline{3} n)$ & $3, \mathrm{E}$ & 3,8 & E-1-4 & cza & $3_{2}\left[{ }_{3} S\right]$ & $3,3,4$ & $\operatorname{Pm} \overline{3} n$ \\
\hline & cyt $(P m \overline{3} m)$ & $\mathrm{S}, \mathrm{E}$ & 4,8 & $E-1-4$ & gee & $\mathrm{S}_{2}[3 \mathrm{~S}]$ & $3,4,4$ & $P m \overline{3} m$ \\
\hline & суе $(\operatorname{Im} \overline{3} m)$ & $\mathrm{H}, \mathrm{E}$ & 6,8 & $E-1-4$ & cze & $\mathrm{H}_{2}\left[{ }_{3} \mathrm{~S}\right]$ & $3,4,6$ & $\operatorname{Im} \overline{3} m$ \\
\hline C & сус $\left(P_{4_{2}} / m m c\right)$ & $\mathrm{S}, \mathrm{C}$ & 4,8 & $C-1-4$ & $\csc ^{\mathrm{e}}$ & $\mathrm{S}_{2}[3 \mathrm{~T}]$ & $3,4,4$ & $P_{4_{2}} / m m c$ \\
\hline \multirow[t]{2}{*}{$\mathrm{D}$} & cyd $(\operatorname{Im} \overline{3} m)$ & $\mathrm{S}, \mathrm{D}$ & 4,12 & $D-1-6$ & czd & $\mathrm{S}_{2}[3 \mathrm{H}]$ & $3,4,6$ & $\operatorname{Im} \overline{3} m$ \\
\hline & cyu $(F d \overline{3} m)$ & H,D & 6,12 & D-1-6 & hxh & $\mathrm{H}_{2}[3 \mathrm{H}]$ & $3,6,6$ & $F d \overline{3} m$ \\
\hline $\mathrm{X}$ & dfs $(P 6 / m m m)$ & $\mathrm{S}, \mathrm{X}$ & 4,12 & $\mathrm{X}-1-3$ & dfv & $\mathrm{S}_{4}\left[\mathrm{Q}_{3}\right]$ & $3,4,5$ & $P 6 / \mathrm{mmm}$ \\
\hline
\end{tabular}




\begin{tabular}{ccccccccc}
$\mathrm{G}$ & $\mathbf{c y g}\left(P_{4} / \mathrm{mmm}\right)$ & $\mathrm{S}, \mathrm{G}$ & \multirow{2}{*}{, 16} & $\mathrm{G}-1-4$ & $\mathbf{c z g}$ & $\mathrm{S}_{4}[\mathrm{QS}]$ & $4,4,5$ & $P_{4} / \mathrm{mmm}$ \\
& & & $\mathrm{G}-1-8$ & $\mathbf{c x g}$ & $\mathrm{S}_{2}\left[{ }_{3} \mathrm{C}\right]$ & $3,4,8$ & $P_{4} / \mathrm{mmm}$ \\
$\mathrm{W}$ & $\mathbf{c y f}(P m \overline{3} m)$ & $\mathrm{S}, \mathrm{W}$ & 4,24 & $\mathrm{~W}-1-8$ & $\mathbf{x b a}$ & $\mathrm{S}_{3}[\mathrm{TC}]$ & $4,4,8$ & $P m \overline{3} m$
\end{tabular}

${ }^{a} \mathrm{VF}=$ vertex figure. ${ }^{b} \mathrm{SPGR}=$ space group. ${ }^{c} \mathrm{CF}=$ coordination figure. ${ }^{d} \mathrm{~W}-n_{1}-n_{2}, \mathrm{~W}$ represent overall shape of the building block; $n_{1}$ denotes the number of one node or several nodes in the center of this building block; $n_{2}$ represents the number of derived nodes between the central nodes and vertices. $\mathrm{D}=$ dodecagon, $\mathrm{Q}=$ square pyramid (others denoted in Table 1). ${ }^{e}$ This derived net is also non-crystallographic.

\section{MOFs based on Minimal Edge-Transitive Nets}

MOFs based on edge-transitive parent net and minimal edge-transitive derived nets have been partly covered in the previous reviews. ${ }^{73,84}$ Here, the examples of MOFs with the novel derived and related nets are highlighted; especially highly connected MOFs will be emphasized to demonstrate our approach of net-coded building (netcBUs).

The minimal edge-transitive derived nets pave the way for the rational design and construction of the highlyconnected MOFs with multiple branched ligands. And the minimal edge-transitive related nets open a new avenue to the highly-coordinated MOFs based on the net-CBUs. Those net-CBUs might be a polynuclear clusters, highlyconnected organic linkers, or the supermolecular building blocks (SBBs).

\subsection{MOFs based on acs and acs-derived Nets}
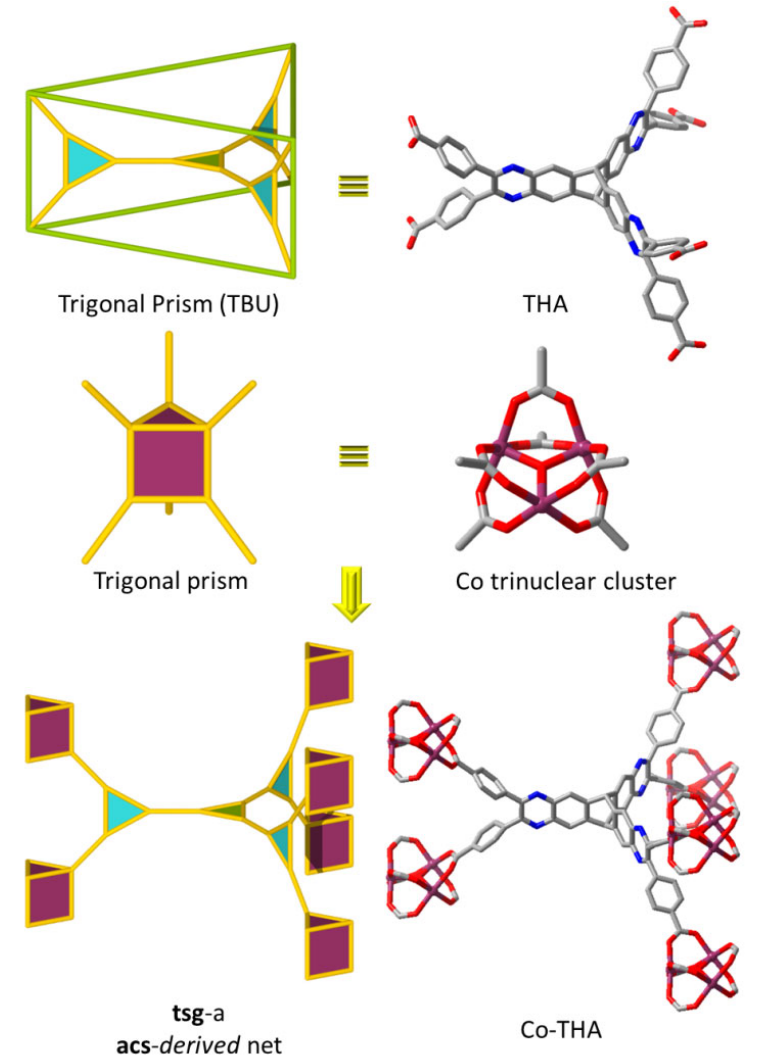

Figure.14 Experimental MOFs (3-fold interpenetration) based on acs net and its derived net, tsg net, from a 6connected cobalt trinuclear cluster and a 6-connected organic ligand. $\mathrm{Co}, \mathrm{C}, \mathrm{N}$ and $\mathrm{O}$ are represented by purple, gray, blue and red, respectively, and $\mathrm{H}$ atoms and solvent molecules are omitted for clarity. ${ }^{150}$

The acs net with transitivity [1122] is the sole possible edge-transitive net ("default net") constructed from a trigonal prism SBU. Early examples included the MIL-88 series or MOF-235, constructed from the metal trinuclear clusters and linear linkers. ${ }^{106,}{ }^{151}$ The initial attempt of combining the hexatopic organic linker and the metal trinuclear clusters led to the formation of MOFs (JUC-101) based on the nia-derived jit net because the overall geometry of hexacarboxylate ligand can transform from the trigonal prism to the octahedron. ${ }^{99,152}$

The Co-THA MOF has been recently reported via the combination of the rigid triptycene-hexacarboxylate ligands and the cobalt trinuclear clusters (Figure. 14). ${ }^{150}$ The high degree of rigidity imparted by the triptycene core in the hexacarboxylate linker led to the entire geometry of the ligands to remain unchanged during the MOF synthesis. Thus, this branched linker can be viewed as a trigonal prismatic $\mathrm{MBB}$, and when combined with the metal trinuclear clusters, led to the generation of a MOF example based on the acs-derived tsg net. It should be noted that the resultant MOF materials are 3 -fold interpenetrated. A series of non-interpenetrated acsMOFs with the same net have been recently reported, and these MOFs are made with shorter triptycene-based ligands and high-valent metal trinuclear clusters. ${ }^{153}$

\subsection{MOFs based on $\mathrm{ftw}$ and $\mathrm{ftw}$-derived Nets}

The power of supermolecular building block approach gave high degree of control at the molecular level prior to the targeted assembly process, with the right choice of building blocks, i.e. the highly-connected MOPs. ${ }^{9}$ The carbazole-based dicarboxylate based MOP can be regarded as a 12-c cuboctahedral SBB to construct the 3periodic framework, considering the carbazole nitrogen as the point of extension. ${ }^{154-156}$ Thus, by the SBB approach, a MOF based on the parent fcu and ftw net can be feasibly synthesized by combining the 12-c cuboctahedral SBB with the linear and square building unitss, respectively. It is worth to be noted that ftw MOFs are often constructed from zirconium or RE hexanuclear clusters and tetretopic organic or organometallic ligands..$^{71,122,157-162} \mathrm{~A} f \mathrm{ftw}$-MOF, DUT- $75^{156}$, was reported via the assembly of the aforementioned 12-c cuboctahedral SBBs and the 4-c square copper paddlewheel clusters by using carbazolebased tricarboxylate as ligands, as indicated in the Figure. 15. By considering the carbazole tricarboxylate ligand as a 
3-c linker, the overall topology of the framework can be viewed as a $(3,4,4)$-c ftw-derived gee net.

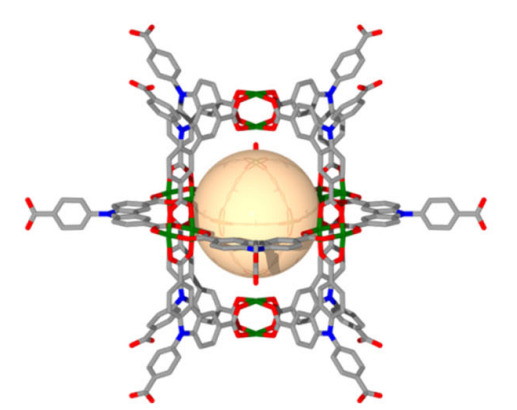

Carbazole based SBB IIII

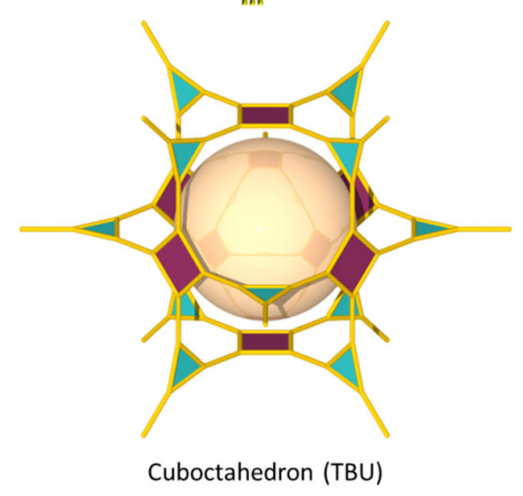

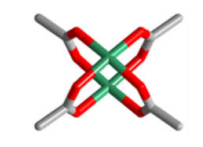

$\mathrm{Cu}(\mathrm{II})$ paddlewheel cluster

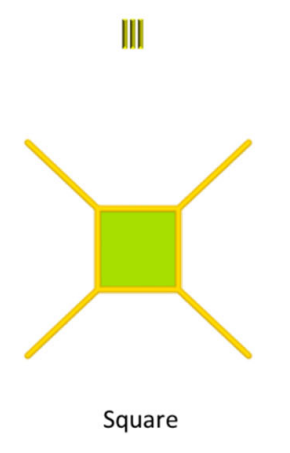

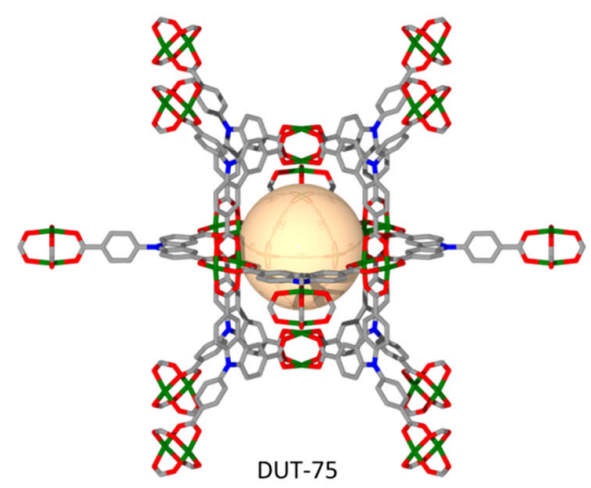
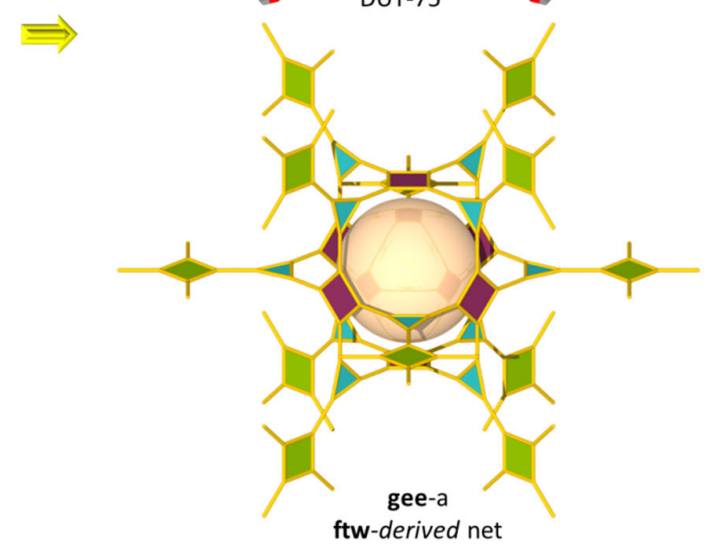

Figure.15 Experimental MOFs (DUT-75) based on ftw net and its derived net, gee net, from a 12-connected cuboctahedral supermolecular building block and a 4-connected copper paddlewheel cluster. $\mathrm{Cu}, \mathrm{C}, \mathrm{N}$ and $\mathrm{O}$ are represented by green, gray, blue and red, respectively, and $\mathrm{H}$ atoms and solvent molecules are omitted for clarity. ${ }^{156}$

\subsection{MOFs based on alb and alb-derived Nets}

The highly coordinated $(6,12)$-c alb net contains two kinds of net-coded building units, namely 6-c trigonal prism and 12-c hexagonal prism (d6R). ${ }^{60}$ The targeted alb-MOFs should be deliberately assembled from the 6-c trigonal prismatic and 12-c hexagonal prismatic building blocks, which encompass precise geometrical information. The replacement of the aforementioned trigonal and hexagonal prismatic nodes with a group of two kinds of nodes, led to a series of minimal edge-transitive albderived nets as mentioned before.

The rational design and assembly of the missing $(6,12)$-c alb-MOFs using the power of reticular chemistry has been recently published." The preselected hexacarboxylate ligand (2,4,6-trimethyl-1,3,5-tri(3,5-di(4-carboxyphenyl-1yl)phenyl-1-yl)-benzene $\left.\left(\mathrm{H}_{6} \mathrm{Me}-\mathrm{TDCPB}\right)\right)$, potentially offered the essential trigonal prismatic building unit. The combination of this hexatopic linker and the 12-c hexagonal prismatic rare earth (RE) hexanuclear carboxylate-based cluster $\quad\left[\mathrm{RE}_{6}\left(\mu_{3}-\mathrm{OH}\right)_{8}(2-\right.$ FBzoate $\left.)_{2}\left(\mathrm{H}_{2} \mathrm{O}\right)_{2}\left(\mathrm{O}_{2} \mathrm{C}-\right)_{12}\right]$ (2-fluorobenzoate (2-FBzoate) $=$ $\left.\mathrm{C}_{7} \mathrm{H}_{4} \mathrm{FO}_{2}\right)$, resulted in the construction of the first 3- periodic alb-MOF, that is RE-alb-MOF-1. Noticeably, the carbon centers of the six carboxylate groups matched the vertices of the desired trigonal prism building unit. This branched ligand can be further deconstructed into two distinct 3-connected nodes. Thus, the topology of the REalb-MOF-1 can alternatively be described as the $(3,3,12)$-c alb-derived ury topology, with a minimal transitivity [32]. $\mathrm{Zr}$-MOFs based on this net can also be constructed from rigid trigonal prismatic carboxylate linkers and zirconiumbased clusters with the overall hexagonal prismatic shape. ${ }^{163}$

The deliberate combination of a purposely-designed 12-c dodecacarboxylate ligand, 1,2,3,4,5,6-hexakis[3,5-bis(4methoxycarbonylphenyl)phenoxymethyl]benzene

$\left(\mathrm{H}_{12} \mathrm{HBCPB}\right)$, the trinuclear trigonal prismatic $\left[\operatorname{In}_{3}\left(\mu_{3}-\right.\right.$ O) $\left(\mathrm{O}_{2} \mathrm{C}-\right)_{6}$ ] carboxylate-based cluster, led to the formation of the In-alb-MOF-1. ${ }^{11}$ Clearly, this branched dodecacarboxylate linker (HBCPB) can be regarded as the essential 12-c net-cBU, rationally affording the positioning of the carbon centers of the twelve carboxylate groups on the vertices of the desired d6R building unit. 
This dodecatopic ligand of the In-alb-MOF-1 can be further split into one 6-c hexagon node and one kind of 3c triangular nodes. The assembly of the hexagon and triangles resulted in a 12-c tertiary building unit, as illustrated in the Figure. 16. Eventually, the points of extension of the 12-c TBU coincided with the vertices of the hexagonal prism, the 12-c vertex figure of the $(6,12)$-c alb net. As a consequence, the underlying net can further be defined as the $(3,6,6)$-c alb-derived kez topology, with a minimal transitivity [32]. Noted that the triangles of the 12-c TBU are not perpendicular to the central hexagon and the linker unit is chiral but the net is not. The space group of the kez net is $P 6 /$ mcc.

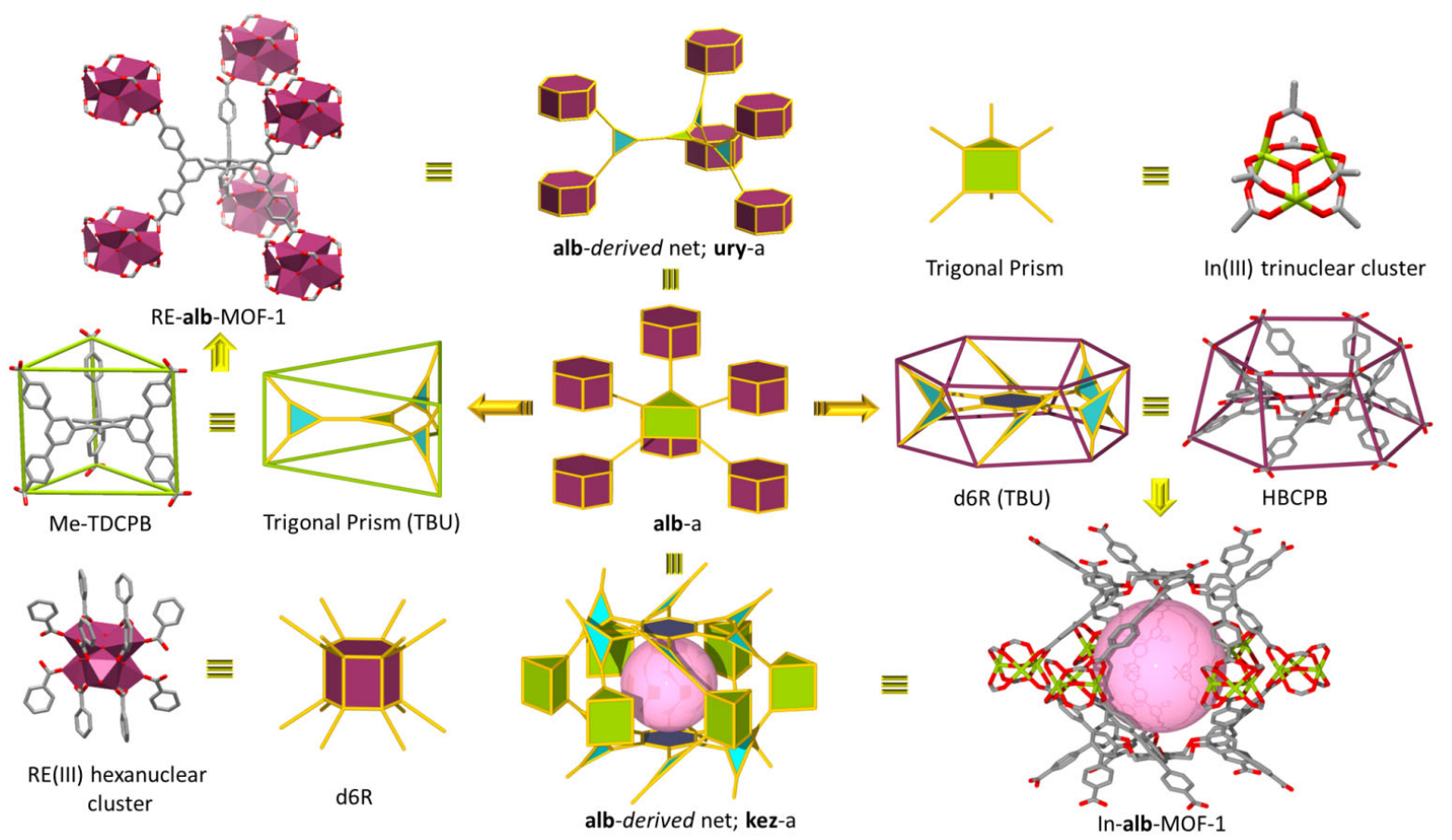

Figure.16 Experimental MOFs (RE-alb-MOF-1 and In-alb-MOF-1) based on alb net and its derived nets, ury and kez net, respectively. RE-alb-MOF-1 is constructed from a 12-connected RE(III) hexanuclear cluster and a 6-connected organic ligand. In-alb-MOF-1 is synthesized from a 6-connected In(III) trinuclear cluster and a 12-connected organic ligand RE, In, $\mathrm{C}$, and $\mathrm{O}$ are represented by purple, lime, gray, and red, respectively, and $\mathrm{H}$ atoms and solvent molecules are omitted for clarity. RE atoms are represented as polyhedra., ${ }^{113}$

derived net including post-synthetic sequential

These examples revealed that the highly-connected edgetransitive nets (i.e. the alb net) are perfect platforms for the topological transplantation and the deliberate construction of highly-connected MOFs based on minimal edge-transitive derived nets.

\subsection{MOFs based on twf and twf-derived Nets}

The highly-coordinated cubic $(4,24)$-c twf net contains two kinds of net-coded building units, namely $4^{-c}$ tetrahedron and 24-c truncated octahedron (Figure.17; top left). One possible way to achieve twf-MOFs is to apply the SBB approach via using truncated octahedron SBBs and $4^{-\mathrm{c}}$ ligands to form 3-periodic network crystals. ${ }^{133}$ Other approach to synthesize twf-MOFs based on twfinstallation of ligands and metal clusters into a known MOF, which have recently been demonstrated by Zhou group. ${ }^{134} \mathrm{~A}$ cubic porphyrinic zirconium MOF PCN-224, with overall framework based on 4,6-c she net, was selected as a prototype material to conduct post-synthetic modification. The organic linkers 4,4'-dicarboxydiphenyl sulfone (DCDPS) and $\mathrm{Hf}_{6}$ (or $\mathrm{Zr}_{6}$ ) clusters were incorporated into the parent framework $\mathrm{PCN}-224(\mathrm{Ni})$, resulting in a mixed-linker MOF PCN-202(Ni)-Hf (or PCN$202(\mathrm{Ni})-\mathrm{Zr}$ ) with two kinds of ligands, i.e. tetrakis $(4-$ carboxyphenyl)porphyrin (TCPP) and DCDPS. PCN$224(\mathrm{Ni})$ and PCN-202 $(\mathrm{Ni})$ denote the TCPP linkers inside MOFs were metalated $\mathrm{Ni}^{2+}$ via incubating crystals in $\mathrm{Ni}\left(\mathrm{NO}_{3}\right)_{2} / \mathrm{DMF}$ solution. After reducing space group of $\mathrm{Im}$ $3 m$ (full symmetry of twf net) to $I-43 m$, the structure with 
ordered DCDPS can be simplified to a $(4,4,7)$-c hcz (space group I-43m) network (Figure.17; down).

As exemplified in Figure.17, a pair of hexanuclear $\mathrm{Zr}$ cluster and $\mathrm{Hf}_{6}$ cluster were connected via three pairs of DCDPS ligands in PCN-202(Ni)-Hf; consequencely, the $\mathrm{Hf}_{6}$ cluster can be simplified as a 4-c tetrahedral node and
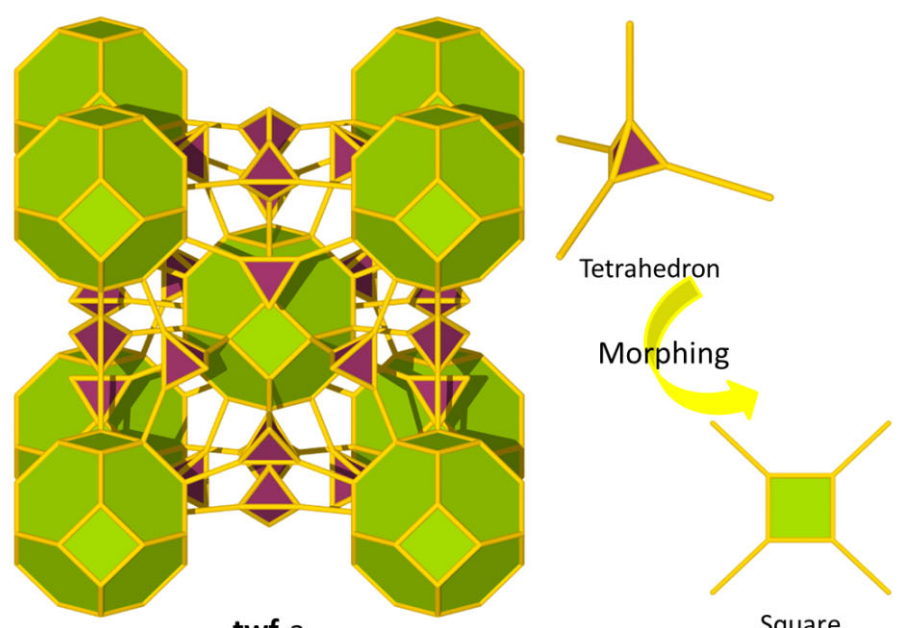

Square

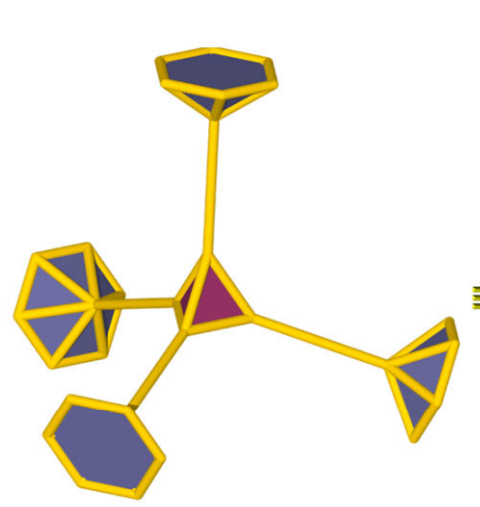

TBU

(tetrahedron+hexagonal pyramids)

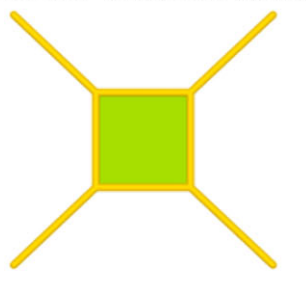

Square

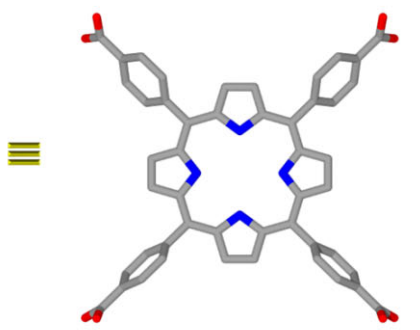

$\mathrm{Zr}_{6}$ cluster can be viewed as a 7 -c hexagonal pyramidal node. TCPP remains a typical square SBU. The hcz net was derived from the twf net by replacing truncated octahedron with tetrahedron and hexagonal pyramids. It should be noted that the square in the hcz net is from the morphing of tetrahedral node inside twf net (Figure.17; top right).

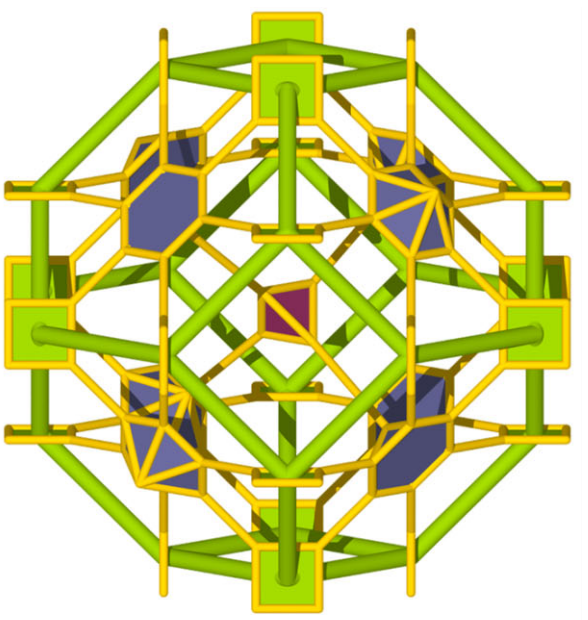

hcz-a

twf-derived net
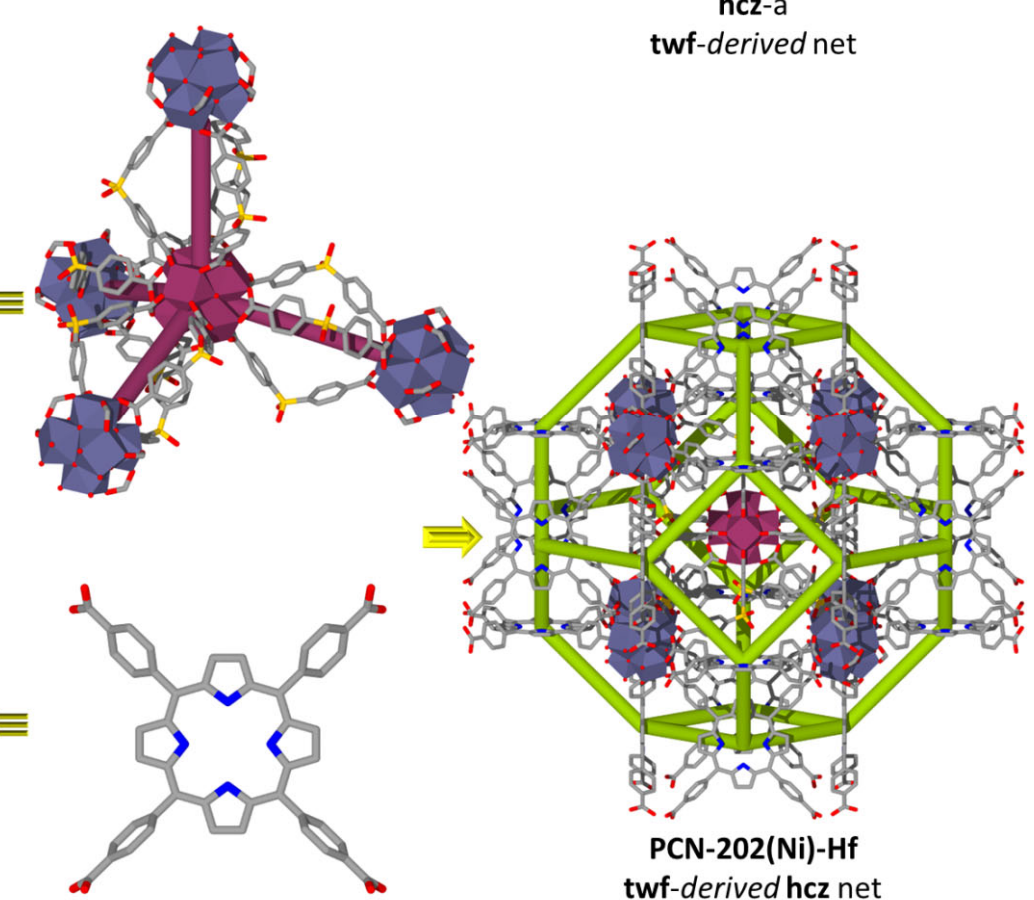

Figure.17 An experimental MOF (PCN-202(Ni)-Hf) based on twf net and its derived net, hcz net. PCN-202(Ni)-Hf is constructed from 12-connected $\mathrm{Zr}(\mathrm{IV})$ hexanuclear clusters, topologically 4-connected $\mathrm{Hf}(\mathrm{IV})$ hexanuclear clusters, and 4-connected square organic ligands. $\mathrm{C}, \mathrm{N}$, and $\mathrm{O}$ are represented by gray, blue, and red, respectively, and $\mathrm{H}$ atoms and solvent molecules are omitted for clarity. $\mathrm{Zr}$ and $\mathrm{Hf}$ atoms are represented as blue gray and purple polyhedral, respectively. ${ }^{134}$

\subsection{MOFs based on nia and nia-related Nets}

The symbol nia comes from the mineral compound nickeline, or nickel arsenide (NiAs). The nia net is a $(6,6)$ - c net, with both octahedron and trigonal prism as basic building units. Replacing the octahedral node in the parent net with a binodal group (operation O-1-6a and $\mathrm{O}-$ 1-6b), two minimal edge-transitive nia-related nets are 
generated. That is to say, the $(3,6,12)$-c kex and urx nets are both with transitivity [3243].

As illustrated in Figure.18, the augmented versions of the kex-a and urx-a nets are shown, and then serve as suitable targets for the assembly of the corresponding MOF structures. Rare earth polynuclear clusters have been well studied to serve as d6R (hexagonal prism) building units to assemble to highly-connected MOFs. ${ }^{11}$, 130 The right choice of the polytopic organic linker with the prerequisite building blocks (i.e., hexagon and triangle), in combination with the proper conditions to in-situ generate the RE polynuclear cluster, led to the formation of the targeted MOFs with aforesaid kex net..$^{92}$

Interestingly, the introduction of the heterofunctional linkers with both tetrazolate and carboxylate moieties results in the first urx-MOFs based on the RE polynuclear clusters. Aside from the well-studied nonanuclear clusters as the d6R building units, the RE hexanuclear cluster directed by the tetrazolate moieties can be viewed as a trigonal anti-prismatic SBU. Thus, those building units led to the construction of MOF structures, mismatching the above-stated $(3,6,12)$-c urx net.

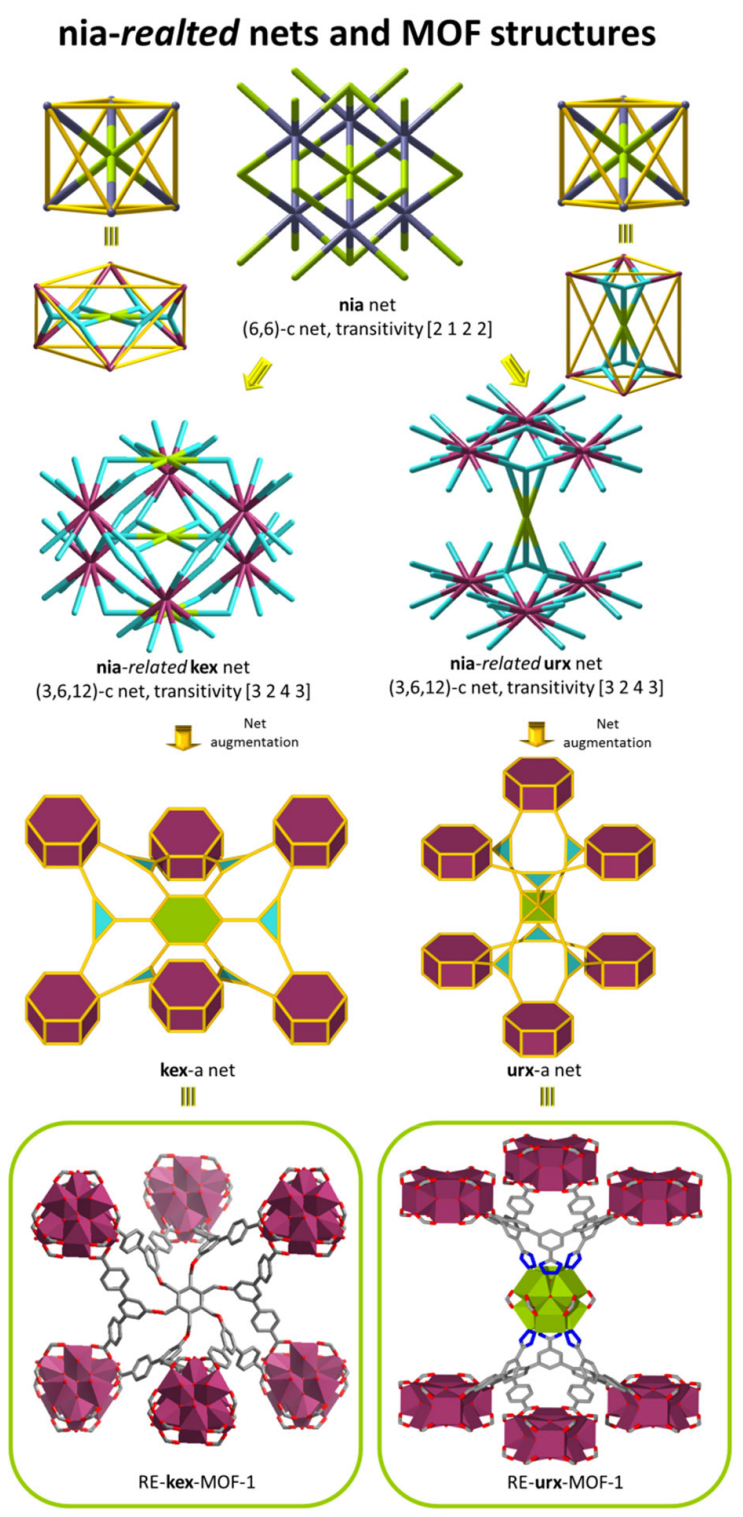

Figure.18 The generation of nia-related nets (kex and urx) from the $(6,6)-c$ nia net by the replacement of the octahedral node. The generated nets can be used as a guide for the assembly of the according highly connected MOF structures. Reproduced with permission from reference ${ }^{92}$. Copyright 2019 American Chemical Society.

\subsection{MOFs based on shp, alb and their related Nets}

As previously mentioned, the operation X-1-12 on the shp and alb net generated the $(3,8,12)$-c shp-related pek net and $(3,12,12)$-c alb-related aea net with the $C F=C_{2}[3 X]$ and $\mathrm{CF}=\left[{ }_{3} \mathrm{X}\right] \mathrm{X}_{2}$, respectively. As illustrated in the Figure.19 (top), the pek net is constructed from the triangle, cube and d6R. By connecting the center of the d6R (the purple node) and the cube (the blue gray node), the shp net is obtained. The coordination number of cube (8) in the related net (pek net) is double compared to that of the 
square (4) in the parent net (shp net). As shown in the Figure.19, each d6R is linked to a cube via two triangles.
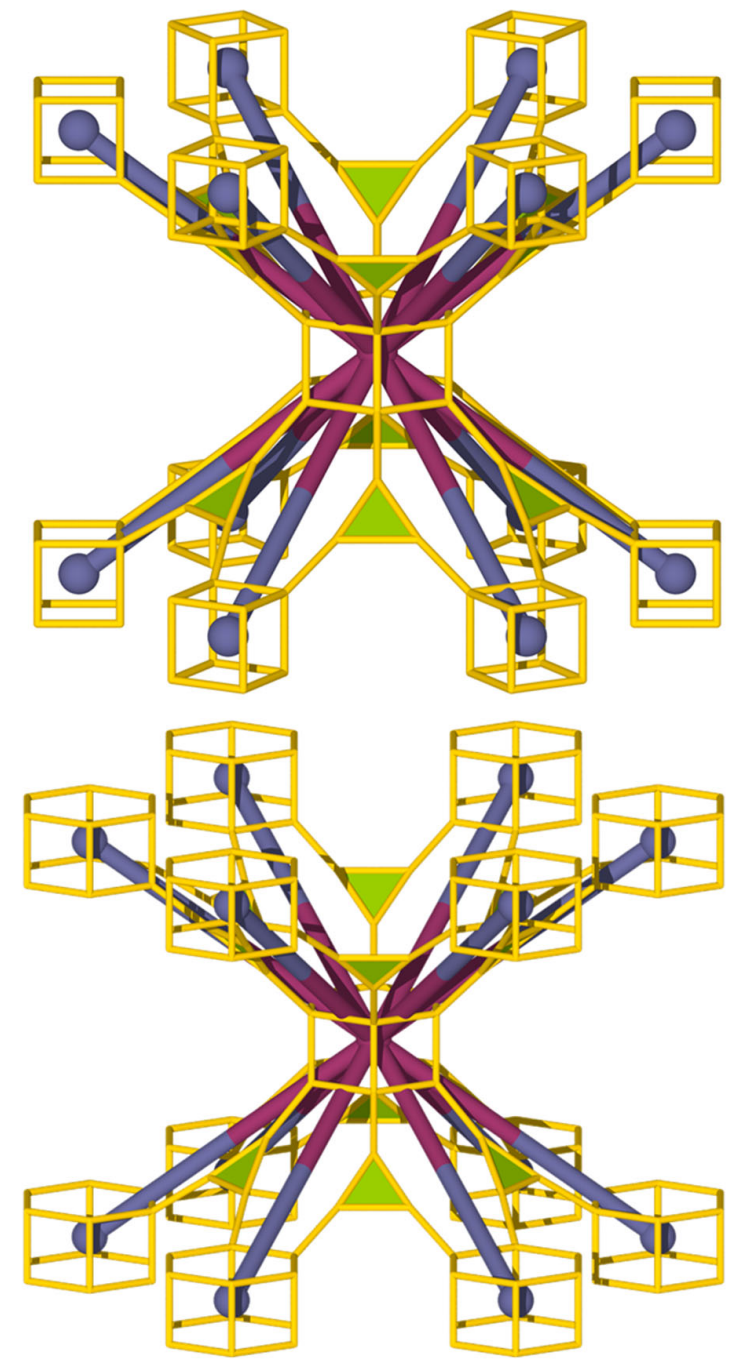

Figure.19 The relationship between the $(3,8,12)$-c pek net and the $(4,12)$-c shp net (top), the square in the parent net transforms to the cube in the related net; the relationship between the $(3,12,12)$-c aea net and the $(6,12)$-c alb net (down), the trigonal prism in the parent net transforms to the hexagonal prism (d6R) in the related net. The pek and aea net are illustrated in their augmented version, pek-a and aea-a, respectively.

The aea net is built from a triangle and two kinds of hexagonal prisms. As exemplified in the down part of Figure.19, the alb net is obtained by linking the centers of two types of d6Rs. The rose hexagonal prism (12-c) in the aea net is generated from the trigonal prism (6-c) in the alb net. Thus, the aea net is an alb-related net. Each purple d6R is linked to a d6R by two triangular linkers.

It is to be noted that the pek and aea net have the same space group as their parent shp and alb net, $P 6 / \mathrm{mmm}$.

The topological exploration of the tritopic ligand with the implemented lower symmetry as compared to the prototype symmetrical linker 1,3,5-tris(4carboxyphenyl)benzene, with the RE polynuclear clusters led to the unprecedented discovery and synthesis of the highly-connected RE-MOFs based on pek and aea topologies. ${ }^{130,164}$ The use of less symmetrical 3-c ligand (e.g. biphenyl-3,4,5-tricarboxylic acid), in presence of $\mathbf{2}^{-}$ fluorobenzoic acid (2-FBA), guided the simultaneous occurrence of nonanuclear $\left[\mathrm{RE}_{9}\left(\mu_{3}-\mathrm{OH}\right)_{12}\left(\mu_{3}-\mathrm{O}\right)_{2}\left(\mathrm{O}_{2} \mathrm{C}-\right)_{12}\right]$ and hexanuclear $\left[\mathrm{RE}_{6}(\mathrm{OH})_{8}\left(\mathrm{O}_{2} \mathrm{C}-\right)_{8}\right]$ carboxylate-based clusters as 12-c and 8-c MBBs in the 3-periodic $(3,8,12)$-c pek-MOF (Figure.2o, left). It is to be noted that this nonanuclear $\left[\mathrm{RE}_{9}\left(\mu_{3}-\mathrm{OH}\right)_{12}\left(\mu_{3}-\mathrm{O}\right)_{2}\left(\mathrm{O}_{2} \mathrm{C}-\right)_{12}\right]$ carboxylatebased cluster represents the first example of RE clusters which can be viewed as a d6R or hexagon prism SBU. The subsequent use of a carbazole-based ligand with modified angles between the carboxylates (e.g. from $120^{\circ}$ to $90^{\circ}$ ) led to the formation of a highly-connected $(3,12,12)$-c MOF enclosing merely nonanuclear clusters and exhibiting a novel aea topology (Figure.2o, right). We didn't recognize the initial discovery of pek-MOFs and aeaMOFs as designed syntheses; however, the coincidence that the combination of highly connected clusters and tritopic ligands led to the construction of structures based of minimal edge-transitive nets (transitivity [32]) could be inspirable to those who want to design experiment. 


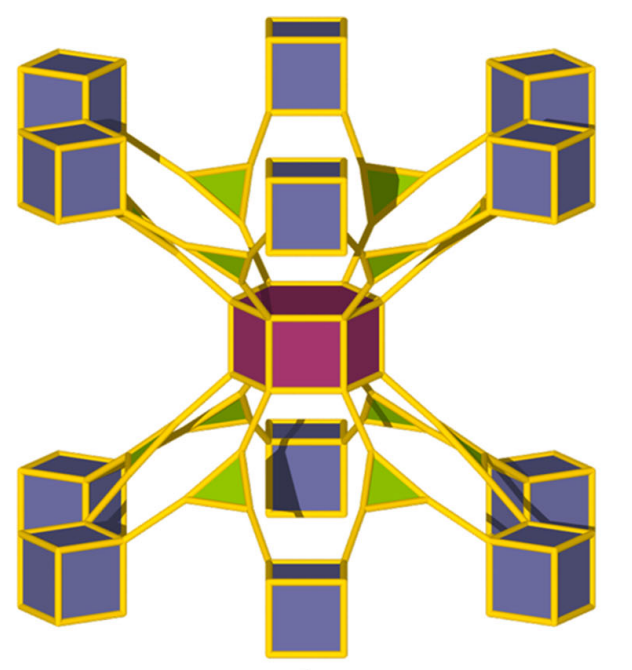

pek-a

shp-related net

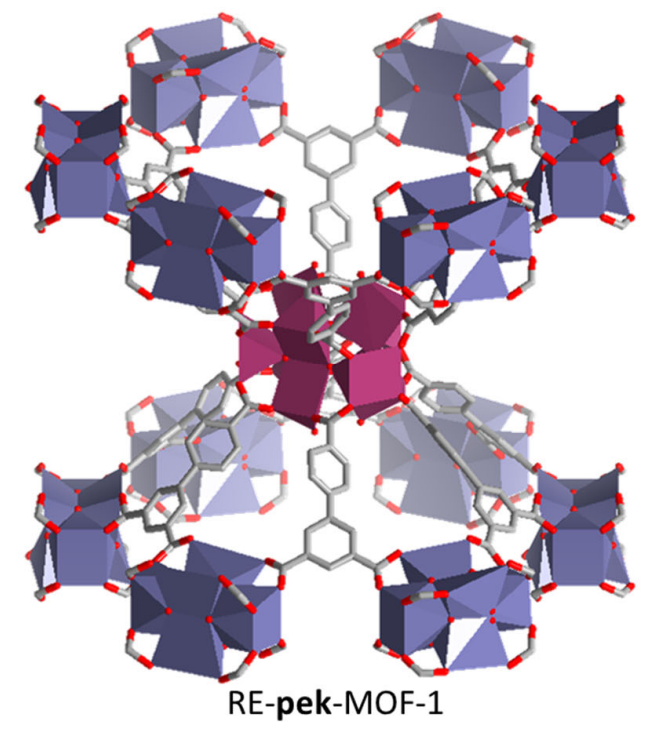

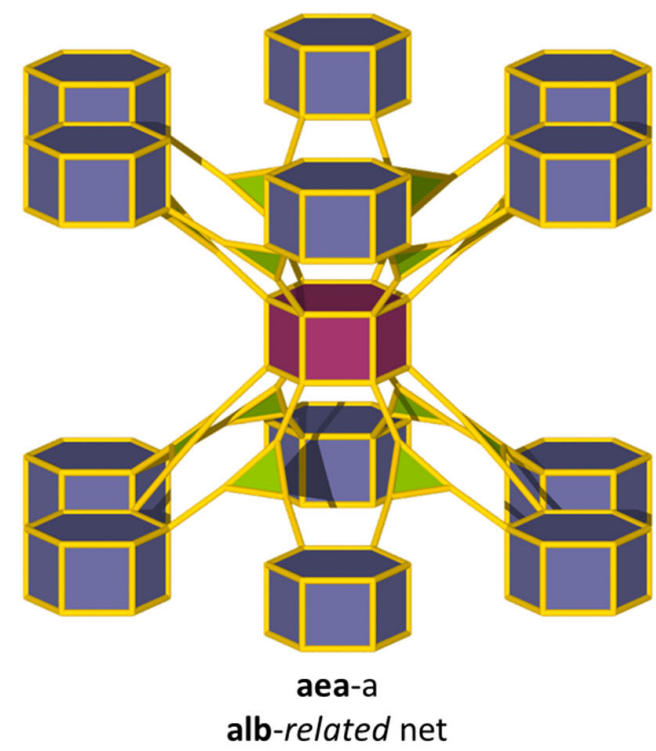

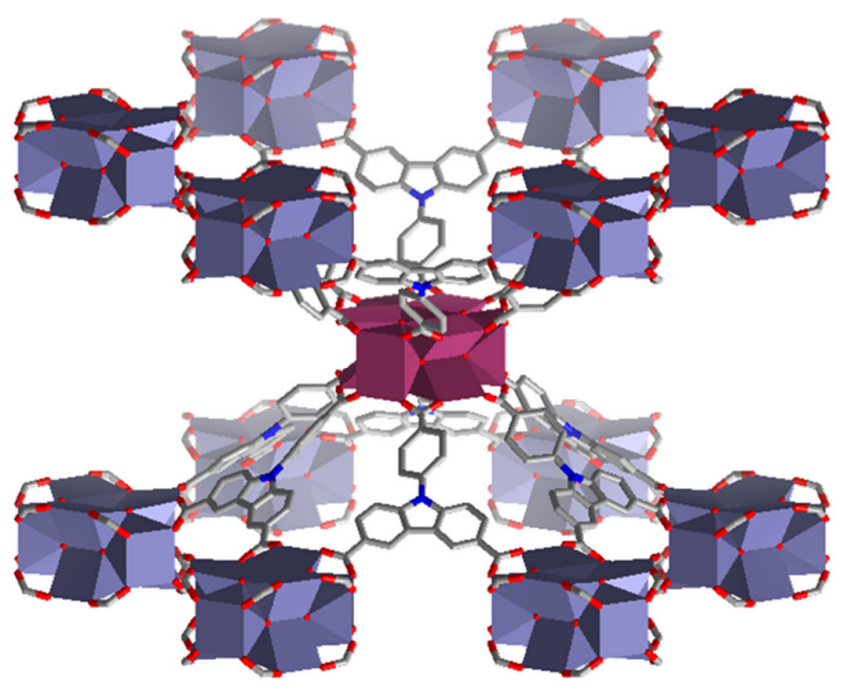

RE-aea-MOF-1

Figure.2o Experimental MOFs (RE-pek-MOF-1 and RE-aea-MOF-1) based on the (3,8,12)-c shp-related pek net and $(3,12,12)$-c alb-related aea net. RE-pek-MOF-1 is constructed from a 12-connected RE(III) nanonuclear cluster, an 8connected RE(III) hexanuclear cluster and a 3-connected organic ligand. RE-aea-MOF-1 is synthesized from a 3connected organic ligand and two kinds of 12 -connected RE(III) nanonuclear cluster. N, C, and O are represented by blue, gray, and red, respectively, and $\mathrm{H}$ atoms and solvent molecules are omitted for clarity. RE atoms are represented as purple/blue gray polyhedra. ${ }^{130}$

\section{Reticular Chemistry 3.2 for the Designed Syn- thesis of MOFs}

It is commonly believed that what matters in an appropriately designed experiment for a definite structure is geometry rather than energetics. ${ }^{89}$ Thus porous solids can be made in the syntheses as the result of a kinetically controlled synthetic pathway, and thermodynamically most stable products (dense structures) do not form in some cases. ${ }^{3,114,165}$

Reticular chemistry opens a new route/connection between the graphic net (geometry) and the 3-periodic extended framework (i.e. MOFs or COFs). It is a powerful strategy to guide the assembly of simple pre-selected building units to the final targeted structures. For example, the structures based on nets with one kind of link or edge (edge-transitive) and, further, minimal edge-transitive nets (e.g. those with MT [3 2] - thus Reticular Chemistry 3.2) are the appropriate objectives to be attained. As illustrated in the Figure 21, TBUs matching the vertices of the the vertex figures of the parent nets, are relevant to the operation as shown in Figures 1-11, which generated derived/related nets. The SBUs of a TBU contain structural coding information of the specific derived/related net. In this part, some of the key prerequisites would be discussed 
(b)
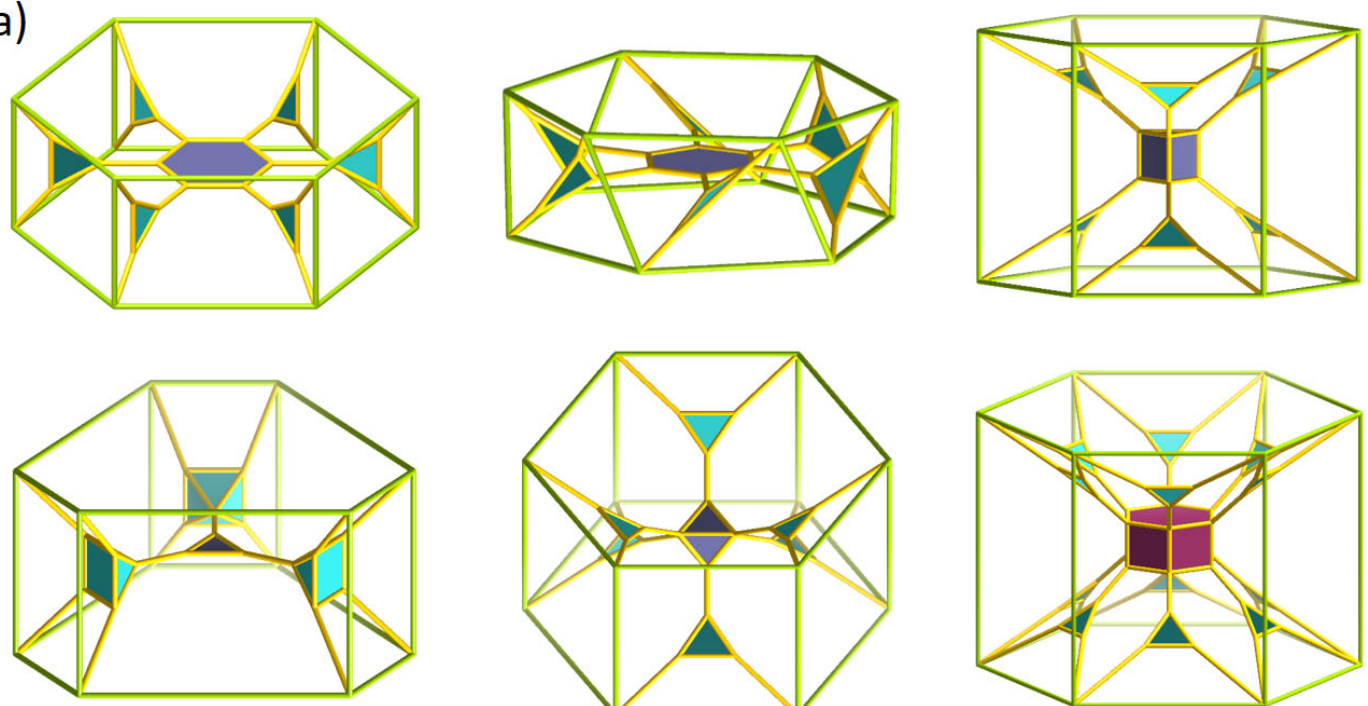

(a)
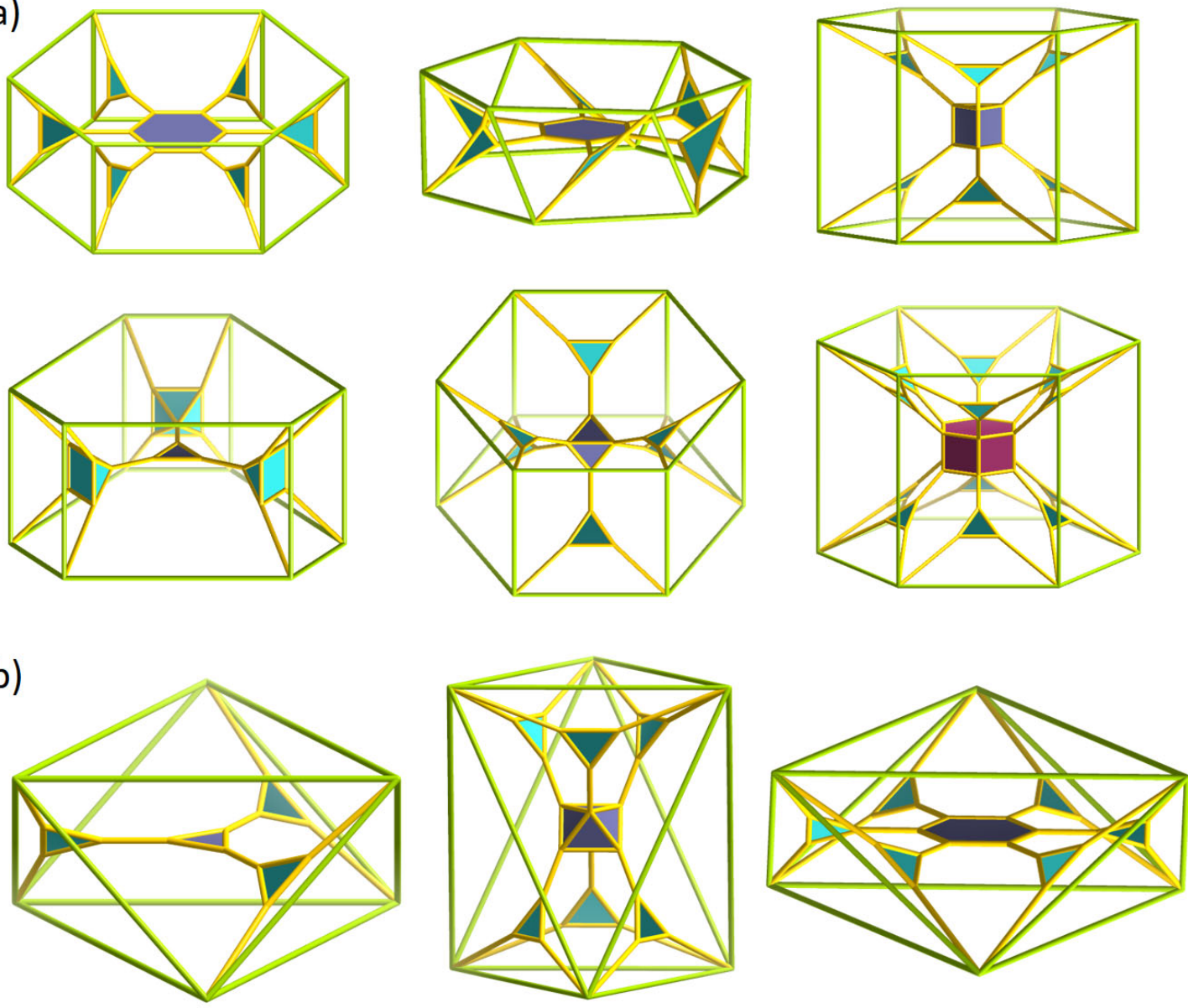

(c)
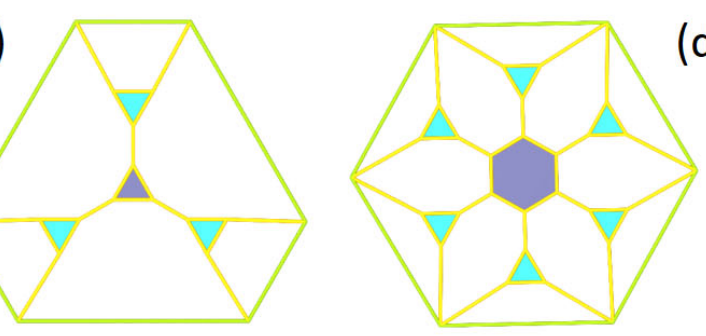

(d)
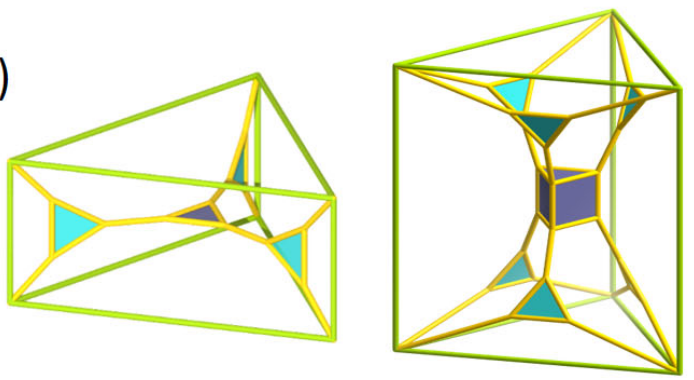

Figure 21. Some tertiary building units (TBUs) are relevant to the operation, which generated derived/related nets from parent nets. (a) TBUs of hexagonal prism (X); (b) TBUs of octahedron (O); (c) TBUs of hexagon (H); (d) TBUs of trigonal prism $(\mathrm{P})$.

First, the right strategies should be chosen to target the desired structures. Many powerful approaches have been well developed by us and others, including the molecular building block approach, supermolecular building block approach, supermolecular building layer approach. ${ }^{9}$, 46, 166168

Second, when the precise approach is elected, it is essential to select the correct/appropriate building blocks to aid and direct the assembly of the desired targets. For example, if a $(6,12)$-c alb-MOF is the targeted materials and the MBB approached is chosen, there are many possible combinations for plausible and suitable building blocks. The 6-c trigonal prismatic organic linker and 12-c d6R-shaped inorganic polynuclear cluster can be an option, and the 12-c hexagonal prismatic organic ligands and the well-know 6-c trigonal prismatic metal trinuclear cluster can be the other. Alternatively, the combination of the 12-c d6R-shaped cluster, the 6-c trigonal prismatic cluster, and a simple linear ditopic ligand could also be a proper candidate if both clusters can be formed at the 
same time. Although there are many options for the real chemical synthesis to choose, the final MOF structures, if formed, are based on the same parent net (i.e. alb), sometimes with different derived net. ${ }^{83}$

Third, when a prototype MOF structure was constructed, the size or type of the linker could be tuned to achieve the specific application by applying isoreticular chemistry. ${ }^{6,169-}$ ${ }_{171}$ For instance, the soc-MOF93, 101 or fcu-MOF90, 172-174 platform can be regulated for gas storage or gas separation, depending on the pore-aperture size of tuned structures. Of course, the interpenetration should be taken into consideration for the some MOF systems when expanding the linker. ${ }^{175-177}$

Fourth, reticular chemistry gives a good opportunity to alter the functionality of the linker while keeping the overall framework unaltered. ${ }^{178}$ Thus, the precise functionality can be accurately imparted into a MOF platform. Multivariate MOFs with certain complexities can be controlled during the framework assembly process. ${ }^{179-182}$ The mixed linker MOFs can even be designed and synthesized via merged nets approach, a new strategy added to the repertoire of reticular chemistry for the design and construction of intricate mixed-ligands MOFs strategy. ${ }^{12}$

To further demonstrate the feasibility of the minimal edge-transitive derived and related nets for the design and synthesis of MOFs, we here selected four minimal edgetransitive nets (i.e. epu (pcu-related), epw (hxg-related), tfp (stp-derived) and tsa (nia-derived)) as suitable blueprint nets and simulated the corresponding MOF structures by using hypothetical organic ligands and known inorganic building blocks (Figure 22). The carbon centers of carboxylate groups on those proposed polytopic branched ligands can position on the vertex figures of the targeted net, making them more feasible to synthesize the proposed MOFs when reacting with selected inorganic building units.

The first example is an epu-MOF constructed from a 12-c ligand and a 12-c hexagonal prismatic RE nonanuclear cluster. (Figure 22, a) This linker overall can be viewed as an octahedral TBU with a central hexagon and one kind of the triangles. As stated previously, the epu $\left(\left[\mathrm{H}_{3}\right] \mathrm{X}_{2}\right)$ net is a pcu-related net, and the coordination number of the new node, namely hexagonal prism, is double compared to the parent pcu net. The second example is an epw-MOF from a 12-c linker and a d6R like RE cluster (Figure 22, b). In this case, this linker can be regarded as a planar hexagon with two carboxylates coordinated to a same RE cluster. This TBU is also from a central hexagon and one kind of the triangles, but with a different conformation to the aforementioned example of epu net. The third example is a MOF based on the stp-derived tfp net, from a common inorganic metal paddlewheel-based cluster and a 6-c trigonal prismatic organic ligand (Figure 22, c). The introduction of methyl group in the ligand forces the three arms to be perpendicular to the central core, and thus provides a rigid trigonal prismatic TBU. This TBU is constructed from a central triangle and one type of the triangles. The combination of this TBU with the square led to the stp-derived $\mathbf{t f p}$ net. The last example of MOF is from a similar 6-c trigonal prismatic linker and $\mathrm{Zn}(\mathrm{II})$ tetranuclear cluster (Figure 22, d). The Zn(II) tetranuclear cluster can be viewed as an octahedron, and the organic TBU can be regarded as the arrangement of one kind of triangle and a central triangle. In general, this MOF is based on the nia-derived tsa net. Finally, it should be mentioned that the proposed organic ligands might be challenging to accomplish in terms of organic chemistry; however, it pinpoints to the prospect to rationally design a MOF using reticular chemistry 3.2 based on special minimal edge transitive nets, resulting from taking into account the information from both parent nets and derived/related nets and the deployment of net-coded building units. It is to be noted using similar principles MOFs based on mixed metal polynuclear clusters and less complicated ligands may also be attained. 
(a)

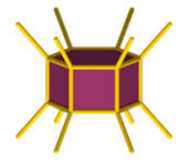

Hexagonal prism SBU $12-c$

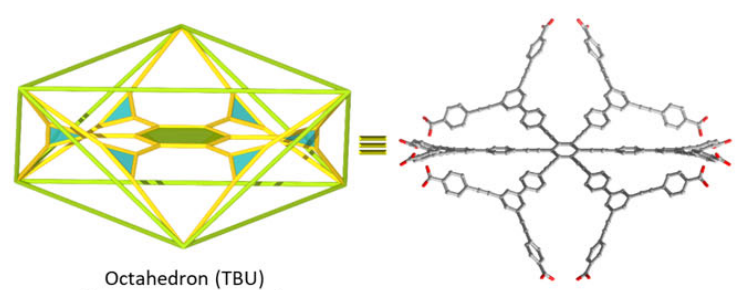

Hexagonal SBU 6-c and Triangular SBU 3-c

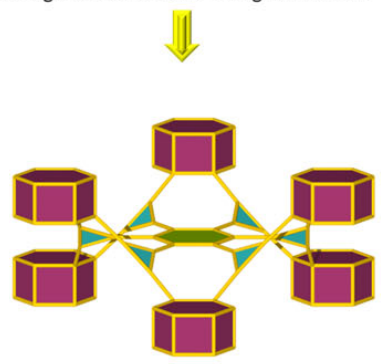

epu-a net (pcu related net)

(c)

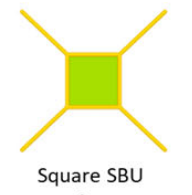
4-c

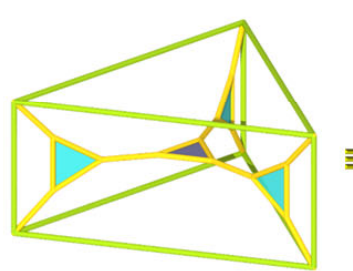

Trigonal Prism (TBU)

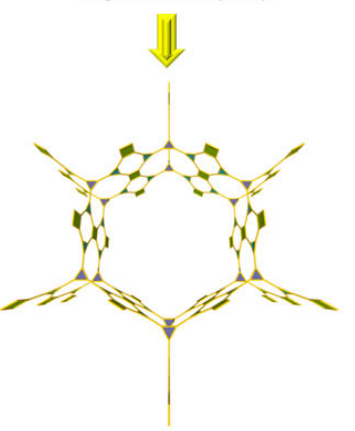

tfp-a net (stp derived net)

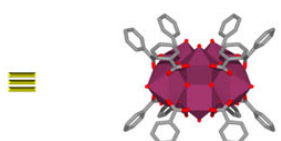

$R E(I I I)$ nonanuclear cluster

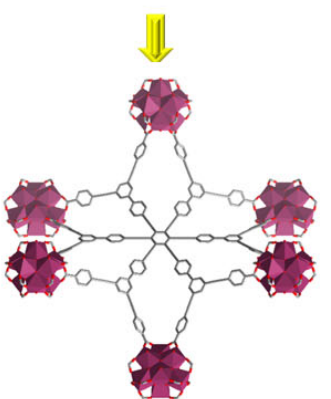

Simulated MOF based on epu net
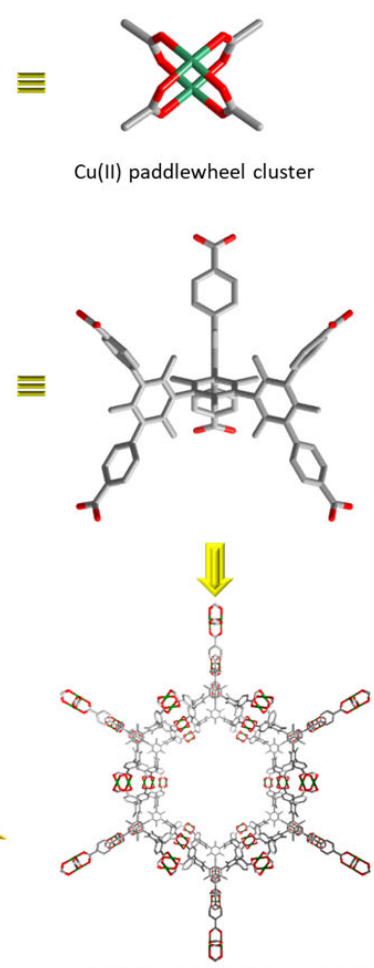

Simulated MOF based on tfp net (b)

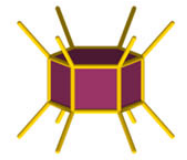

Hexagonal prism SBU $12-c$

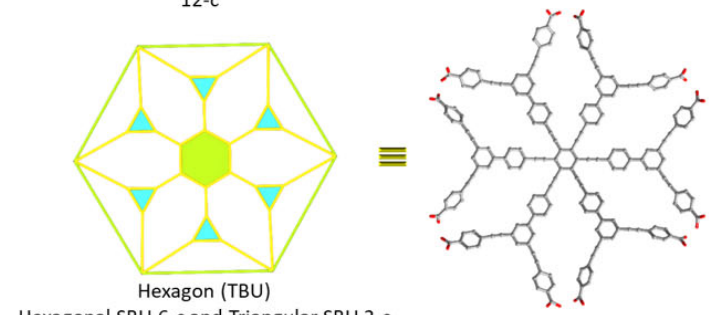

Hexagonal SBU 6-c and Triangular SBU 3-c

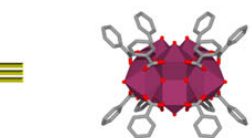

$\mathrm{RE}$ (III) nonanuclear cluster

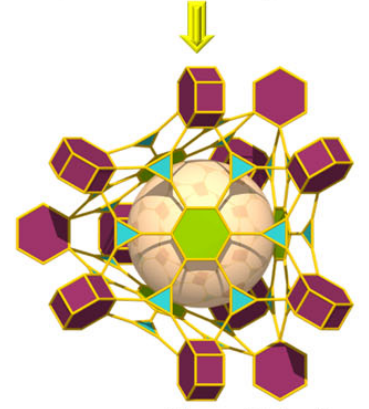

epw-a net (hxg related net)

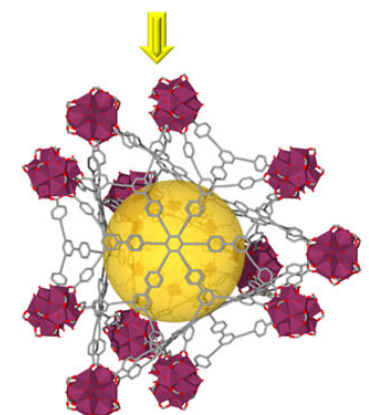

Simulated MOF based on epw net

(d)
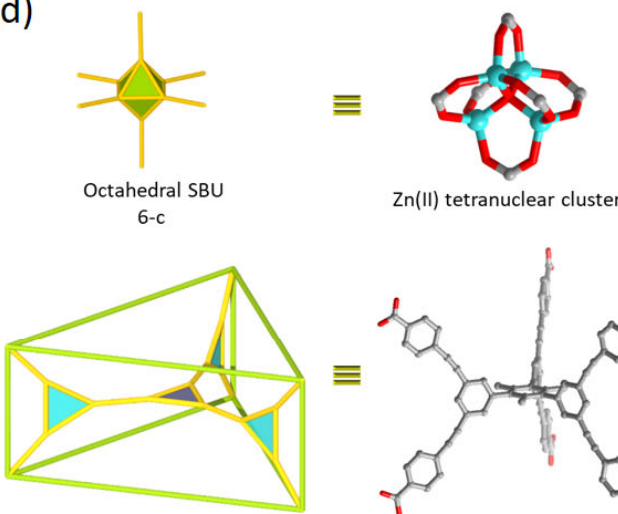

Trigonal Prism (TBU)

11.

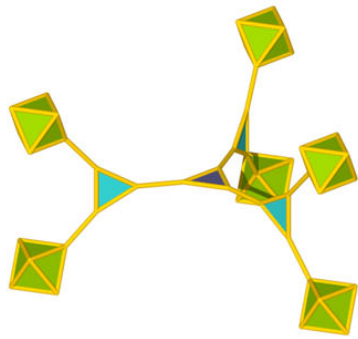

tsa-a net (nia derived net)

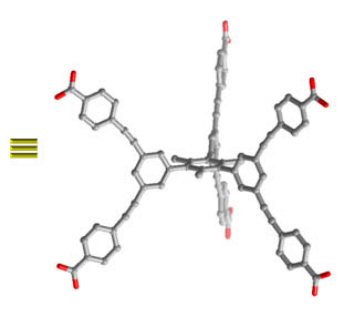

$\sqrt{1}$

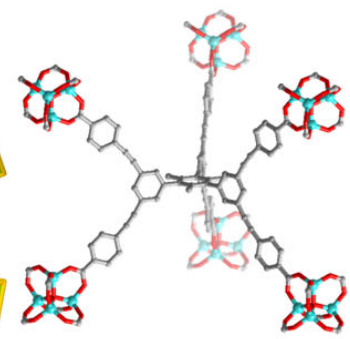

Simulated MOF based on tsa net

Figure 22. Simulated MOFs based on minimal edge-transitive nets (i.e. epu (pcu-related), epw (hxg-related), tfp (stpderived) and tsa (nia-derived)). 


\section{Concluding Remarks and Future Prospects}

In this review we have delineated a reliable approach to the enumeration of a special class of 3-periodic trinodal nets with transitivity [32] (minimal edge-transitive nets). We called these newly generated nets as derived or related nets compared to the parent net, depending on their relationship to the original nets. These minimal edgetransitive nets enrich the lexicon and toolbox of reticular chemistry with appropriate blueprints net as ideal targets for designed syntheses of possible MOFs and related materials. The resultant inclusive list of the enumerated minimal edge-transitive nets provides a unique toolbox for the material's designer as it offers ideal blueprints for the deliberate design and rational assembly of building blocks with embedded multiple branch points into intricate trinodal MOFs. Some of those nets have been recently used to guide the design and synthesis of MOF crystal structures. It is recommended to give both the parent net and the corresponding derived/related net for a MOF with multiple branched nodes, e.g. "alb-derived ury net" and "nia-related kex net", consistent with the proposal of an IUPAC project. $^{83},{ }^{183}$ For example, a clear procedure for the deconstruction of the branched linker of a MOF structure should be provided for the topological analysis to give its underlying net (a derived or related net). The parent net, on the other hand, provides the desired directional information for selecting the looked-for MBBs in the MOF design process.

We believe this new development of reticular chemistry 3.2 is of special importance to the future advance of MOFs and related materials due to the following reasons: i) the minimal edge-transitive nets give the most possible MOF structures which can be assembled from the pre-selected MBBs, and thus a high degree of control on the assembly system could be achieved; ii) the enriched vocabulary of reticular chemistry could enable material chemists to find and achieve the proper targeted structures for the specific use; iii) the reticular chemistry allows the deliberately fabrication of MOF materials with controlled poreaperture size and shape for targeted applications.

The enumeration of the nets in this work was conducted in program Systre ${ }^{147}$ and CrystalMaker (available from gavrog.org and www.crystalmaker.com). The topological analysis was done in Systre, Materials Studio and ToposPro $^{184}$ (available from accelrys.com and topospro.com). The occurrences of nets in crystal structures can be checked on The Samara Topological Data Center (available from topcryst.com).

\section{AUTHOR INFORMATION}

Corresponding Author mohamed.eddaoudi@kaust.edu.sa and mokeeffe@asu.edu

Biographies
Zhijie Chen was born in Fuzhou, Fujian, China in 1989. He received his B.S. (2012) degree from Shanghai Jiao Tong University (SJTU) in China under the supervision of Prof. Yong Cui, and Ph.D. (2018) from King Abdullah University of Science and Technology (KAUST) under the supervision of Prof. Mohamed Eddaoudi. He joined Prof. Omar Farha's group at Northwestern University as a postdoctoral researcher in 2018. His research interest is related to the reticular synthesis of functional porous materials, as well as their structure-property relationships.

Hao Jiang was born in Qitaihe, Heilongjiang, China, in 1988. He received his B.S. from Jilin University in 2011 with Prof. Jihong Yu and Prof. Wenfu Yan. Then, he attended King Abdullah University of Science and Technology (KAUST) and received his M.S. in 2012 and Ph.D. in 2018 with Prof. Mohamed Eddaoudi. His Ph.D. research focused on the rational design of Intricate metal-organic frameworks. He continued his work about the design of periodic materials as a Postdoctoral Fellow with Prof. Mohamed Eddaoudi. His research interest includes the design and synthesis of crystalline materials and the prediction of structural, chemical, photo-, electro- and mechanical properties.

Mian Li was born in Shantou, China in 1982. He attended Nanjing University and developed interest in 1-peroidic spin-crossover systems. Now he works independently for Shantou University studying photophysics of $\mathrm{Cu}$ complexes, clusters and coordination networks. Since 2007 he has been doing research on geometrical/topological aspects of reticular chemistry--in particular the Minimal Transitivity Principle, and rods--under the guidance of Prof. Michael O'Keeffe.

Michael O'Keeffe was born in England in 1934. He attended Bristol University (B. Sc., Ph. D., D. Sc.). In 1963 he joined Arizona State University where he is currently Regents' Professor Emeritus. He has published widely in various areas of inorganic materials chemistry. His current interests are foremost in the geometrical aspects of reticular chemistry - particularly periodic nets, knots, tilings, and weavings. In 2019 he received the Aminoff award in crystallography.

Dr Mohamed Eddaoudi was born in Agadir, Morocco. He is currently Distinguished Professor of Chemistry and Director of the Advanced Membranes and Porous Materials Center, King Abdullah University of Science and Technology (KAUST, Kingdom of Saudi Arabia). He received his $\mathrm{PhD}$ in chemistry from Université Denis Diderot (Paris VII), France. After postgraduate research experience (Arizona State University, University of Michigan), he started his independent academic career as Assistant Professor, University of South Florida (2002), Associate Professor (2008), and Professor (2010). His research focuses on developing strategies, based on (super)-molecular building approaches (MBB, SBB, SBL, Merged nets), for the rational construction of functional solid-state materials, namely metal-organic frameworks (MOFs); and their subsequent use to address some of the persisting challenges pertaining to energy security and environmental sustainability. Dr Eddaoudi's eminent contribution to the burgeoning field of Reticular 
Chemistry and MOF design \& applications is evident from his selection in 2014, 2015, 2016, 2017, 2018 and 2019 as a Thomson Reuters Highly Cited Researcher.

\section{ACKNOWLEDGMENT}

Research reported in this publication was supported by King Abdullah University of Science and Technology (KAUST). We are grateful to a referee for very many helpful comments and suggestions.

\section{Supporting Information}

The excel version of tables of derived and related nets. This material is available free of charge via the Internet at http://pubs.acs.org.

\section{REFERENCES}

(1) Hawthorne, F. C. Crystals from First Principles. Nature 1990, 345, 297-297.

(2) Corma, A. State of the Art and Future Challenges of Zeolites as Catalysts. J. Catal. 2003, 216, 298-312.

(3) Davis, M. E. Ordered Porous Materials for Emerging Applications. Nature 2002, 417, 813-821.

(4) Kim, K.; Lee, T.; Kwon, Y.; Seo, Y.; Song, J.; Park, J. K.; Lee, H.; Park, J. Y.; Ihee, H.; Cho, S. J., et al. Lanthanum-Catalysed Synthesis of Microporous 3D Graphene-Like Carbons in a Zeolite Template. Nature 2016, 535, 131-135.

(5) Li, H.; Eddaoudi, M.; O'Keeffe, M.; Yaghi, O. M. Design and Synthesis of an Exceptionally Stable and Highly Porous MetalOrganic Framework. Nature 1999, 402, 276-279.

(6) Eddaoudi, M.; Kim, J.; Rosi, N.; Vodak, D.; Wachter, J.; O'Keeffe, M.; Yaghi, O. M. Systematic Design of Pore Size and Functionality in Isoreticular MOFs and Their Application in Methane Storage. Science 2002, 295, 469-472.

(7) Jansen, M.; Schön, J. C. "Design" in Chemical Synthesis - an Illusion? Angew. Chem. Int. Ed. 2006, 45, 3406-3412.

(8) Eddaoudi, M.; Sava, D. F.; Eubank, J. F.; Adil, K.; Guillerm, V. Zeolite-Like Metal-Organic Frameworks (ZMOFs): Design, Synthesis, and Properties. Chem Soc Rev 2015, 44, 228-49.

(9) Guillerm, V.; Kim, D.; Eubank, J. F.; Luebke, R.; Liu, X.; Adil, K.; Lah, M. S.; Eddaoudi, M. A Supermolecular Building Approach for the Design and Construction of Metal-Organic Frameworks. Chem. Soc. Rev. 2014, 43, 6141-6172.

(10) Liu, T. F.; Feng, D.; Chen, Y. P.; Zou, L.; Bosch, M.; Yuan, S.; Wei, Z.; Fordham, S.; Wang, K.; Zhou, H. C. Topology-Guided Design and Syntheses of Highly Stable Mesoporous Porphyrinic Zirconium Metal-Organic Frameworks with High Surface Area. $J$. Am. Chem. Soc. 2015, 137, 413-419.

(11) Chen, Z.; Weseliński, Ł. J.; Adil, K.; Belmabkhout, Y.; Shkurenko, A.; Jiang, H.; Bhatt, P. M.; Guillerm, V.; Dauzon, E.; Xue, D.-X., et al. Applying the Power of Reticular Chemistry to Finding the Missing alb-MOF Platform Based on the $(6,12)$ Coordinated Edge-Transitive Net. J. Am. Chem. Soc. 2017, 139, 3265-3274.

(12) Jiang, H.; Jia, J.; Shkurenko, A.; Chen, Z.; Adil, K.; Belmabkhout, Y.; Weselinski, L. J.; Assen, A. H.; Xue, D.-X.; O'Keeffe, M., et al. Enriching the Reticular Chemistry Repertoire: Merged Nets Approach for the Rational Design of Intricate Mixed-
Linker Metal-Organic Framework Platforms. J. Am. Chem. Soc. 2018, 140, 8858-8867.

(13) Kitagawa, S.; Kitaura, R.; Noro, S.-i. Functional Porous Coordination Polymers. Angew. Chem. Int. Ed. 2004, 43, 23342375.

(14) Zhou, H.-C.; Long, J. R.; Yaghi, O. M. Introduction to MetalOrganic Frameworks. Chem. Rev. 2012, 112, 673-674.

(15) Furukawa, H.; Cordova, K. E.; O'Keeffe, M.; Yaghi, O. M. The Chemistry and Applications of Metal-Organic Frameworks. Science 2013, 341, 1230444.

(16) Cohen, S. M. Postsynthetic Methods for the Functionalization of Metal-Organic Frameworks. Chem. Rev. 2012, 112, 970-1000.

(17) Cook, T. R.; Zheng, Y.-R.; Stang, P. J. Metal-Organic Frameworks and Self-Assembled Supramolecular Coordination Complexes: Comparing and Contrasting the Design, Synthesis, and Functionality of Metal-Organic Materials. Chem. Rev. 2013, 113, 734-777.

(18) Cadiau, A.; Adil, K.; Bhatt, P. M.; Belmabkhout, Y.; Eddaoudi, M. A Metal-Organic Framework-Based Splitter for Separating Propylene from Propane. Science 2016, 353, 137-140. (19) Adil, K.; Belmabkhout, Y.; Pillai, R. S.; Cadiau, A.; Bhatt, P. M.; Assen, A. H.; Maurin, G.; Eddaoudi, M. Gas/Vapour Separation Using Ultra-Microporous Metal-Organic Frameworks: Insights into the Structure/Separation Relationship. Chem. Soc. Rev. 2017, 46, 3402-3430.

(20) He, Y.; Zhou, W.; Qian, G.; Chen, B. Methane Storage in Metal-Organic Frameworks. Chem. Soc. Rev. 2014, 43, 5657-5678. (21) Herm, Z. R.; Wiers, B. M.; Mason, J. A.; van Baten, J. M.; Hudson, M. R.; Zajdel, P.; Brown, C. M.; Masciocchi, N.; Krishna, R.; Long, J. R. Separation of Hexane Isomers in a Metal-Organic Framework with Triangular Channels. Science 2013, 340, 960-964. (22) Peng, Y.; Krungleviciute, V.; Eryazici, I.; Hupp, J. T.; Farha, O. K.; Yildirim, T. Methane Storage in Metal-Organic Frameworks: Current Records, Surprise Findings, and Challenges. J. Am. Chem. Soc. 2013, 135, 11887-11894.

(23) Lin, R.-B.; Li, L.; Zhou, H.-L.; Wu, H.; He, C.; Li, S.; Krishna, R.; Li, J.; Zhou, W.; Chen, B. Molecular Sieving of Ethylene from Ethane Using a Rigid Metal-Organic Framework. Nat. Mater 2018, 17, 1128-1133.

(24) Cui, X.; Chen, K.; Xing, H.; Yang, Q.; Krishna, R.; Bao, Z.; Wu, H.; Zhou, W.; Dong, X.; Han, Y., et al. Pore Chemistry and Size Control in Hybrid Porous Materials for Acetylene Capture from Ethylene. Science 2016, 353, 141-144.

(25) Li, B.; Wen, H.-M.; Zhou, W.; Xu, Jeff Q.; Chen, B. Porous Metal-Organic Frameworks: Promising Materials for Methane Storage. Chem 2016, 1, 557-580.

(26) Kim, H.; Yang, S.; Rao, S. R.; Narayanan, S.; Kapustin, E. A.; Furukawa, H.; Umans, A. S.; Yaghi, O. M.; Wang, E. N. Water Harvesting from Air with Metal-Organic Frameworks Powered by Natural Sunlight. Science 2017, 356, 430-434.

(27) Cadiau, A.; Belmabkhout, Y.; Adil, K.; Bhatt, P. M.; Pillai, R. S.; Shkurenko, A.; Martineau-Corcos, C.; Maurin, G.; Eddaoudi, M. Hydrolytically Stable Fluorinated Metal-Organic Frameworks for Energy-Efficient Dehydration. Science 2017, 356, 731-735.

(28) Furukawa, H.; Gándara, F.; Zhang, Y.-B.; Jiang, J.; Queen, W. L.; Hudson, M. R.; Yaghi, O. M. Water Adsorption in Porous Metal-Organic Frameworks and Related Materials. J. Am. Chem. Soc. 2014, 136, 4369-4381.

(29) Towsif Abtab, S. M.; Alezi, D.; Bhatt, P. M.; Shkurenko, A.; Belmabkhout, Y.; Aggarwal, H.; Weseliński, Ł. J.; Alsadun, N.; Samin, U.; Hedhili, M. N., et al. Reticular Chemistry in Action: A 
Hydrolytically Stable MOF Capturing Twice Its Weight in Adsorbed Water. Chem 2018, 4, 94-105.

(30) Rieth, A. J.; Yang, S.; Wang, E. N.; Dincă, M. Record Atmospheric Fresh Water Capture and Heat Transfer with a Material Operating at the Water Uptake Reversibility Limit. ACS Cent. Sci. 2017, 3, 668-672.

(31) Lenzen, D.; Zhao, J.; Ernst, S.-J.; Wahiduzzaman, M.; Ken Inge, A.; Fröhlich, D.; Xu, H.; Bart, H.-J.; Janiak, C.; Henninger, S., et al. A Metal-Organic Framework for Efficient Water-Based Ultra-Low-Temperature-Driven Cooling. Nat. Commun 2019, 10, 3025.

(32) Wang, S.; Lee, J. S.; Wahiduzzaman, M.; Park, J.; Muschi, M.; Martineau-Corcos, C.; Tissot, A.; Cho, K. H.; Marrot, J.; Shepard, W., et al. A Robust Large-Pore Zirconium Carboxylate MetalOrganic Framework for Energy-Efficient Water-Sorption-Driven Refrigeration. Nat. Energy 2018, 3, 985-993.

(33) Hanikel, N.; Prévot, M. S.; Fathieh, F.; Kapustin, E. A.; Lyu, H.; Wang, H.; Diercks, N. J.; Glover, T. G.; Yaghi, O. M. Rapid Cycling and Exceptional Yield in a Metal-Organic Framework Water Harvester. ACS Cent. Sci. 2019, 5, 1699-1706.

(34) Kalmutzki, M. J.; Diercks, C. S.; Yaghi, O. M. Metal-Organic Frameworks for Water Harvesting from Air. Adv. Mater. 2018, 30, 1704304.

(35) Inokuma, Y.; Yoshioka, S.; Ariyoshi, J.; Arai, T.; Hitora, Y.; Takada, K.; Matsunaga, S.; Rissanen, K.; Fujita, M. X-Ray Analysis on the Nanogram to Microgram Scale Using Porous Complexes. Nature 2013, 495, 461-466.

(36) Lee, S.; Kapustin, E. A.; Yaghi, O. M. Coordinative Alignment of Molecules in Chiral Metal-Organic Frameworks. Science 2016, 353,808 .

(37) Mondloch, J. E.; Katz, M. J.; Isley Iii, W. C.; Ghosh, P.; Liao, P.; Bury, W.; Wagner, G. W.; Hall, M. G.; DeCoste, J. B.; Peterson, G. W., et al. Destruction of Chemical Warfare Agents Using MetalOrganic Frameworks. Nat. Mater. 2015, 14, 512-516.

(38) Liu, J.; Chen, L.; Cui, H.; Zhang, J.; Zhang, L.; Su, C.-Y. Applications of Metal-Organic Frameworks in Heterogeneous Supramolecular Catalysis. Chem. Soc. Rev. 2014, 43, 6011-6061.

(39) Seo, J. S.; Whang, D.; Lee, H.; Jun, S. I.; Oh, J.; Jeon, Y. J.; Kim, K. A Homochiral Metal-Organic Porous Material for Enantioselective Separation and Catalysis. Nature 2000, 404, 982986.

(40) Zhang, T.; Lin, W. Metal-Organic Frameworks for Artificial Photosynthesis and Photocatalysis. Chem. Soc. Rev. 2014, 43, 5982-5993.

(41) Liu, Y.; Xuan, W.; Cui, Y. Engineering Homochiral MetalOrganic Frameworks for Heterogeneous Asymmetric Catalysis and Enantioselective Separation. Adv. Mater. 2010, 22, 4112-4135.

(42) Wasson, M. C.; Buru, C. T.; Chen, Z.; Islamoglu, T.; Farha, O. K. Metal-Organic Frameworks: A Tunable Platform to Access Single-Site Heterogeneous Catalysts. Appl. Catal., A. 2019, 586, 117214.

(43) Chen, Z.; Ma, K.; Mahle, J. J.; Wang, H.; Syed, Z. H.; Atilgan, A.; Chen, Y.; Xin, J. H.; Islamoglu, T.; Peterson, G. W., et al. Integration of Metal-Organic Frameworks on Protective Layers for Destruction of Nerve Agents under Relevant Conditions. J. Am. Chem. Soc. 2019, 141, 20016-20021.

(44) Zeng, L.; Guo, X.; He, C.; Duan, C. Metal-Organic Frameworks: Versatile Materials for Heterogeneous Photocatalysis. ACS Catal. 2016, 6, 7935-7947.

(45) Yoon, M.; Srirambalaji, R.; Kim, K. Homochiral MetalOrganic Frameworks for Asymmetric Heterogeneous Catalysis. Chem. Rev. 2012, 112, 1196-1231.
(46) Yaghi, O. M.; O'Keeffe, M.; Ockwig, N. W.; Chae, H. K.; Eddaoudi, M.; Kim, J. Reticular Synthesis and the Design of New Materials. Nature 2003, 423, 705-714.

(47) Hunt, J. R.; Doonan, C. J.; LeVangie, J. D.; Côté, A. P.; Yaghi, O. M. Reticular Synthesis of Covalent Organic Borosilicate Frameworks. J. Am. Chem. Soc. 2008, 130, 11872-11873.

(48) Yaghi, O. M.; Kalmutzki, M. J.; Diercks, C. S., Introduction to Reticular Chemistry: Metal-Organic Frameworks and Covalent Organic Frameworks. John Wiley \& Sons: 2019.

(49) Diercks, C. S.; Yaghi, O. M. The Atom, the Molecule, and the Covalent Organic Framework. Science 2017, 355, 923- 930.

(50) Yaghi, O. M. Reticular Chemistry-Construction, Properties, and Precision Reactions of Frameworks. J. Am. Chem. Soc. 2016, 138, 15507-15509.

(51) Rungtaweevoranit, B.; Diercks, C. S.; Kalmutzki, M. J.; Yaghi, O. M. Spiers Memorial Lecture:. Progress and Prospects of Reticular Chemistry. Faraday Discuss. 2017, 201, 9-45.

(52) O'Keeffe, M. Design of MOFs and Intellectual Content in Reticular Chemistry: A Personal View. Chem. Soc. Rev. 2009, 38, 1215-1217.

(53) Li, P.; Vermeulen, N. A.; Malliakas, C. D.; Gómez-Gualdrón, D. A.; Howarth, A. J.; Mehdi, B. L.; Dohnalkova, A.; Browning, N. D.; O'Keeffe, M.; Farha, O. K. Bottom-up Construction of a Superstructure in a Porous Uranium-Organic Crystal. Science 2017, 356, 624-627.

(54) Alezi, D.; Spanopoulos, I.; Tsangarakis, C.; Shkurenko, A.; Adil, K.; Belmabkhout, Y.; O' Keeffe, M.; Eddaoudi, M.; Trikalitis, P. N. Reticular Chemistry at Its Best: Directed Assembly of Hexagonal Building Units into the Awaited Metal-Organic Framework with the Intricate Polybenzene Topology, pbz-MOF. $J$. Am. Chem. Soc. 2016, 138, 12767-12770.

(55) Chen, Z.; Hanna, S. L.; Redfern, L. R.; Alezi, D.; Islamoglu, T.; Farha, O. K. Reticular Chemistry in the Rational Synthesis of Functional Zirconium Cluster-Based MOFs. Coord. Chem. Rev. 2019, 386, 32-49.

(56) Guillerm, V.; Maspoch, D. Geometry Mismatch and Reticular Chemistry: Strategies to Assemble Metal-Organic Frameworks with Non-Default Topologies. J. Am. Chem. Soc. 2019, 141, 16517 16538.

(57) Delgado Friedrichs, O.; O'Keeffe, M.; Yaghi, O. M. ThreePeriodic Nets and Tilings: Regular and Quasiregular Nets. Acta Cryst. A 2003, 59, 22-27.

(58) Bonneau, C.; Delgado-Friedrichs, O.; O'Keeffe, M.; Yaghi, O. M. Three-Periodic Nets and Tilings: Minimal Nets. Acta Cryst. A 2004, 60, 517-520.

(59) Ockwig, N. W.; Delgado-Friedrichs, O.; O'Keeffe, M.; Yaghi, O. M. Reticular Chemistry: Occurrence and Taxonomy of Nets and Grammar for the Design of Frameworks. Acc. Chem. Res. 2005, 38, 176-182.

(60) Delgado-Friedrichs, O.; O'Keeffe, M.; Yaghi, O. M. ThreePeriodic Nets and Tilings: Edge-Transitive Binodal Structures. Acta Cryst. A 2006, 62, 350-355.

(61) Delgado-Friedrichs, O.; O'Keeffe, M. Three-Periodic Tilings and Nets: Face-Transitive Tilings and Edge-Transitive Nets Revisited. Acta Cryst. A 2007, 63, 344-347.

(62) Delgado-Friedrichs, O.; O'Keeffe, M.; Yaghi, O. M. Taxonomy of Periodic Nets and the Design of Materials. Phys. Chem. Chem. Phys. 2007, 9, 1035-1043.

(63) Liu, Q.; Song, Y.; Ma, Y.; Zhou, Y.; Cong, H.; Wang, C.; Wu, J.; Hu, G.; O'Keeffe, M.; Deng, H. Mesoporous Cages in Chemically Robust MOFs Created by a Large Number of Vertices with Reduced Connectivity. J. Am. Chem. Soc. 2019, 141, 488-496. 
(64) Friedrichs, O. D.; Dress, A. W. M.; Huson, D. H.; Klinowski, J.; Mackay, A. L. Systematic Enumeration of Crystalline Networks. Nature 1999, 400, 644-647.

(65) Delgado Friedrichs, O.; Huson, D. H. 4-Regular VertexTransitive Tilings of E3. Discrete Comput. Geom. 2000, 24, 279292.

(66) Delgado Friedrichs, O.; O'Keeffe, M.; Yaghi, O. M. ThreePeriodic Nets and Tilings: Semiregular Nets. Acta Crystallogr A 2003, 59, 515-25.

(67) Chen, B.; Eddaoudi, M.; Hyde, S. T.; Keeffe, M.; Yaghi, O. M. Interwoven Metal-Organic Framework on a Periodic Minimal Surface with Extra-Large Pores. Science 2001, 291, 1021.

(68) Eubank, J. F.; Mouttaki, H.; Cairns, A. J.; Belmabkhout, Y.; Wojtas, Ł.; Luebke, R.; Alkordi, M.; Eddaoudi, M. The Quest for Modular Nanocages: Tbo-MOF as an Archetype for Mutual Substitution, Functionalization, and Expansion of Quadrangular Pillar Building Blocks. J. Am. Chem. Soc. 2011, 133, 14204-14207. (69) Nouar, F.; Eubank, J. F.; Bousquet, T.; Wojtas, L.; Zaworotko, M. J.; Eddaoudi, M. Supermolecular Building Blocks (SBBs) for the Design and Synthesis of Highly Porous Metal-Organic Frameworks. J. Am. Chem. Soc. 2008, 130, 1833-1835.

(70) Bai, Y.; Dou, Y.; Xie, L.-H.; Rutledge, W.; Li, J.-R.; Zhou, H.C. Zr-Based Metal-Organic Frameworks: Design, Synthesis, Structure, and Applications. Chem. Soc. Rev. 2016, 45, 2327-2367. (71) Muldoon, P. F.; Liu, C.; Miller, C. C.; Koby, S. B.; Gamble Jarvi, A.; Luo, T.-Y.; Saxena, S.; O'Keeffe, M.; Rosi, N. L. Programmable Topology in New Families of Heterobimetallic Metal-Organic Frameworks. J. Am. Chem. Soc. 2018, 140, 61946198.

(72) Pauling, L. The Principles Determining the Structure of Complex Ionic Crystals. J. Am. Chem. Soc. 1929, 51, 1010-1026.

(73) Li, M.; Li, D.; O'Keeffe, M.; Yaghi, O. M. Topological Analysis of Metal-Organic Frameworks with Polytopic Linkers and/or Multiple Building Units and the Minimal Transitivity Principle. Chem. Rev. 2014, 114, 1343-1370.

(74) Delgado-Friedrichs, O.; O'Keeffe, M. Edge - 2 - Transitive Trinodal Polyhedra and 2 - Periodic Tilings. Acta Cryst. A 2017, 73, 227-230.

(75) Colón, Y. J.; Gómez-Gualdrón, D. A.; Snurr, R. Q. Topologically Guided, Automated Construction of Metal-Organic Frameworks and Their Evaluation for Energy-Related Applications. Cryst. Growth Des. 2017, 17, 5801-5810.

(76) Yuan, S.; Qin, J.-S.; Li, J.; Huang, L.; Feng, L.; Fang, Y.; Lollar, C.; Pang, J.; Zhang, L.; Sun, D., et al. Retrosynthesis of Multi-Component Metal-Organic Frameworks. Nat. Commun 2018, 9,808 .

(77) Zhang, L.; Yuan, S.; Feng, L.; Guo, B.; Qin, J.-S.; Xu, B.; Lollar, C.; Sun, D.; Zhou, H.-C. Pore-Environment Engineering with Multiple Metal Sites in Rare-Earth Porphyrinic MetalOrganic Frameworks. Angew. Chem. Int. Ed. 2018, 57, 5095-5099. (78) Wang, Y.; Feng, L.; Fan, W.; Wang, K.-Y.; Wang, X.; Wang, X.; Zhang, K.; Zhang, X.; Dai, F.; Sun, D., et al. Topology Exploration in Highly Connected Rare-Earth Metal-Organic Frameworks Via Continuous Hindrance Control. J. Am. Chem. Soc. 2019, 141, 6967-6975.

(79) Wang, H.; Dong, X.; Lin, J.; Teat, S. J.; Jensen, S.; Cure, J.; Alexandrov, E. V.; Xia, Q.; Tan, K.; Wang, Q., et al. Topologically Guided Tuning of Zr-MOF Pore Structures for Highly Selective Separation of C6 Alkane Isomers. Nat. Commun 2018, 9, 1745. (80) He, Y.; Li, B.; O'Keeffe, M.; Chen, B. Multifunctional MetalOrganic Frameworks Constructed from Meta-
Benzenedicarboxylate Units. Chem. Soc. Rev. 2014, 43, 56185656 .

(81) El-Kaderi, H. M.; Hunt, J. R.; Mendoza-Cortés, J. L.; Côté, A. P.; Taylor, R. E.; Keeffe, M.; Yaghi, O. M. Designed Synthesis of 3D Covalent Organic Frameworks. Science 2007, 316, 268.

(82) Bureekaew, S.; Schmid, R. Hypothetical 3D-Periodic Covalent Organic Frameworks: Exploring the Possibilities by a First Principles Derived Force Field. CrystEngComm 2013, 15, 1551-1562.

(83) Chen, Z.; Jiang, H.; O'Keeffe, M.; Eddaoudi, M. Minimal Edge-Transitive Nets for the Design and Construction of MetalOrganic Frameworks. Faraday Discuss. 2017, 201, 127-143.

(84) O'Keeffe, M.; Yaghi, O. M. Deconstructing the Crystal Structures of Metal-Organic Frameworks and Related Materials into Their Underlying Nets. Chem. Rev. 2012, 112, 675-702.

(85) Alexandrov, E. V.; Blatov, V. A.; Kochetkov, A. V.; Proserpio, D. M. Underlying Nets in Three-Periodic Coordination Polymers: Topology, Taxonomy and Prediction from a ComputerAided Analysis of the Cambridge Structural Database. CrystEngComm 2011, 13, 3947-3958.

(86) Not all possible derived/related nets are listed in Table 2-3. Specifically nets in which unbonded vertices come in very close proximity or nets with unfavorable coordination geometry. The latter include cases where all or most of the coordinating vertices are in one hemisphere - for example a coordination figure of the 7c hexagonal pyramid which is a very unfavorable target for chemical synthesis.

(87) O'Keeffe, M.; Peskov, M. A.; Ramsden, S. J.; Yaghi, O. M. The Reticular Chemistry Structure Resource (RCSR) Database of, and Symbols for, Crystal Nets. Acc. Chem. Res. 2008, 41, 17821789.

(88) Blatov, V. A.; O'Keeffe, M.; Proserpio, D. M. Vertex-, Face-, Point-, Schlafli-, and Delaney-Symbols in Nets, Polyhedra and Tilings: Recommended Terminology. CrystEngComm 2010, 12, 44-48.

(89) O'Keeffe, M.; Eddaoudi, M.; Li, H.; Reineke, T.; Yaghi, O. M. Frameworks for Extended Solids: Geometrical Design Principles. J. Solid State Chem. 2000, 152, 3-20.

(90) Xue, D.-X.; Cairns, A. J.; Belmabkhout, Y.; Wojtas, L.; Liu, Y.; Alkordi, M. H.; Eddaoudi, M. Tunable Rare-Earth fcu-MOFs: A Platform for Systematic Enhancement of CO2 Adsorption Energetics and Uptake. J. Am. Chem. Soc. 2013, 135, 7660-7667.

(91) Luebke, R.; Belmabkhout, Y.; Weseliński, Ł. J.; Cairns, A. J.; Alkordi, M.; Norton, G.; Wojtas, L.; Adil, K.; Eddaoudi, M. Versatile Rare Earth Hexanuclear Clusters for the Design and Synthesis of Highly-Connected ftw-MOFs. Chem. Sci. 2015, 6, 4095-4102.

(92) Chen, Z.; Thiam, Z.; Shkurenko, A.; Weselinski, L. J.; Adil, K.; Jiang, H.; Alezi, D.; Assen, A. H.; O'Keeffe, M.; Eddaoudi, M. Enriching the Reticular Chemistry Repertoire with Minimal EdgeTransitive Related Nets: Access to Highly-Coordinated MOFs Based on Double Six-Membered Rings as Net-Coded Building Units. J. Am. Chem. Soc. 2019, 141, 20480-20489.

(93) Alezi, D.; Belmabkhout, Y.; Suyetin, M.; Bhatt, P. M.; Weseliński, Ł. J.; Solovyeva, V.; Adil, K.; Spanopoulos, I.; Trikalitis, P. N.; Emwas, A.-H., et al. MOF Crystal Chemistry Paving the Way to Gas Storage Needs: Aluminum-Based soc-MOF for $\mathrm{CH}_{4}, \mathrm{O}_{2}$, and $\mathrm{CO}_{2}$ Storage. J. Am. Chem. Soc. 2015, 137, 1330813318.

(94) Raghuvanshi, A.; Strohmann, C.; Tissot, J.-B.; Clément, S.; Mehdi, A.; Richeter, S.; Viau, L.; Knorr, M. Assembly of Coordination Polymers Using Thioether-Functionalized 
Octasilsesquioxanes: Occurrence of $(\mathrm{CuX}) \mathrm{n}$ Clusters $(\mathrm{X}=\mathrm{Br}$ and $\mathrm{I})$ within 3D-POSS Networks. Chem. Eur. J. 2017, 23, 16479-16483. (95) Chen, Z.; Xiang, S.; Liao, T.; Yang, Y.; Chen, Y.-S.; Zhou, Y.; Zhao, D.; Chen, B. A New Multidentate Hexacarboxylic Acid for the Construction of Porous Metal-Organic Frameworks of Diverse Structures and Porosities. Cryst. Growth Des. 2010, 10, 2775-2779. (96) Jia, J.; Sun, F.; Fang, Q.; Liang, X.; Cai, K.; Bian, Z.; Zhao, H.; Gao, L.; Zhu, G. A Novel Low Density Metal-Organic Framework with pcu Topology by Dendritic Ligand. Chem. Commun. 2011, 47, 9167-9169.

(97) Eryazici, I.; Farha, O. K.; Hauser, B. G.; Yazaydın, A. Ö.; Sarjeant, A. A.; Nguyen, S. T.; Hupp, J. T. Two Large-Pore MetalOrganic Frameworks Derived from a Single Polytopic Strut. Cryst. Growth Des. 2012, 12, 1075-1080.

(98) Davies, R. P.; Lickiss, P. D.; Robertson, K.; White, A. J. P. An Organosilicon Hexacarboxylic Acid and Its Use in the Construction of a Novel Metal Organic Framework Isoreticular to MOF-5. CrystEngComm 2012, 14, 758-760.

(99) Jia, J.; Sun, F.; Borjigin, T.; Ren, H.; Zhang, T.; Bian, Z.; Gao, L.; Zhu, G. Highly Porous and Robust Ionic MOFs with Nia Topology Constructed by Connecting an Octahedral Ligand and a Trigonal Prismatic Metal Cluster. Chem. Commun. 2012, 48, 60106012.

(100) He, Y.; Furukawa, H.; Wu, C.; O'Keeffe, M.; Krishna, R.; Chen, B. Low-Energy Regeneration and High Productivity in a Lanthanide-Hexacarboxylate Framework for High-Pressure CO2CH4-H2 Separation. Chem. Commun. 2013, 49, 6773-6775.

(101) Liu, Y.; Eubank, J. F.; Cairns, A. J.; Eckert, J.; Kravtsov, V. C.; Luebke, R.; Eddaoudi, M. Assembly of Metal-Organic Frameworks (MOFs) Based on Indium-Trimer Building Blocks: A Porous MOF with soc Topology and High Hydrogen Storage. Angew. Chem. Int. Ed. 2007, 46, 3278-3283.

(102) He, Y.; Furukawa, H.; Wu, C.; O'Keeffe, M.; Chen, B. A Mesoporous Lanthanide-Organic Framework Constructed from a Dendritic Hexacarboxylate with Cages of $2.4 \mathrm{~nm}$. CrystEngComm 2013, 15, 9328-9331.

(103) Qin, J.-S.; Du, D.-Y.; Li, M.; Lian, X.-Z.; Dong, L.-Z.; Bosch, M.; Su, Z.-M.; Zhang, Q.; Li, S.-L.; Lan, Y.-Q., et al. Derivation and Decoration of Nets with Trigonal-Prismatic Nodes: A Unique Route to Reticular Synthesis of Metal-Organic Frameworks. J. Am. Chem. Soc. 2016, 138, 5299-5307.

(104) Wang, K.; Feng, D.; Liu, T.-F.; Su, J.; Yuan, S.; Chen, Y.-P.; Bosch, M.; Zou, X.; Zhou, H.-C. A Series of Highly Stable Mesoporous Metalloporphyrin Fe-MOFs. J. Am. Chem. Soc. 2014, 136, 13983-13986.

(105) Souto, M.; Santiago-Portillo, A.; Palomino, M.; VitóricaYrezábal, I. J.; Vieira, B. J. C.; Waerenborgh, J. C.; Valencia, S.; Navalón, S.; Rey, F.; García, H., et al. A Highly Stable and Hierarchical Tetrathiafulvalene-Based Metal-Organic Framework with Improved Performance as a Solid Catalyst. Chem. Sci. 2018, 9, 2413-2418.

(106) Sudik, A. C.; Côté, A. P.; Yaghi, O. M. Metal-Organic Frameworks Based on Trigonal Prismatic Building Blocks and the New “acs" Topology. Inorg. Chem. 2005, 44, 2998-3000.

(107) Serre, C.; Mellot-Draznieks, C.; Surblé, S.; Audebrand, N.; Filinchuk, Y.; Férey, G. Role of Solvent-Host Interactions That Lead to Very Large Swelling of Hybrid Frameworks. Science 2007, $315,1828$.

(108) Elsaidi, S. K.; Mohamed, M. H.; Wojtas, L.; Cairns, A. J.; Eddaoudi, M.; Zaworotko, M. J. Two-Step Crystal Engineering of Porous Nets from $[\mathrm{Cr} 3(\mu 3-\mathrm{O})(\mathrm{RCO} 2) 6]$ and $[\mathrm{Cu} 3(\mu 3-$
Cl)(RNH2)6Cl6] Molecular Building Blocks. Chem. Commun. 2013, 49, 8154-8156.

(109) Chae, H. K.; Eddaoudi, M.; Kim, J.; Hauck, S. I.; Hartwig, J. F.; O'Keeffe, M.; Yaghi, O. M. Tertiary Building Units: Synthesis, Structure, and Porosity of a Metal-Organic Dendrimer Framework (MODF-1). J. Am. Chem. Soc. 2001, 123, 11482-11483.

(110) Guo, Z.; Wu, H.; Srinivas, G.; Zhou, Y.; Xiang, S.; Chen, Z.; Yang, Y.; Zhou, W.; O'Keeffe, M.; Chen, B. A Metal-Organic Framework with Optimized Open Metal Sites and Pore Spaces for High Methane Storage at Room Temperature. Angew. Chem. Int. Ed. 2011, 50, 3178-3181.

(111) Yuan, S.; Lu, W.; Chen, Y.-P.; Zhang, Q.; Liu, T.-F.; Feng, D.; Wang, X.; Qin, J.; Zhou, H.-C. Sequential Linker Installation: Precise Placement of Functional Groups in Multivariate MetalOrganic Frameworks. J. Am. Chem. Soc. 2015, 137, 3177-3180.

(112) Guillerm, V.; Grancha, T.; Imaz, I.; Juanhuix, J.; Maspoch, D. Zigzag Ligands for Transversal Design in Reticular Chemistry: Unveiling New Structural Opportunities for Metal-Organic Frameworks. J. Am. Chem. Soc. 2018, 140, 10153-10157.

(113) McManus, G. J.; Wang, Z.; Zaworotko, M. J. Suprasupermolecular Chemistry: Infinite Networks from Nanoscale Metal-Organic Building Blocks. Cryst. Growth Des. 2004, 4, 11-13.

(114) Liu, L.; Chen, Z.; Wang, J.; Zhang, D.; Zhu, Y.; Ling, S.; Huang, K.-W.; Belmabkhout, Y.; Adil, K.; Zhang, Y., et al. Imaging Defects and Their Evolution in a Metal-Organic Framework at Sub-Unit-Cell Resolution. Nat. Chem. 2019, 11, $622-628$.

(115) Nohra, B.; El Moll, H.; Rodriguez Albelo, L. M.; Mialane, P.; Marrot, J.; Mellot-Draznieks, C.; O'Keeffe, M.; Ngo Biboum, R.; Lemaire, J.; Keita, B., et al. Polyoxometalate-Based Metal Organic Frameworks (POMOFs): Structural Trends, Energetics, and High Electrocatalytic Efficiency for Hydrogen Evolution Reaction. J. Am. Chem. Soc. 2011, 133, 13363-13374.

(116) Hao, X.-R.; Wang, X.-L.; Shao, K.-Z.; Yang, G.-S.; Su, Z.M.; Yuan, G. Remarkable Solvent-Size Effects in Constructing Novel Porous 1,3,5-Benzenetricarboxylate Metal-Organic Frameworks. CrystEngComm 2012, 14, 5596-5603.

(117) Ma, L.; Mihalcik, D. J.; Lin, W. Highly Porous and Robust 4,8-Connected Metal-Organic Frameworks for Hydrogen Storage. J. Am. Chem. Soc. 2009, 131, 4610-4612.

(118) Tan, C.; Yang, S.; Champness, N. R.; Lin, X.; Blake, A. J.; Lewis, W.; Schröder, M. High Capacity Gas Storage by a 4,8Connected Metal-Organic Polyhedral Framework. Chem. Commun. 2011, 47, 4487-4489.

(119) Lin, Z.-J.; Liu, T.-F.; Zhao, X.-L.; Lü, J.; Cao, R. Designed 4,8-Connected Metal-Organic Frameworks Based on Tetrapodal Octacarboxylate Ligands. Cryst. Growth Des. 2011, 11, 42844287.

(120) Lu, W.; Yuan, D.; Makal, T. A.; Li, J.-R.; Zhou, H.-C. A Highly Porous and Robust $(3,3,4)$-Connected Metal-Organic Framework Assembled with a $90^{\circ}$ Bridging-Angle Embedded Octacarboxylate Ligand. Angew. Chem. Int. Ed. 2012, 51, 15801584.

(121) Feng, D.; Gu, Z.-Y.; Li, J.-R.; Jiang, H.-L.; Wei, Z.; Zhou, H.-C. Zirconium-Metalloporphyrin PCN-222: Mesoporous MetalOrganic Frameworks with Ultrahigh Stability as Biomimetic Catalysts. Angew. Chem. Int. Ed. 2012, 51, 10307-10310. (122) Morris, W.; Volosskiy, B.; Demir, S.; Gándara, F.; McGrier, P. L.; Furukawa, H.; Cascio, D.; Stoddart, J. F.; Yaghi, O. M. Synthesis, Structure, and Metalation of Two New Highly Porous 
Zirconium Metal-Organic Frameworks. Inorg. Chem. 2012, 51, 6443-6445.

(123) Chen, Y.; Hoang, T.; Ma, S. Biomimetic Catalysis of a Porous Iron-Based Metal-Metalloporphyrin Framework. Inorg. Chem. 2012, 51, 12600-12602.

(124) Mondloch, J. E.; Bury, W.; Fairen-Jimenez, D.; Kwon, S.; DeMarco, E. J.; Weston, M. H.; Sarjeant, A. A.; Nguyen, S. T.; Stair, P. C.; Snurr, R. Q., et al. Vapor-Phase Metalation by Atomic Layer Deposition in a Metal-Organic Framework. J. Am. Chem. Soc. 2013, 135, 10294-10297.

(125) Lincke, J.; Lässig, D.; Kobalz, M.; Bergmann, J.; Handke, M.; Möllmer, J.; Lange, M.; Roth, C.; Möller, A.; Staudt, R., et al. An Isomorphous Series of Cubic, Copper-Based Triazolyl Isophthalate MOFs: Linker Substitution and Adsorption Properties. Inorg. Chem. 2012, 51, 7579-7586.

(126) Kitazawa, T.; Kikuyama, T.; Takahashi, M.; Takeda, M. Cadmium Cyanide-Ether Clathrates: Crystal Structures of $\mathrm{Cd} 8(\mathrm{CN}) 16(\mathrm{H} 2 \mathrm{O}) 6 \cdot 6 \mathrm{G} \quad(\mathrm{G}=\mathrm{Et} 2 \mathrm{O}$ or Pri2O $)$ and Cd3(CN)6(H2O)2.2Prn2O. J. Chem. Soc., Dalton Trans. 1994, 2933-2937.

(127) Yuan, S.; Deng, Y.-K.; Xuan, W.-M.; Wang, X.-P.; Wang, S.-N.; Dou, J.-M.; Sun, D. Spontaneous Chiral Resolution of a 3D (3,12)-Connected MOF with an Unprecedented ttt Topology Consisting of Cubic [Cd4 $(\mu 3-\mathrm{OH}) 4]$ Clusters and Propeller-Like Ligands. CrystEngComm 2014, 16, 3829-3833.

(128) Wong-Foy, A. G.; Lebel, O.; Matzger, A. J. Porous Crystal Derived from a Tricarboxylate Linker with Two Distinct Binding Motifs. J. Am. Chem. Soc. 2007, 129, 15740-15741.

(129) Duan, J.; Yang, Z.; Bai, J.; Zheng, B.; Li, Y.; Li, S. Highly Selective CO2 Capture of an agw-Type Metal-Organic Framework with Inserted Amides: Experimental and Theoretical Studies. Chem. Commun. 2012, 48, 3058-3060.

(130) Alezi, D.; Peedikakkal, A. M. P.; Weseliński, Ł. J.; Guillerm, V.; Belmabkhout, Y.; Cairns, A. J.; Chen, Z.; Wojtas, Ł.; Eddaoudi, M. Quest for Highly Connected Metal-Organic Framework Platforms: Rare-Earth Polynuclear Clusters Versatility Meets Net Topology Needs. J. Am. Chem. Soc. 2015, 137, 5421-5430.

(131) Li, S.; Chen, Y.-S.; Mulfort, K. L. Structural Modification in Bimetallic $\mathrm{Ru}(\mathrm{III})-\mathrm{Co}(\mathrm{II}) \quad$ Metal-Organic Frameworks. CrystEngComm 2015, 17, 1005-1009.

(132) Zheng, S.-T.; Bu, J. T.; Li, Y.; Wu, T.; Zuo, F.; Feng, P.; Bu, $X$. Pore Space Partition and Charge Separation in Cage-withinCage Indium-Organic Frameworks with High CO2 Uptake. J. Am. Chem. Soc. 2010, 132, 17062-17064.

(133) Sun, D.; Li, Y.-H.; Wu, S.-T.; Hao, H.-J.; Liu, F.-J.; Huang, R.-B.; Zheng, L.-S. An Unprecedented $(4,24)$-Connected MetalOrganic Framework Sustained by Nanosized Ag12 Cuboctahedral Node. CrystEngComm 2011, 13, 7311-7315.

(134) Yuan, S.; Qin, J. S.; Li, J.; Huang, L.; Feng, L.; Fang, Y.; Lollar, C.; Pang, J.; Zhang, L.; Sun, D., et al. Retrosynthesis of Multi-Component Metal-Organic Frameworks. Nat. Commun 2018, 9, 808.

(135) Eubank, J. F.; Nouar, F.; Luebke, R.; Cairns, A. J.; Wojtas, Ł.; Alkordi, M.; Bousquet, T.; Hight, M. R.; Eckert, J.; Embs, J. P., et al. On Demand: The Singular rht Net, an Ideal Blueprint for the Construction of a Metal-Organic Framework (MOF) Platform. Angew. Chem. Int. Ed. 2012, 51, 10099-10103.

(136) Yuan, D.; Zhao, D.; Sun, D.; Zhou, H.-C. An Isoreticular Series of Metal-Organic Frameworks with Dendritic Hexacarboxylate Ligands and Exceptionally High Gas-Uptake Capacity. Angew. Chem. Int. Ed. 2010, 49, 5357-5361.
(137) Farha, O. K.; Yazaydın, A. O.; Eryazici, I.; Malliakas, C. D.; Hauser, B. G.; Kanatzidis, M. G.; Nguyen, S. T.; Snurr, R. Q.; Hupp, J. T. De Novo Synthesis of a Metal-Organic Framework Material Featuring Ultrahigh Surface Area and Gas Storage Capacities. Nat. Chem. 2010, 2, 944-948.

(138) Luebke, R.; Weseliński, Ł. J.; Belmabkhout, Y.; Chen, Z.; Wojtas, Ł.; Eddaoudi, M. Microporous Heptazine Functionalized (3,24)-Connected rht-Metal-Organic Framework: Synthesis, Structure, and Gas Sorption Analysis. Cryst. Growth Des. 2014, 14, 414-418.

(139) Yuan, D.; Zhao, D.; Zhou, H.-C. Pressure-Responsive Curvature Change of a "Rigid" Geodesic Ligand in a $(3,24)$ Connected Mesoporous Metal-Organic Framework. Inorg. Chem. 2011, 50, 10528-10530.

(140) Farha, O. K.; Eryazici, I.; Jeong, N. C.; Hauser, B. G.; Wilmer, C. E.; Sarjeant, A. A.; Snurr, R. Q.; Nguyen, S. T.; Yazaydın, A. Ö.; Hupp, J. T. Metal-Organic Framework Materials with Ultrahigh Surface Areas: Is the Sky the Limit? J. Am. Chem. Soc. 2012, 134, 15016-15021.

(141) Zheng, B.; Bai, J.; Duan, J.; Wojtas, L.; Zaworotko, M. J. Enhanced CO2 Binding Affinity of a High-Uptake rht-Type Metal-Organic Framework Decorated with Acylamide Groups. $J$. Am. Chem. Soc. 2010, 133, 748-751.

(142) Yan, Y.; Suyetin, M.; Bichoutskaia, E.; Blake, A. J.; Allan, D. R.; Barnett, S. A.; Schröder, M. Modulating the Packing of [Cu24(Isophthalate)24] Cuboctahedra in a Triazole-Containing Metal-Organic Polyhedral Framework. Chem. Sci. 2013, 4, 17311736.

(143) Wang, X.-J.; Li, P.-Z.; Chen, Y.; Zhang, Q.; Zhang, H.; Chan, X. X.; Ganguly, R.; Li, Y.; Jiang, J.; Zhao, Y. A Rationally Designed Nitrogen-Rich Metal-Organic Framework and Its Exceptionally High CO2 and H2 Uptake Capability. Sci. Rep. 2013, 3, 1149-1149.

(144) Zou, Y.; Park, M.; Hong, S.; Lah, M. S. A Designed MetalOrganic Framework Based on a Metal-Organic Polyhedron. Chem. Commun. 2008, 2340-2342.

(145) Wu, M.; Jiang, F.; Wei, W.; Gao, Q.; Huang, Y.; Chen, L.; Hong, M. A Porous Polyhedral Metal-Organic Framework Based on $\mathrm{Zn} 2(\mathrm{COO}) 3$ and Zn2(COO)4 SBUs. Cryst. Growth Des. 2009, 9, 2559-2561.

(146) Liu, Y.; O'Keeffe, M. Regular Figures, Minimal Transitivity, and Reticular Chemistry. Isr. J. Chem. 2018, 58, 962-970.

(147) Delgado-Friedrichs, O.; O'Keeffe, M. Identification of and Symmetry Computation for Crystal Nets. Acta Cryst. A 2003, 59, 351-360.

(148) Delgado-Friedrichs, O.; Hyde, S. T.; Mun, S.-W.; O'Keeffe, M.; Proserpio, D. M. Nets with Collisions (Unstable Nets) and Crystal Chemistry. Acta Cryst. A 2013, 69, 535-542.

(149) Feng, L.; Wang, Y.; Zhang, K.; Wang, K.-Y.; Fan, W.; Wang, X.; Powell, J. A.; Guo, B.; Dai, F.; Zhang, L., et al. Molecular Pivot-Hinge Installation to Evolve Topology in Rare-Earth MetalOrganic Frameworks. Angew. Chem. Int. Ed. 2019, 58, 1668216690.

(150) Chandrasekhar, P.; Savitha, G.; Moorthy, J. N. Robust MOFs of "tsg" Topology Based on Trigonal Prismatic Organic and Metal Cluster SBUs: Single Crystal to Single Crystal Postsynthetic Metal Exchange and Selective CO2 Capture. Chem. Eur. J. 2017, 23, 7297-7305.

(151) Serre, C.; Millange, F.; Surblé, S.; Férey, G. A Route to the Synthesis of Trivalent Transition-Metal Porous Carboxylates with Trimeric Secondary Building Units. Angew. Chem. Int. Ed. 2004, $43,6285-6289$. 
(152) Jia, J.; Sun, F.; Ma, H.; Wang, L.; Cai, K.; Bian, Z.; Gao, L.; Zhu, G. Trigonal Prism or Octahedron: The Conformational Change of a Dendritic Six-Node Ligand in MOFs. J. Mater. Chem. A 2013, 1, 10112-10115.

(153) Chen, Z.; Li, P.; Zhang, X.; Li, P.; Wasson, M. C.; Islamoglu, T.; Stoddart, J. F.; Farha, O. K. Reticular Access to Highly Porous acs-MOFs with Rigid Trigonal Prismatic Linkers for Water Sorption. J. Am. Chem. Soc. 2019, 141, 2900-2905.

(154) Stoeck, U.; Krause, S.; Bon, V.; Senkovska, I.; Kaskel, S. A Highly Porous Metal-Organic Framework, Constructed from a Cuboctahedral Super-Molecular Building Block, with Exceptionally High Methane Uptake. Chem. Commun. 2012, 48, 10841-10843.

(155) Lu, W.; Yuan, D.; Makal, T. A.; Wei, Z.; Li, J.-R.; Zhou, H.C. Highly Porous Metal-Organic Framework Sustained with 12Connected Nanoscopic Octahedra. Dalton Trans. 2013, 42, 17081714.

(156) Stoeck, U.; Senkovska, I.; Bon, V.; Krause, S.; Kaskel, S. Assembly of Metal-Organic Polyhedra into Highly Porous Frameworks for Ethene Delivery. Chem. Commun. 2015, 51, 10461049.

(157) Feng, D.; Jiang, H.-L.; Chen, Y.-P.; Gu, Z.-Y.; Wei, Z.; Zhou, H.-C. Metal-Organic Frameworks Based on Previously Unknown Zr8/Hf8 Cubic Clusters. Inorg. Chem. 2013, 52, 12661-12667.

(158) Lin, Q.; Bu, X.; Kong, A.; Mao, C.; Zhao, X.; Bu, F.; Feng, P. New Heterometallic Zirconium Metalloporphyrin Frameworks and Their Heteroatom-Activated High-Surface-Area Carbon Derivatives. J. Am. Chem. Soc. 2015, 137, 2235-2238.

(159) Liu, T.-F.; Feng, D.; Chen, Y.-P.; Zou, L.; Bosch, M.; Yuan, S.; Wei, Z.; Fordham, S.; Wang, K.; Zhou, H.-C. Topology-Guided Design and Syntheses of Highly Stable Mesoporous Porphyrinic Zirconium Metal-Organic Frameworks with High Surface Area. $J$. Am. Chem. Soc. 2015, 137, 413-419.

(160) Wang, T. C.; Bury, W.; Gómez-Gualdrón, D. A.; Vermeulen, N. A.; Mondloch, J. E.; Deria, P.; Zhang, K.; Moghadam, P. Z.; Sarjeant, A. A.; Snurr, R. Q., et al. Ultrahigh Surface Area Zirconium MOFs and Insights into the Applicability of the Bet Theory. J. Am. Chem. Soc. 2015, 137, 3585-3591.

(161) Zheng, J.; Wu, M.; Jiang, F.; Su, W.; Hong, M. Stable Porphyrin Zr and Hf Metal-Organic Frameworks Featuring $2.5 \mathrm{~nm}$ Cages: High Surface Areas, Scsc Transformations and Catalyses. Chem. Sci. 2015, 6, 3466-3470.

(162) Xue, D.-X.; Cadiau, A.; Weseliński, Ł. J.; Jiang, H.; Bhatt, P. M.; Shkurenko, A.; Wojtas, L.; Chen, Z.; Belmabkhout, Y.; Adil, K., et al. Topology Meets MOF Chemistry for Pore-Aperture Fine Tuning: ftw-MOF Platform for Energy-Efficient Separations Via Adsorption Kinetics or Molecular Sieving. Chem. Commun. 2018, 54, 6404-6407.

(163) Chen, Z.; Li, P.; Wang, X.; Otake, K.-i.; Zhang, X.; Robison, L.; Atilgan, A.; Islamoglu, T.; Hall, M. G.; Peterson, G. W., et al. Ligand-Directed Reticular Synthesis of Catalytically Active Missing Zirconium-Based Metal-Organic Frameworks. J. Am. Chem. Soc. 2019, 141, 12229-12235.

(164) Guillerm, V.; Weseliński, Ł., J.; Belmabkhout, Y.; Cairns, A. J.; D'Elia, V.; Wojtas, Ł.; Adil, K.; Eddaoudi, M. Discovery and Introduction of a $(3,18)$-Connected Net as an Ideal Blueprint for the Design of Metal-Organic Frameworks. Nat. Chem. 2014, 6, 673680.

(165) Feng, D.; Wang, K.; Wei, Z.; Chen, Y.-P.; Simon, C. M.; Arvapally, R. K.; Martin, R. L.; Bosch, M.; Liu, T.-F.; Fordham, S., et al. Kinetically Tuned Dimensional Augmentation as a
Versatile Synthetic Route Towards Robust Metal-Organic Frameworks. Nat. Commun 2014, 5, 5723.

(166) Eddaoudi, M.; Moler, D. B.; Li, H.; Chen, B.; Reineke, T. M.; O'Keeffe, M.; Yaghi, O. M. Modular Chemistry: Secondary Building Units as a Basis for the Design of Highly Porous and Robust Metal-Organic Carboxylate Frameworks. Acc. Chem. Res. 2001, 34, 319-330.

(167) Chen, Z.; Adil, K.; Weselinski, L. J.; Belmabkhout, Y.; Eddaoudi, M. A Supermolecular Building Layer Approach for Gas Separation and Storage Applications: The eea and rtl MOF Platforms for CO2 Capture and Hydrocarbon Separation. J. Mater. Chem. A 2015, 3, 6276-6281.

(168) Du, L.; Lu, Z.; Zheng, K.; Wang, J.; Zheng, X.; Pan, Y.; You, X.; Bai, J. Fine-Tuning Pore Size by Shifting Coordination Sites of Ligands and Surface Polarization of Metal-Organic Frameworks to Sharply Enhance the Selectivity for CO2. J. Am. Chem. Soc. 2012, 135, 562-565.

(169) Moreau, F.; Kolokolov, D. I.; Stepanov, A. G.; Easun, T. L.; Dailly, A.; Lewis, W.; Blake, A. J.; Nowell, H.; Lennox, M. J.; Besley, E., et al. Tailoring Porosity and Rotational Dynamics in a Series of Octacarboxylate Metal-Organic Frameworks. Proc. Natl. Acad. Sci. U.S.A. 2017, 114, 3056.

(170) Li, P.; Chen, Q.; Wang, T. C.; Vermeulen, N. A.; Mehdi, B. L.; Dohnalkova, A.; Browning, N. D.; Shen, D.; Anderson, R.; Gómez-Gualdrón, D. A., et al. Hierarchically Engineered Mesoporous Metal-Organic Frameworks toward Cell-Free Immobilized Enzyme Systems. Chem 2018, 4, 1022-1034.

(171) Furukawa, H.; Go, Y. B.; Ko, N.; Park, Y. K.; Uribe-Romo, F. J.; Kim, J.; O'Keeffe, M.; Yaghi, O. M. Isoreticular Expansion of Metal-Organic Frameworks with Triangular and Square Building Units and the Lowest Calculated Density for Porous Crystals. Inorg. Chem. 2011, 50, 9147-9152.

(172) Xue, D. X.; Belmabkhout, Y.; Shekhah, O.; Jiang, H.; Adil, K.; Cairns, A. J.; Eddaoudi, M. Tunable Rare Earth fcu-MOF Platform: Access to Adsorption Kinetics Driven Gas/Vapor Separations Via Pore Size Contraction. J Am Chem Soc 2015, 137, 5034-40.

(173) Assen, A. H.; Belmabkhout, Y.; Adil, K.; Bhatt, P. M.; Xue, D.-X.; Jiang, H.; Eddaoudi, M. Ultra-Tuning of the Rare-Earth fcuMOF Aperture Size for Selective Molecular Exclusion of Branched Paraffins. Angew. Chem. Int. Ed. 2015, 54, 14353-14358.

(174) Cavka, J. H.; Jakobsen, S.; Olsbye, U.; Guillou, N.; Lamberti, C.; Bordiga, S.; Lillerud, K. P. A New Zirconium Inorganic Building Brick Forming Metal Organic Frameworks with Exceptional Stability. J. Am. Chem. Soc. 2008, 130, 13850-13851. (175) Lippke, J.; Brosent, B.; von Zons, T.; Virmani, E.; Lilienthal, S.; Preuße, T.; Hülsmann, M.; Schneider, A. M.; Wuttke, S.; Behrens, P., et al. Expanding the Group of Porous Interpenetrated Zr-Organic Frameworks (PIZOFs) with Linkers of Different Lengths. Inorg. Chem. 2017, 56, 748-761.

(176) Schaate, A.; Roy, P.; Preuße, T.; Lohmeier, S. J.; Godt, A.; Behrens, P. Porous Interpenetrated Zirconium-Organic Frameworks (PIZOFs): A Chemically Versatile Family of MetalOrganic Frameworks. Chem. Eur. J. 2011, 17, 9320-9325.

(177) Feng, L.; Yuan, S.; Qin, J.-S.; Wang, Y.; Kirchon, A.; Qiu, D.; Cheng, L.; Madrahimov, S. T.; Zhou, H.-C. Lattice Expansion and Contraction in Metal-Organic Frameworks by Sequential Linker Reinstallation. Matter 2019, 1, 156-167.

(178) Deng, H.; Doonan, C. J.; Furukawa, H.; Ferreira, R. B.; Towne, J.; Knobler, C. B.; Wang, B.; Yaghi, O. M. Multiple Functional Groups of Varying Ratios in Metal-Organic Frameworks. Science 2010, 327, 846. 
(179) Feng, L.; Yuan, S.; Li, J.-L.; Wang, K.-Y.; Day, G. S.; Zhang, P.; Wang, Y.; Zhou, H.-C. Uncovering Two Principles of Multivariate Hierarchical Metal-Organic Framework Synthesis Via Retrosynthetic Design. ACS Cent. Sci. 2018, 4, 1719-1726.

(180) Luo, T.-Y.; Liu, C.; Gan, X. Y.; Muldoon, P. F.; Diemler, N. A.; Millstone, J. E.; Rosi, N. L. Multivariate Stratified MetalOrganic Frameworks: Diversification Using Domain Building Blocks. J. Am. Chem. Soc. 2019, 141, 2161-2168.

(181) Kwon, O.; Kim, J. Y.; Park, S.; Lee, J. H.; Ha, J.; Park, H.; Moon, H. R.; Kim, J. Computer-Aided Discovery of Connected Metal-Organic Frameworks. Nat. Commun 2019, 10, 3620.

(182) Tu, B.; Diestel, L.; Shi, Z.-L.; Bandara, W. R. L. N.; Chen, Y.; Lin, W.; Zhang, Y.-B.; Telfer, S. G.; Li, Q. Harnessing Bottomup Self-Assembly to Position Five Distinct Components in an
Ordered Porous Framework. Angew. Chem. Int. Ed. 2019, 58, 5348-5353.

(183) Bonneau, C.; O’Keeffe, M.; Proserpio, D. M.; Blatov, V. A.; Batten, S. R.; Bourne, S. A.; Lah, M. S.; Eon, J.-G.; Hyde, S. T.; Wiggin, S. B., et al. Deconstruction of Crystalline Networks into Underlying Nets: Relevance for Terminology Guidelines and Crystallographic Databases. Cryst. Growth Des. 2018, 18, 34113418.

(184) Blatov, V. A.; Shevchenko, A. P.; Proserpio, D. M. Applied Topological Analysis of Crystal Structures with the Program Package Topospro. Cryst. Growth Des. 2014, 14, 3576-3586.

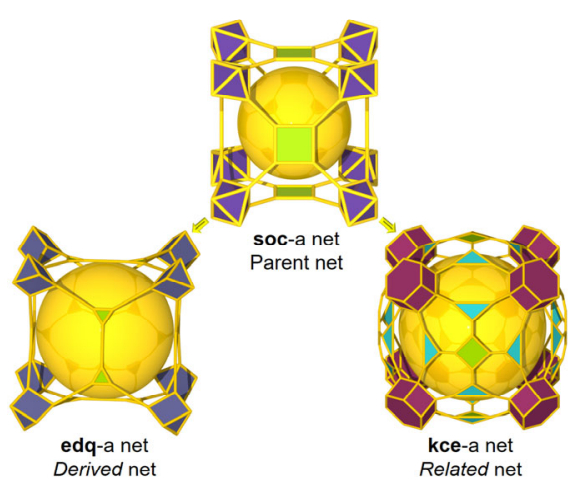

